Summer 8-23-2019

\title{
Assessing Workplace Wellness for the Occupation of Hairdressing
}

\author{
Alex Kim \\ University of St. Augustine for Health Sciences \\ DOI: https://doi.org/10.46409/sr.KQNN8928
}

Follow this and additional works at: https://soar.usa.edu/capstones

Part of the Musculoskeletal Diseases Commons, Occupational Therapy Commons, Other Analytical, Diagnostic and Therapeutic Techniques and Equipment Commons, and the Other Mental and Social Health Commons

\section{Recommended Citation}

Kim, A. (2019). Assessing Workplace Wellness for the Occupation of Hairdressing. [Doctoral project, University of St Augustine for Health Sciences]. SOAR @ USA: Student Capstone Projects Collection. https://doi.org/10.46409/sr.KQNN8928

This Capstone is brought to you for free and open access by the Student Research at SOAR @ USA. It has been accepted for inclusion in Student Capstone Projects by an authorized administrator of SOAR @ USA. For more information, please contact soar@usa.edu, erobinson@usa.edu. 
ASSESSING WORKPLACE WELLNESS FOR THE OCCUPATION OF HAIRDRESSING

by

Alex W. Kim

A Capstone Project Proposal Presented in Partial Fulfillment

of the Requirement for the Degree of

DOCTOR OF OCCUPATIONAL THERAPY

University of Saint Augustine

August, 2019 


\section{ASSESSING WORKPLACE WELLNESS FOR THE OCCUPATION OF HAIRDRESSING}

by

Alex W. Kim

has been approved

August, 2019

APPROVED:

Erin Schwier, EdD, OTR/L, Program Director

Susan MacDermott, OTD, OTR/L, Doctoral Coordinator

ACCEPTED AND SIGNED:

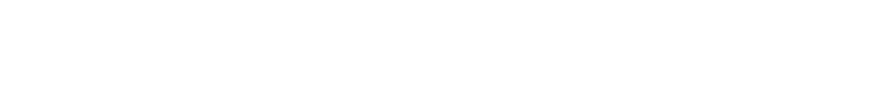

Erin Schwier, EdD, OTD, OTR/L, Program Director

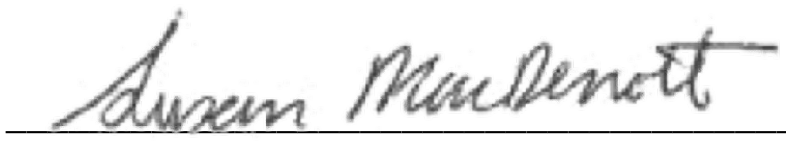

Susan MacDermott, OTD, OTR/L, Doctoral Coordinator 


\section{Table of Contents}

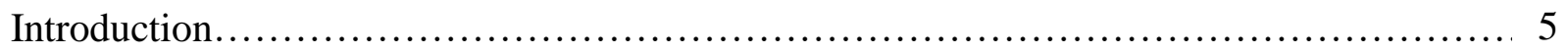

Background .................................................................. 5

Statement of the Problem...................................................... 6

Significance of the Proposed Project.......................................... 7

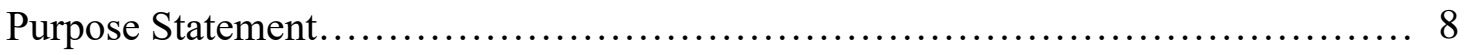

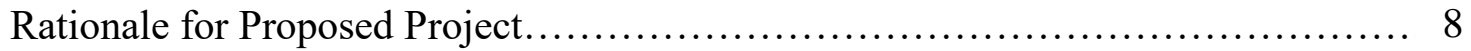

Preliminary Project Objectives............................................. 9

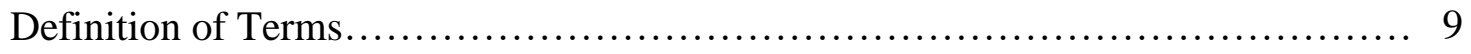

Assumptions, Limitations, and Delimitations............................... 10

Literature Review............................................................ 11

Risk Factors................................................................ 11

Occupational Therapy's Current Role....................................... 17

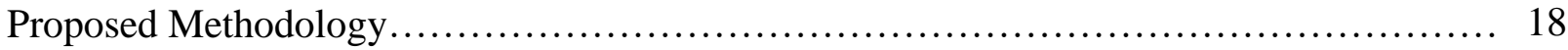

Planned Analysis and Envisioned Next Steps........................................ 21

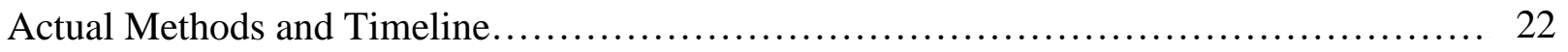

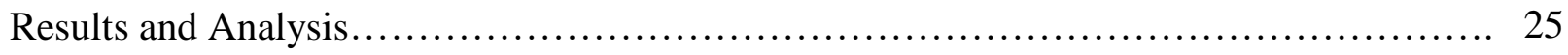

Themes.......................................................................... 25

Assessments................................................................. 28

Summary, Conclusion, and Discussion.............................................. 34

Discussion...................................................................... 34

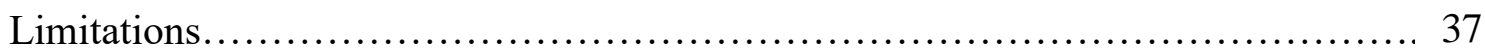

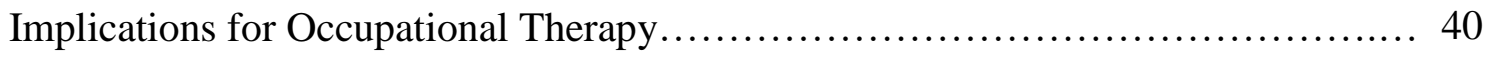


Running head: ASSESSING WORKPLACE WELLNESS FOR THE OCCUPATION OF

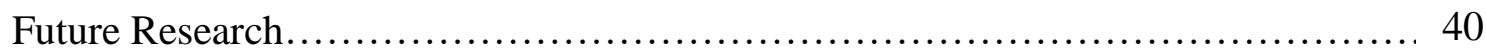

Future Projects ........................................................ 41

Conclusions ...................................................... 41

References............................................................. 43

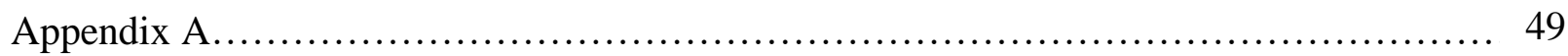

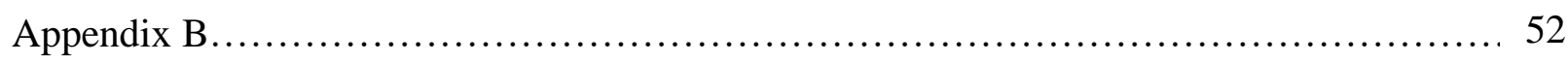

Appendix C............................................................ 55

Appendix D............................................................. 58

Appendix E............................................................... 60

Appendix F............................................................ 65 


\section{Introduction}

\section{Background}

The hairdressing population, which include barbers, cosmetologists, and hairstylists, is a physically involved occupational field. A study conducted by Mahdavi et al. (2014) found a high prevalence of symptomatic pain in areas of the neck, waist and wrist that were reported by 172 participating hairdressers in Iran. They determined that a multitude of physical factors, including prolonged standing and repetitive movements, may all contribute to high prevalence of symptoms found in various regions of the upper extremities. Furthermore, Norlander et al. (2016) included hairdressers as part of their study, which examined the prevalence of workrelated musculoskeletal disorders (WRMSDs) in occupations that are constantly exposed to repetitive motions, extreme postures, and/or lack of rest breaks, among other things. Researchers from a previous study established that repetitive and/or constrained work increased the risk for musculoskeletal disorders regardless of occupational settings or gender (Norlander et al., 2009). Such tasks can ultimately increase the risk for work-related musculoskeletal disorders (WRMSDs), such as thoracic outlet syndrome that can negatively impact the wellness of hairdressers. (Laulan et al., 2010).

Roll (2016) identifies musculoskeletal conditions as "the second greatest cause of disability worldwide" and suggests new means in expanding the role of occupational therapy to better provide for this practice area (p. 1). However, Takata and Roll (2018), identified multiple gaps found in the current evidence of treatments provided by occupational therapy professionals for upper extremity musculoskeletal disorders. Their review found limited evidence on interventions practitioners provided and reinforced "the need to develop evidence for the use of occupation-based interventions to support and advance the distinct value of occupational therapy 
practitioners in this practice setting" (Takata \& Roll, 2018, p.1). The results from a study conducted by Hardison and Roll (2017) suggests intervention strategies using occupations and activities correlate to the participants' success in occupational rehabilitation because it centered on the participants' occupations, which represents their life roles and provides them with a sense of meaning and purpose. "Although often eclipsed by a focus on activities of daily living within physical rehabilitation research, the use of work-related occupation based activities warrants further exploration” (Hardison \& Roll, 2017, p. 7).

\section{Statement of the Problem}

There appears to be a possibility that even low force activities (muscular contraction levels less than or equal to $15 \%$ maximum voluntary contraction) may cause fatigue, which can influence musculoskeletal disorders and occupational performance (De Kesel, Donceel, \& De Smet, 2008; de Looze, Bosch, \& van Dieën, 2009). De Looze, Bosch, and van Dieën (2009) found that maximum voluntary contraction (MVC) as low as 0.5 to one percent can be correlated to musculoskeletal disorders found in the shoulder region. In addition, Hanvold, Wærsted, Mengshoel, Bjertness, \& Veiersted, (2015) conducted a longitudinal study among young adults involved in manual work exposed to arm elevation and found that arm elevation may be a risk factor for WRMSDs in females. Interestingly, researchers were unable to produce a definitive conclusion for the male participants due to low pain levels. However, another study found that musculoskeletal symptoms were more prevalent in female hairdressers than male hairdressers (Chen, Chang, Liu, \& Chen, 2010). These findings suggest that anthropometry may be another risk factor that may impact the wellness of hairdressers. The literature continues to list other possible risk factors that may impact the wellness of the hairdressing population, including psychosocial and chemical exposure factors, which suggests the need of a wellness program that 
would help prevent and promote the well-being of hairdressers (Mussi \& Gouveia, 2008;

Galiotte, Kohler, Mussi, \& Figaro Gattas, 2008).

Yet, there is limited information that analyzes the hairdressing occupation as a whole.

Many of the studies provided focus on one or few aspects of the occupation rather than addressing the whole occupation. This limitation of focus can cause researchers to overlook possible confounding variables that may play a role in impacting these workers. Additionally, other studies include multiple manual occupations into their research, thus deviating their attention away from the specific needs of the hairdressing population. While there are studies which have developed and implemented their own intervention programs to address WRMSDs in the hairdressing settings, they fail to address the needs of this occupation in its entirety and limit their programs to address only one area of need.

\section{Significance of the Proposed Project}

As of 2016, the employment size of the hairdressing occupation was roughly 673,700 workers in the United States alone with an average age of 39.2 years ("Bureau of Labor Statistics", 2018; "Hairdressers", 2016). This is a sizable workforce and it further emphasizes the significance of addressing the risk factors that threaten the welfare for this population. Failure to provide a holistic wellness program may consequently lead to decreased productivity, increased costs, and reduced prosperity for hairdressers. Therefore, this capstone project aims to address these needs by completing a needs assessment that focuses on examining the needs of hairdressers through observations made in their specific environments and conducting interviews with them and the salon owners. With these information, occupational therapists can then 
develop a program designed to promote the well-being of hairdressers in their workspace. This capstone project also aims to analyze the limitations and strengths of safety education currently provided by beauty schools.

\section{Purpose Statement}

The purpose of this evaluation is to examine the occupation of hairdressing; assess the health-related needs of hairdressers; and design a program with a holistic approach to address the current needs as well as preventative approaches for this occupation. Currently, there is lack of treatment approaches that address the hairdresser as a whole to improve their overall well-being and prevent health-related concerns. By implementing this holistic approach, this capstone project will focus on identifying and addressing risk factors that influence negative health outcomes, with the intent to create programming focus on improving overall wellness for this population.

\section{Rationale for Proposed Project}

The Person Environment Occupation Performance (PEOP) model is a useful model for this project to implement as it identifies personal intrinsic factors, such as endurance, reasoning, and spirituality; extrinsic factors, including culture, environment, and social support; and the occupation of hairdressing (Krupa, 2008). Naweed, Trigg, Allen, and Chapman (2017) included the PEOP model in their study because it "suggests that occupational performance is the outcome of interdependent transactions among people, occupations and their environments" (p. 476). Cho and Han (2018) also utilized this model for their research because they hypothesized that positive work environments would contribute to healthy behaviors, which in turn would lead to improved work performance. In order to effectively carry out this program, this needs assessment must observe the various risk factors that these hairdressers are exposed to in their workplace settings. 
Such factors include, but are not limited to: age, anthropometric, biomechanical, chemical exposure, organizational, and psychosocial aspects. Appropriate Frames of References (FOR), such as biomechanical FORs, used for these factors would facilitate the interpretations of information gathered through observations and interviews.

\section{Preliminary Project Objectives}

- Complete a needs assessment focused on examining the needs of the hairdressing population through observations and interviews.

- Design a wellness program that promotes well-being and aims to reduces/prevents workrelated risk factors.

- Analyze the strengths and limitations of current safety education provided by beauty schools through interviews of hairdressers.

\section{Definition of Terms}

- Work-related musculoskeletal disorders (WRMSDs) - Injuries or dysfunctions caused in the workplace (hairdressing) setting that affect the musculoskeletal system, including bones, cartilage, joints, ligaments, muscles, nerves, spinal discs, and tendons (Da Costa \& Vieira, 2009).

- Workplace wellness - “[A]ny workplace health promotion activity or organizational practice or policy designed to support healthy behavior in your workplace" (Alberta Blue Cross, 2019, p.1).

- Hairdresser - Any licensed worker that is involved in the hairstyling process for a client. This process may involve blow drying, cleansing, hair coloring, and hair cutting.

- Full work day - A work shift that consists of eight total working hours in a 24-hour day. 
Anthropometric risk factors are gender-related factors that influence a hairdresser's participation in the workplace. Aging risk factors observe how a hairdresser's age and experience in the hairdressing field can impact his or her performance in the occupation. Biomechanical risk factors are specific factors that involve irregular movement, joint stability, or postural alignment of the human body, including repetitive movements and awkward stances. Chemical risk factors are defined as any hair products used for services that may negatively impact the hairdressers. These factors are not limited to shampoos, conditions, and hair coloring dyes. Organizational risk factors can be defined as policies, or a lack thereof, in the workplace which fail to uphold healthy outcomes for hairdressers. Finally, psychosocial risk factors involve factors which negatively impact a hairdresser's "psychosocial, emotional, and social capacities to meet demands, challenges, and even hardships" (Krupa, Kirsh, Pitts, Fossey, Bruce, 2016, p. 4).

\section{Assumptions, Limitations, and Delimitations}

This capstone project makes the assumption that all hairdressers have or are at risk for musculoskeletal pain, condition, and some other form of negative risk factor (e.g., psychosocial) which impact their abilities to participate in meaningful occupation. Another assumption that is made is their willingness to learn these wellness and preventative approaches. Furthermore, this project assumes that ergonomics can be applied to this workplace setting; that hairdressers lack in-depth knowledge of occupational therapy; and that this workplace impacts both genders equally.

There is the inherent inconsistency that dictates the schedule of the hairdressers. Some hairdressers may be scheduled for a full work day one day and may only work half of a work day the next day. The aforementioned limitation can be directly influenced by the rate of clients that 
request for services on a given day. Although many clients may schedule for an appointment ahead of time, some clients may be taken in as a walk-in by hairdressers if these hairdressers have time slots available. Hairdressers will also exercise their own unique habits, roles, and techniques on their clients, who also command different preferences and hairstyles. Thus, no one performance will be identical, which further complicates the project's ability to generalize to this population. Delimiting factors involved with this capstone project include the schedule of the study (e.g., high volume of clients, consistency) and one set location (e.g., consistency) for the observations. The choice of the PEOP model also influenced data collection in that it was used to inspire the content and organization of interview questions (including intrinsic and extrinsic factors).

\section{Literature Review}

\section{Risk Factors}

Risk factors are any qualities or aspects that may increase the risk of any negative health outcomes, such as cancer development, elevated stress, and WRMSD (i.e., neck, shoulder, and low back pain). Because the hairdressing population is commonly exposed to any combination of these factors, their relationship with risk factors have been the subject of focus on several epidemiological researches. Risk factors found in other occupations (e.g., physical therapists and nurses), such as anthropometric, biomechanical, and chemical factors, can also be associated with hairdressing as the latter may share similar work routines and tasks with other occupations. For this review, risk factors found in hairdressing and in other occupations are included to more thoroughly investigate the potential relationship between these factors and the hairdressers' overall well-being. 
Age Risk Factor. Workplace injuries from awkward postures, repetitive motions, or other issues may increase with age (da Costa \& Vieria, 2009; Mahdavi, Mahdavi, Safari, Rashidi, Dehghani, \& Kosari, 2015). In the current literature, studies have found that the risk factor of aging can be associated with varicose vein development in hairdressers. Besides the cosmetic presentation, the symptoms experienced by affected hairdressers greatly vary, with some having asymptomatic conditions and others developing complications such as eczema, thrombophlebitis, or venous ulcers (Chen \& Guo 2014; Ebrahimi, Amanpour, \& Haghighi, 2015). Consequently, these symptoms can reduce the hairdressers' quality of life and their abilities to participate in meaningful tasks. While there are several factors which may influence the prevalence of varicose veins, including sex, family history, and prolonged standing, studies have shown that age is also a contributing factor to this condition (Chen \& Guo, 2014; Ebrahimi, Amanpour, Hachichi, 2015). The aim of this capstone project, then, is to consider how age and work experience may influence other signs of symptomatic behaviors that would impact this population's overall well-being.

Anthropometric Risk Factors. Another risk factor to consider for this population are anthropometric (the study of measurements/proportions of the human body) risk factors. The hairdressing occupation is predominately female-employed, with over $90 \%$ of the hairdressing population in the United States identified as female ("Hairdressers", 2016). However, female hairdressers tend to be more susceptible to work-related symptoms (Chen, Chang, Liu, \& Chen, 2010; Côté, 2011). One reason for this may be due to the inherent gender-biased tasks found in this occupation (Pollard, 2012). According to Côté (2011), biological differences (e.g., height), can also result in increased exposures to certain risk factors (e.g., elevated muscle activities in forearm extensors and trapezius), that can ultimately lead to WRMSDs. Even more so, the 
research suggests that symptoms of this disorder may localize in different regions of the body depending on the gender. However, based on their study, de Looze, Bosch, and van Dieën (2009) were unable to determine a relationship between gender and fatigue development, which they consider to be a precursor to shoulder disorders. In light of these evidence, it is important to identify if the etiology of WRMSDs is a result of biological differences, task differences, or a combination of both so that this capstone project may properly consider this population's needs.

Biomechanical Risk Factors. Biomechanical risk factors are one of the most frequently recognized risk factors found within the literature associated with WRMSDs. Numerous studies identified certain activities performed at varying intensities and degrees, such as repetitive movements, shoulder elevations, and specific postures, to be linked with WRMSDs (Adegoke, Akodu, \& Oyeyemi, 2008; De Looze, Bosch, \& van Dieën, 2009; Hanvold, Wærsted, Mengshoel, Bjertness, \& Veiersted, 2015; Mahdavi, et al., 2013; Nordander, Hansson, Ohlsson, Arvidsson, Balogh, Strömberg, Rittner, \& Skerfving, 2016; Szeto, Ho, Ting, Poon, Cheng, \& Tsang, 2009; Sy \& Phillips, 2016; Wahlström, Mathiassen, Liv, Hedlund, Ahlgren, \& Forsman, 2010; Yarandi, Koohpaei, Arsang., \& Ebrahimi, 2018). Madeleine (2010) stated that the "two highest exposures to physical risks are painful/tiring position and repetitive movement" (p. 2) and that one of the known risk factors associated with WRMSDs was physical workloads. Nordander et al. (2009) also found that repetitive and constrained work increased risks for musculoskeletal disorders across all settings when compared to varied/mobile work. This study defined repetitive work as "a cycle time $<30 \mathrm{~s}$ or $>50 \%$ of the cycle time involved the same fundamental cycle" (p. 1227) and constrained work as " $>50 \%$ of working time involved [in] prolonged awkward postures" (p. 1227). Although one study (Laulan et al., 2010) was unable to 
establish a strong evidence between thoracic outlet syndrome (TOS) and workplace activity, it also did not discount the possibility of a link existing between the two variables.

Risk factors pertaining to WRMSDs, especially biomechanical variables, are important to consider as hairdressers are typically susceptible for WRMSDs (Mahdavi, Mahdavi, Safary, Rashidi, Dehghani, \& Kosari, 2013; Norlander et al., 2009; Sy \& Phillips, 2016; Wahlström, Mathiassen, Liv, Hedlund, Ahlgren, \& Forsman, 2010). The hairdressing occupation can be a laborious and physically-taxing affair, with hairdressers constantly involved in the aforementioned activities. These occupational exposures consequently fatigue their bodies and ultimately affect their abilities to participate in their occupations. Biomechanical risk factors, therefore, must be examined and addressed as part of this capstone project in an effort to alleviate symptomatic behaviors, prevent any potential development of WRMSDs, and promote what is a part of the hairdressers' overall well-being.

Chemical Risk Factors. Hairdressers must oftentimes work with hair products during their tasks, which exposes them to potentially harmful chemical agents (Mussi \& Gouveia, 2008; Pak, Powers, \& Liu, 2013). These chemical risk factors have been linked with several health issues, including cancer development and respiratory issues (Galiotte, Kohler, Mussi, \& Figaro Gattas, 2008; Hassan \& Bayomy, 2015; Letašiová, Medved’ová, Šovčíková, Dušinská, Volkovová, Mosoiu, \& Bartonová, 2012; Mussi \& Gouveia, 2008). In addition, hairdressers are often tasked with wet-work, which results in constant wetting and drying of their hands and increasing the risk for hand dermatitis. Moreover, hairdressers would use hair products, such as shampoos and hair conditioners, during wet-work tasks, which would further exacerbate these hand conditions (Behroozy \& Keegel, 2014; Galiotte, Kohler, Mussi, \& Figaro Gattas, 2008). While some studies have suggested possible solutions, the literature did not provide any evidence 
regarding effective implementations. This capstone project will therefore look to validate these risks factors to propose recommendations into a health promotion program.

Psychosocial Risk Factors. WRMSDs is a critical marker for employee health outcomes and the risks for these disorders can also be heavily correlated with psychosocial (interrelationship between social factors and personal behavior and thoughts) factors (Eatough, Way, \& Chang, 2011; Hauke, Flintrop, Brun, \& Rugulies, 2011; Madeleine, 2010; Macfarlane et al., 2008). Stress, as defined by Widanarko, Legg, Devereux, and Stevenson, (2014) is, “a nonspecific 'defence' response of the body that can help to protect it from threats" (p. 1616). These researchers suggest that several factors, including psychosocial factors, contribute to the increased occurrence of WRMSDs because the body naturally assumes a hunched (curved-back) posture when adopting a protective stance, which results in increased tension in the back musculature. Additionally, studies conducted on nursing staffs identified emotional distress, including anxiety and lack of social support, as factors which elevated the risk for WRMSDs (Amin, Quek, Oxley, Noah, \& Nordin, 2018; Yan, Yang, Zhang, Li, Huang, Wang, Dai, \& Yao, 2018). Hairdressers are routinely exposed to similar psychosocial stressors (e.g., emotional distress, anxiety, and amount of social support) mentioned in these studies, as well. Given how this occupation is physically demanding, fast-paced, and emotionally involving, this population may therefore also be at risk for WRMSDs due to these factors. However, there is a lack of evidence specifically for hairdressers in the current literature to support this.

Mussi and Gouveia (2008) found psychosocial factors for the hairdressing population to be one of the three occupational factors that was linked to WRMSD occurrence. Yet the only psychosocial variable identified in this study was the "lack of acknowledgment of work" (Mussi \& Gouveia, 2008, p. 369). This provides only a narrow insight of how psychosocial factors may 
have an involvement with increased risks for WRMSDs. Furthermore, there is a clear need to explore the impact psychosocial factors have not only with WRMSDs, but with the occupation as a whole. Although WRMSDs may have a large impact on a hairdresser's well-being, there may be other facets of the individual that can be affected by psychosocial stressors. Conversely, there may be other psychosocial factors that have yet been identified by the literature. It is the aim of this capstone project to identify these aspects and understand the relationship they have with psychosocial risk factors.

Organizational and Environmental Risk Factors. Another important risk factors to consider when examining workplace wellness for hairdressing are organizational risk factors. Hairdressers are routinely exposed to stressors which impact their occupational performance, such as long work hours, lack of rest breaks, privation of protective measures, and work organization (Bradshaw, Harris-Roberts, Bowen, Rahman, \& Fishwick, 2011; Deschamps, Langrand, \& Lesage, 2013; Widanarko, Legg, Devereux, \& Stevenson, 2014). Temperature found in this occupational setting may also affect muscular activities (Côté, 2011). However, it is uncertain if the health education and training they received is adequate to reduce these risks.

In their study, Bradshaw, Harris-Roberts, Bowen, Rahman, and Fishwick (2011) argue that hairdressers reported a higher frequency of symptoms as a result of their workplace even though they received training courses because these courses failed to deliver specific health content. Furthermore, hairdressers in this study also demonstrated poor awareness of potential health risks, which suggests substandard application of risk assessment practices by the hair salons. Yarandi, Koohpaei, Arsang, and Ebrahimi (2018) suggests corrective actions should be implemented, including training programs and work rest cycle, in an effort to improve 
WRMSDs. These approaches would also be applicable for this capstone project as WRMSDs are found prominently in hairdressers and is a large component that can affect their overall wellness.

\section{Occupational Therapy's Current Role}

The scope of occupational therapy practice qualifies this progression to address the occupational needs of a given individual or population with a holistic approach. Occupational therapy places the client first, rather than the problem, so that one becomes enabled to participate in one's own recovery (“About Occupational Therapy”, 2019). The hairdressing population continues to demonstrate physical and psychosocial work-related injuries which could impact their health and work performance. Is occupational therapy a viable discipline to address the needs of this population, and if so, how? The second theme for this literature review will explore the current role of occupational therapy to address this population's needs.

While there have been a few studies which examined the effectiveness of occupational therapy in treating musculoskeletal disorders, the treatments utilized to address them have not necessarily been correlated with the extent of the scope of this discipline. A systematic review conducted by Roll and Hardison (2016) appraised 59 articles with the aim of examining the available evidence for the efficacy of occupational therapy interventions regarding functional outcomes for adults with upper extremity musculoskeletal disorders. Although the researchers found early active range of motion procedures and splinting for postsurgical status as beneficial for successful functional outcomes, there was also a lack of studies found for occupation-based interventions. Takata and Roll (2018) further highlights these gaps in the literature and emphasizes the need to develop more evidence "for the use of occupation-based interventions...in this practice setting" (p. 6). Thus, there is an apparent need to further explore 
occupational therapy-based interventions which can be applied for different workplace settings. This capstone project will attempt to explore these interventions in a hairdressing setting.

The literature review reveals two gaps of knowledge. First, the current evidence presented in the literature offer criterion-based assessments that only provide analyses of certain aspects of the occupation. To address the overall needs of this population, it is necessary to examine the occupation holistically and avoid including confounding variables, such as alcohol consumption, amount of exercise, and smoking. Second, there is a lack of occupational therapybased interventions for hairdressers, specifically occupation-based interventions, which warrants the need to further explore potential interventions that may be applicable for this work setting.

\section{Proposed Methodology}

The gaps in the literature reveal a current lack of client-centered treatment approaches for improving or maintaining the wellness of hairdressers.

Data will be collected through an ethnographic method using direct observational design at Nova Arts Salon in Los Angeles, California to observe how participants performed in their occupational setting. According to Creswell (2014), ethnography "is a design of inquiry coming from anthropology and sociology in which the researcher studies the shared patterns of behaviors, language, and actions of an intact cultural group in a natural setting over a prolonged period of time (six to eight weeks). Data collection often involves observations and interviews" (p. 14). The design is appropriate for this study as it looks to identify the occurrence and frequency of risk factors participants are exposed to as they interact within their occupational demands and environment. The design process will include the use of recorded interviews and direct observations to identify risk factors in a holistic manner without intruding on the participants' performance. Information collected will then be used to develop a program focused 
on either one prioritized aspect or an entire holistic program depending on the results and feasibility.

Convenience sampling will be used to select the participants for this study due to the research design used (direct observation); time allotted to conduct this research (six to eight weeks); and limited available resources. Dunieir (2011) states that although data drawn through this method is not statistically representative of the population as a whole, it provides researchers opportunities to find insightful discoveries that would otherwise be considered inconvenient facts. Convenience sampling was utilized because this study sampled participants from one location (Portney \& Watkin, 2015). Thus, participants will be selected based on the available hairdressers present on the days visited. Two participants will be approached prior to the start of their work shift, one on Thursday and one on Friday, and will be asked to participant in the study. Observations will be made on the salon floor with the attention committed solely to the one designated hairdresser for that given day due to the degree of involvement the occupation requires. Included in this study will also be hairdressers that currently work either part-time or full-time and regardless of pre-existing conditions. Exclusion criteria include hairdressing assistants, staff members not directly involved in the hairstyling process; and non-English speaking hairdressers. This study will need to collect consent forms from participants to confirm that they are made aware of the purpose of this capstone research and will be observed.

Several materials and methods will be used in this study to facilitate a deeper understanding of the observational data. The first will be a semi-structured interview that will comprise of open-ended and closed-ended question. Consent forms will be needed to obtain participants' permissions to conduct and record these interviews. Furthermore, an electronic recording device will be needed to transcribe the verbal conversations for thematic coding. The 
second will be the Rapid Upper Limb Assessment (RULA) which considers the biomechanical load requirements of the occupation on the upper body, including the neck and the upper extremities (McAtamney \&Corlett, 1993). A stop watch will also be needed to measure the amount of time the hairdresser spends attending a client's hair. A task analysis worksheet will be included for this study to facilitate a deeper understanding of the occupational task demands (see Appendix E).

The hairdressing population is consistently exposed to work-related risk factors that negatively impact their general well-being. However, there is a lack of occupation-focused treatment interventions available that holistically address these needs. Therefore, this study will examine the occupation of hairdressing as a whole to identify health-related needs and develop an occupation-focused wellness program. The objectives for this capstone project are to complete a needs assessment using recorded interviews and direct observations to look at this population's needs; create a wellness program that promotes well-being and reduce or prevent exposures to work-related risk factors; and to examine the strengths and limitations of safety education currently offered by beauty schools through recorded interviews.

This capstone project is expected to last between 14 to 16 weeks, with the ethnographical study portion starting in the second half of week six. The first week of this study (on week six) will revolve around the recruitment process, which will consist of introductions and initial observations. One-one-one interviews will be conducted ideally on the third week (once rapport has been established between the observer and the participants) and it will be administered in the most convenient timeframe for the participants. The interviews will be concluded by the end of the third week. One participant will be observed every Thursdays and another will be observed every Fridays for the next six to eight weeks depending on the amount of observable data 
acquired. In total, 12 to 16 days will be spent for observations between two participants. Direct observations will be carried out in an eight-hour shift spread out between 9:00 am to 6:00 pm. Observations and thematic coding will be made throughout the entire observational period of this study to record any new themes that may be discovered during this time. The final week of this study will entail the completion of data collection. Data analysis and program development will be processed until the conclusion of this capstone project.

\section{Planned Analysis and Envisioned Next Steps}

Data will be analyzed immediately after the recorded interviews and direct observations are finalized. As mentioned previously, the interviews will be semi-structured and recorded consisting of a list of questions with a combination of open-ended and closed-ended questions (see Appendix B). Consent forms will be provided prior to the interview so that participants are aware of being recorded and agree to participate in this study (see Appendix D).

Sociodemographic questions pertaining strictly to occupation such as age, years of work experience; years working at Nova Arts Salon; and if they were taught in some form of safety education, will be included. The interview will also expand on the latter topic, discussing what they were taught for safety education; how they were taught; and the duration of the safety program. Anthropometric-related questions, such as gender, height, and weight, and psychosocial-related question, including levels of anxiety and stress, will also be recorded. Interviews will be conducted on participants before or after their work shifts in face-to-face format and in a secluded area to facilitate participants' attention and focus. Oral recordings from the interviews will be transcribed and be used to identify themes which most influences the occupational performance of the hairdressers. Direct observations will identify biomechanical risk factors using the RULA Worksheet (see Appendix A). Variables of biomechanical risk 
factors, including degrees of wrist flexion and shoulder extension, will be evaluated and scored based off the assessment's scoring rubric and will then be compiled using the tables provided to create a single score. This score will represent the level of risk the hairdresser is exposed to for WRMSDs and will be used to determine if and how work tasks should be modified to reduce these risk exposures (McAtamney \&Corlett, 1993). Participants' work performances will also be timed for each client they attend to using a stop watch to measure duration of specific activity demands (e.g. awkward posture) as well as the overall length of service that is provided.

The data analysis will be delivered through a poster board and it will focus on sharing insight on common factors reported by the participants that increase the risk of WRMSDs. In addition, the presentation will provide possible adjustments hairdressers can make in their performance to reduce these risks. This study will be presented at Nova Arts Studio, if permitted, to benefit the participants' performances in their occupational setting by encouraging adaptive strategies into their own work behaviors and routines. It will also be presented at the University of Saint Augustine at the San Marcos location for their Research Day to bring attention to prospective practitioners the needs and services of the hairdressing population.

\section{Actual Methods and Timeline}

Prior to data collecting, the observer spent one month shadowing a professional ergonomist with an occupational therapy background as part of the capstone experience to learn how to identify risk factors and use ergonomic assessments to evaluate clients across a variety of workplace settings. In addition, the observer spent another 40 working hours shadowing a professional ergonomist with a physical therapy background at hospital settings to generalize the skills necessary to assess needs for individuals in various occupations. 
Data was collected through an ethnographic method using direct observational design at two locations: Nova Arts Salon in Los Angeles, California and Inter Hair in San Diego, California. Two locations were used to expand the number of participants included in this study. Originally, the study was planned to observe only two participants from Nova Arts Salon, but another participant from Inter Hair agreed to participate during the later stages of data collection. For the data collection, interviews were conducted, but they were not recorded because the intent was to be less formalized and adaptable to the workplace environment. Notes were taken, instead, for thematic coding.

Convenience sampling was used for both sites. Two participants from Nova Arts were pre-determined by the salon's owners and were observed Thursdays and Fridays for three weeks. For Thursdays, one female hairdresser was observed, while for Fridays the other male hairdresser was observed. The frequency of visits at Nova Arts Salon reduced to one day a week (Fridays) the following three weeks because enough collection of data was achieved after week three. Both participants continued to be monitored during weeks four to six, but during this time, data interpretation and observations of their environment were prioritized. At Inter Hair, one female hairdresser was observed working during two separate days. The days observed were determined on her availability. Observations of the third participant were made in both days of her work shift, while an interview was successfully completed during the first opportunity of observation. In total, 11 days were spent observing three participants across two locations.

Several materials and methods were used in this research. First, a semi-structured interview was provided to all three participants during periods most convenient to their schedules. For the interview consent forms, signatures were not required because this was a needs assessment, and not a formal research study, and it was decided that the interviews would 
not be recorded. However, a proposed consent form for the interviews were verbally reviewed by all three participants and were given the option to sign the forms afterwards. Participants 1 and 3 provided their signatures, but Participant 2 simply provided the observer with her verbal consent. The Cornell Musculoskeletal Discomfort Questionnaires (CMDQs) were also used during the interview to screen specific areas of pain or discomfort participants experienced and how they impacted their work participation (see Appendix C) (Hedge, Morimoto, \& McCrobie, 1999). Second, this research included both the Rapid Entire Body Assessment (REBA) and the Rapid Upper Limb Assessment (RULA) to roughly quantify the data observed (see Appendix A) (Hignett \& McAtamney, 2000; McAtamney \&Corlett, 1993). The REBA “is a postural analysis tool sensitive to musculoskeletal risks in a variety of tasks and assessment of working postures found in health care and other service industries" (Ansari \& Sheikh, 2014, p. 18). This assessment tool was added into the data collection process to more thoroughly evaluate the degree of risks the participants were exposed to during their work performance. Unlike the RULA, the REBA prioritizes assessing the general postures of the whole body rather than specific regions of it (e.g. upper extremities), making it helpful in providing additional information about the risks involved, as well. Skills to utilize both assessments were acquired from the observer's capstone experience after extensive use of both during ergonomic evaluations. Finally, the plan intended to measure the amount of time the hairdresser spends attending a client's hair. However, it was later discovered that the participants would not be with their clients throughout the entirety of the hairdressing process. They would either transition to another client to work on or do something else while waiting for their clients' hair to set (e.g., dry or dye). Therefore, it became apparent that measuring the participants' time spent on hair became impractical. 


\section{Results and Analysis}

\section{Themes}

The following themes were derived from the interviews used to determine which aspects of intrinsic and extrinsic factors affected the participants' performance in hairdressing beyond the nature of the tasks. A few themes were drawn from these interviews:

Person-Intrinsic. These factors are the characteristics unique to the individual which impact occupational performance.

Years of Experience.

Participant $1-9$ years

Participant $2-38$ years

Participant $3-17$ years

Safety Education. All three participants reported a lack of training received regarding personal safety during their training. The participants were only taught on how to avoid any accidents or maintain sanitation around their clients and their workspaces. Thus, they were unaware of how to participate in their occupations safely and efficiently.

\section{Anthropometric.}

Participant 1 - Height: 5 feet, 7 inches / Age: 35 years old

Participant 2 - Height: 5 feet, 0 inches / Age: 50 years old

Participant 3 - Height: 5 feet, 3 inches / Age: 31 years old

Cognitive. None of the participants reported having any difficulty with processing information from multiple sources; solving problems while making decisions in the moment; or losing focus at work.

Physiological 
Varying levels of physiological pain and discomfort. Each participant reported to experience varying levels of physiological pain and discomfort across different areas of the body, including at the time of interview. Participant 1 reported chronic aching discomfort prominently (several times in one day) in both of her feet, forearms, and wrists; daily discomfort (once every day) in her lower back; and inconsistent discomfort (one to four times a week) in her upper back, right upper arm, hip flexors, neck, and both sides of the shoulders. Discomfort lasted for three years and the primary activities the participant engages in that would encourage such discomfort include coloring hair and standing for long periods of time. After work, the participant would feel 5/10 fatigued. Participant 2 reported experiencing dull aches and sharp pains in the lower back and both shoulders. The participant also mentioned having chronic back issues, but that the shoulder pain occurred in the last six months. Consequently, shoulder elevation was reported as the most difficult posture. Activities such as blow-drying and cleansing would exacerbate these symptoms and the participant would feel 8/10 fatigued after work. Finally, Participant 3 had described prominent discomfort found in the mid-back, neck, and both shoulders as tense and sore. On his CMDQs, he labeled his neck, right shoulder, and right wrist as areas he experienced discomfort multiple times throughout a given day. He also reported experiencing discomfort in his left shoulder, upper back, right upper arm, lower back, and both feet once every day and in his left upper arm, both forearms, left wrist, hips, and left thigh one to four times each week. These symptoms have reoccurred inconsistently for the past five years and was reported to be primarily caused by cutting hair. Fatigue levels would be 7/10 after work and activities involving neck and trunk tilt and shoulder elevation were stated to be the most difficult tasks for this participant.

\section{Psychological}


Inconsistent diet. Participants reported to take varying amounts of lunch breaks during their work shifts. Participant 1 would take a 30-minute lunch break on a consistent basis and stated that missing this break would affect her energy and mood. Similarly, Participant 2 also reported that missing a lunch break would affect her energy and mood. However, she also admitted that she does not eat regularly throughout the day and when she does take a lunch break, it would only be for 15-30 minutes. Participant 3 reported not taking any lunch breaks because having a meal during the day would make him feel drowsy and tired.

Psychological impact from work. Each participant described different effects from their occupation. Participant 2 reported feeling extremely proud of her job and feels the need to try her best to satisfy her clients' needs. Participant 3 stated that the business aspect of this job affected him heavily. While he mentioned that he could control his emotions when he is working with his clients, he explained that making decisions at the administrative level gave him anxiety and stress. This leads him to feel mentally fatigued. Similarly, Participant 1 also reported feeling some stress from work, although overall, she felt "good, not bad" from it.

Environmental-Extrinsic. These factors are environmental influences on occupational performance.

\section{Organizational Culture}

Varied impressions of workplace culture. Participants had varied impressions of the workplace culture. Participant 1 described the culture of her salon to be emotional, draining, and stressful. Participant 2 described her workplace to be "smooth-running" and friendly. Participant 3 describes the culture of Nova Arts Salon as community-based and fun, but serious about their craft and the expectations of the salon.

\section{Social Support}


Stress from client tardiness. Tardiness was a common denominator shared between these three participants regarding what caused them stress. Other reasons included equipment failure (Participant 1); clients changing their minds on a hair design that was already prepared for (Participant 2); clients not being taken care of, and payments (Participant 3).

Time management handled differently. At the time of this interview, Participant 1 had three personal assistants working for her, while Participant 3 had two personal assistants for himself. Participant 2, however, had no assistants. Participants 1 and 2 both reported to be able to manage their time independently, but Participant 3 admitted that he relied on his two assistants to help him keep track of his time.

Measures taken to ensure that time is managed efficiently differs between participants. Participant 2 follows up with her clients prior to the scheduled date to remind them of their appointments, while Participant 1 allows the front office to manage a system that works to her advantage. Participant 3 would, once again, rely primarily on his assistants, but the manager may sometimes get involved to help keep him on track.

Frequency of breaks taken between participants also vary. Participant 2 stated taking more breaks between her clients as of late, with breaks lasting at least 15 minutes. Participant 3 would occasionally take breaks when he feels mentally fatigued by stepping outside and sunbathing for three to five minutes. However, Participant 1 reported that she does not take any breaks at all between clients.

\section{Assessments}

The hairdressers who participated were $66 \%$ female $(n=2)$ and $33 \%$ male $(n=1)$. Their mean age was 41 years and their average working experience was 21.3 years. Table 1 shows the main tasks observed during the data collection process; risk factors that the participants were 
found to be exposed with; and recommendations on strategies that would help eliminate or reduce such risk factors. Based on the score assessments of the REBA, the coloring and cleansing tasks were found to be at the highest risks, followed by cutting, extension removing, and blow-drying tasks, respectively. Interestingly with the RULA, the extension removing task was the highest risks for upper extremities WRMSDs, with cutting, coloring, cleansing, and blow-drying tasks assessed as the second to fifth highest risks.

However, there was only one instance of a participant engaging in the extension removing task during the time of observation, so it does not properly represent the task assessment. Furthermore, the REBA focuses risks placed on the entire body, whereas the RULA limits itself to concentrate more towards the upper extremities. Since the participants would either sit or stand during their work performance, this can explain why certain tasks were rated lower or higher for the REBA when compared to the RULA.

Table 1. Average Assessment Scores of Each Task

\begin{tabular}{|c|c|c|}
\hline \multicolumn{3}{|c|}{ Average Assessment Scores } \\
\hline General Tasks & REBA & RULA \\
\hline Blow-dry & 5.71 & 5.43 \\
\hline Cleanse & 7.57 & 6.00 \\
\hline Color & 7.58 & 6.75 \\
\hline Curl & 6.10 & 6.20 \\
\hline Cut & 7.00 & 6.76 \\
\hline Extension Removal & 6.00 & 7.00 \\
\hline \multicolumn{3}{|l|}{$\begin{array}{l}\text { REBA Scoring } \\
\text { Implications }\end{array}$} \\
\hline 4-7 & \multicolumn{2}{|c|}{ Medium risk. Further investigate. Change soon. } \\
\hline $8-10$ & \multicolumn{2}{|c|}{ High risk. Investigate and implement change. } \\
\hline \multicolumn{3}{|l|}{$\begin{array}{l}\text { RULA Scoring } \\
\text { Implications }\end{array}$} \\
\hline $5-6$ & \multicolumn{2}{|c|}{ Further investigation, change soon. } \\
\hline 7 & \multicolumn{2}{|c|}{ Investigate and implement change. } \\
\hline
\end{tabular}

Table 2. Task Assessments and Suggestive Controls 


\begin{tabular}{|c|c|c|c|}
\hline $\begin{array}{l}\text { Tasks } \\
\text { Evaluated }\end{array}$ & Risk Factors Identified & $\begin{array}{l}\text { REBA/RULA } \\
\text { Scores }\end{array}$ & Suggested Controls \\
\hline Blow-dry & $\begin{array}{l}\text { Standing: } \\
\text { - Neck } \\
\text { flexion/extension, } \\
\text { side-bending, twisting } \\
\text { - } \text { Trunk flexion, side- } \\
\text { bending } \\
\text { - Leg unsupported } \\
\text { - Upper Arm flexed, } \\
\text { abducted } \\
\text { - Lower Arm outside } \\
\text { 80-100-degree range, } \\
\text { crosses midline } \\
\text { - Wrist outside of 15- } \\
\text { degree range, crosses } \\
\text { midline, twisted } \\
\text { - Repetitive movements } \\
\text { in the neck and upper } \\
\text { extremities }\end{array}$ & $\begin{array}{l}\text { REBA } \\
\text { Average (n=7) } \\
4,7,4,5,9,7, \\
4=40 \\
40 / 7=\mathbf{5 . 7 1} \\
\text { "4-7 = Medium } \\
\text { Risk. Further } \\
\text { investigate. } \\
\text { Change soon." } \\
\text { RULA } \\
\text { Average (n=7) } \\
\text { 3, 7, 3, 6, 7, 7, } \\
\text { 5= 38 } \\
\text { 38/7 = 5.43 } \\
\text { “5-6 = Further } \\
\text { investigation, } \\
\text { change soon.” }\end{array}$ & $\begin{array}{l}\text { Work practice controls: } \\
\text { - Utilizing the height-adjustable } \\
\text { seats to reposition clients as needed } \\
\text { - Mobile application reminders for } \\
\text { breaks } \\
\text { - Use mirror to check for posture } \\
\text { - Tucking chin in to align ears with } \\
\text { shoulders to keep neck straight } \\
\text { - Maintaining a straight back and } \\
\text { allowing the spine to be in its } \\
\text { natural curve } \\
\text { - Keeping shoulders low and } \\
\text { relaxed } \\
\text { - Positioning elbows low and close } \\
\text { to trunk, as possible } \\
\text { - Maintaining the alignment of the } \\
\text { hands and wrists with the forearm } \\
\text { (neutral grip), as possible } \\
\text { - Avoid locking knees by having } \\
\text { both knees slightly flexed (<30 } \\
\text { degrees) to reduce joint stress } \\
\text { - Keeping both feet on the ground, } \\
\text { shoulder-width apart, for even } \\
\text { distribution of body weight } \\
\text { Administrative controls: } \\
\text { Taking a } 5 \text { to } 10 \text { minute break per } 1 \\
\text { hour of work } \\
\text { Engineering controls: } \\
\text { - Anti-fatigue mat } \\
\text { - Blow dryer attachment (Smooth } \\
\text { Air T-360) } \\
\text { - Comfortable, supportive footwear } \\
\text { - Considering ergonomic solutions } \\
\text { for future investments in equipment } \\
\text { (e.g., lighter blow-dryer [<300 g]) }\end{array}$ \\
\hline Cleanse & $\begin{array}{l}\text { Standing: } \\
\text { - Neck flexion, side- } \\
\text { bending, twisting } \\
\text { - } \text { Trunk flexion, side- } \\
\text { bending } \\
\text { - } \quad \text { Leg supported }\end{array}$ & $\begin{array}{l}\text { REBA } \\
\text { Average }(\mathrm{n}=7): \\
7,9,7,9,8,7 \\
6=53 \\
53 / 7=7.57\end{array}$ & $\begin{array}{l}\text { Work practice controls: } \\
\text { - Mobile application reminders for } \\
\text { breaks } \\
\text { - Tucking chin in to align ears with } \\
\text { shoulders to keep neck straight }\end{array}$ \\
\hline
\end{tabular}




\begin{tabular}{|c|c|c|c|}
\hline & $\begin{array}{l}\text { - Upper Arm flexed, } \\
\text { abducted } \\
\text { - Lower Arm outside } \\
\text { 80-100-degree range, } \\
\text { crosses midline } \\
\text { - } \quad \text { Wrist outside of 15- } \\
\text { degree range, bent } \\
\text { from midline, twisted } \\
\text { - Repetitive movements } \\
\text { in the neck and upper } \\
\text { extremities }\end{array}$ & $\begin{array}{l}\text { "4-7 = Medium } \\
\text { Risk. Further } \\
\text { investigate. } \\
\text { Change soon." } \\
\text { "8-10 = High } \\
\text { Risk. } \\
\text { Investigate and } \\
\text { implement } \\
\text { change." } \\
\text { RULA } \\
\text { Average (n=7): } \\
6,7,6,6,7,5, \\
5=42 \\
\text { 42/7 = 6.00 } \\
\text { "5-6 = Further } \\
\text { investigation, } \\
\text { change soon." }\end{array}$ & $\begin{array}{l}\text { - Maintaining a straight back and } \\
\text { allowing the spine to be in its } \\
\text { natural curve } \\
\text { - Keeping shoulders low and } \\
\text { relaxed } \\
\text { - Positioning elbows low and close } \\
\text { to trunk, as possible } \\
\text { - Maintaining the alignment of the } \\
\text { hands and wrists with the forearm } \\
\text { (neutral grip), as possible } \\
\text { - Avoid locking knees by having } \\
\text { both knees slightly flexed (<30 } \\
\text { degrees) to reduce joint stress } \\
\text { - Keeping both feet on the ground, } \\
\text { shoulder-width apart, for even } \\
\text { distribution of body weight } \\
\text { Administrative controls: } \\
\text { Taking a } 5 \text { to } 10 \text { minute break per } 1 \\
\text { hour of work } \\
\text { Engineering controls: } \\
\text { - Anti-fatigue mat } \\
\text { - Upright GO posture correcting } \\
\text { device } \\
\text { - Comfortable, supportive footwear } \\
\text { - Considering ergonomic solutions } \\
\text { for future investments in equipment } \\
\text { (e.g., re-installing the wash basin to } \\
\text { be free-standing to allow improved } \\
\text { hairdresser posture) }\end{array}$ \\
\hline Color & $\begin{array}{l}\text { Standing and Sitting: } \\
\text { - Neck flexion, side- } \\
\text { bending, twisting } \\
\text { - } \text { Trunk flexion, side- } \\
\text { bending } \\
\text { - } \text { Leg supported, bent } \\
\text { - } \quad \text { Upper Arm flexed, } \\
\text { abducted } \\
\text { - } \quad \text { Lower Arm outside } \\
\text { 80-100-degree range, } \\
\text { crosses midline } \\
\text { - Wrist outside of 15- } \\
\text { degree range, crosses, } \\
\text { twisted }\end{array}$ & $\begin{array}{l}\text { REBA } \\
\text { Average } \\
(\mathrm{n}=24): 9,9,7, \\
8,9,8,7,9,6, \\
9,7,8,8,5,7, \\
5,8,7,7,7,7, \\
9,6,10=182 \\
182 / 24=7.58 \\
\text { "4-7 = Medium } \\
\text { Risk. Further } \\
\text { investigate. } \\
\text { Change soon." } \\
\text { "8-10 = High } \\
\text { Risk. }\end{array}$ & $\begin{array}{l}\text { Work practice controls: } \\
\text { - Utilizing the height-adjustable } \\
\text { seats to reposition clients as needed } \\
\text { - Mobile application reminders for } \\
\text { breaks } \\
\text { - Use mirror to check for posture } \\
\text { - Tucking chin in to align ears with } \\
\text { shoulders to keep neck straight } \\
\text { - Maintaining a straight back and } \\
\text { allowing the spine to be in its } \\
\text { natural curve } \\
\text { - Keeping shoulders low and } \\
\text { relaxed } \\
\text { - Positioning elbows low and close } \\
\text { to trunk, as possible }\end{array}$ \\
\hline
\end{tabular}




\begin{tabular}{|c|c|c|c|}
\hline & $\begin{array}{l}\text { - Repetitive movements } \\
\text { in the neck and upper } \\
\text { extremities }\end{array}$ & $\begin{array}{l}\begin{array}{l}\text { Investigate and } \\
\text { implement } \\
\text { change." }\end{array} \\
\text { RULA } \\
\text { Average } \\
\text { (n=24): } 7,7,7, \\
7,7,7,7,7,6, \\
7,7,7,6,6,6, \\
7,7,6,7,7,7, \\
7,6,7=162 \\
162 / 24=6.75 \\
\text { "5-6 = Further } \\
\text { investigation, } \\
\text { change soon." } \\
\text { "7 = Investigate } \\
\text { and implement } \\
\text { change." }\end{array}$ & $\begin{array}{l}\text { - Maintaining the alignment of the } \\
\text { hands and wrists with the forearm } \\
\text { (neutral grip), as possible } \\
\text { - Avoid locking knees by having } \\
\text { both knees slightly flexed ( }<30 \\
\text { degrees) to reduce joint stress } \\
\text { - Keeping both feet on the ground, } \\
\text { shoulder-width apart, for even } \\
\text { distribution of body weight } \\
\text { Administrative controls: } \\
\text { Taking a } 5 \text { to } 10 \text { minute break per } 1 \\
\text { hour of work } \\
\text { Engineering controls: } \\
\text { - Anti-fatigue mat } \\
\text { - Blow dryer attachment (Smooth } \\
\text { Air T-360) } \\
\text { - Comfortable, supportive footwear }\end{array}$ \\
\hline Curl & 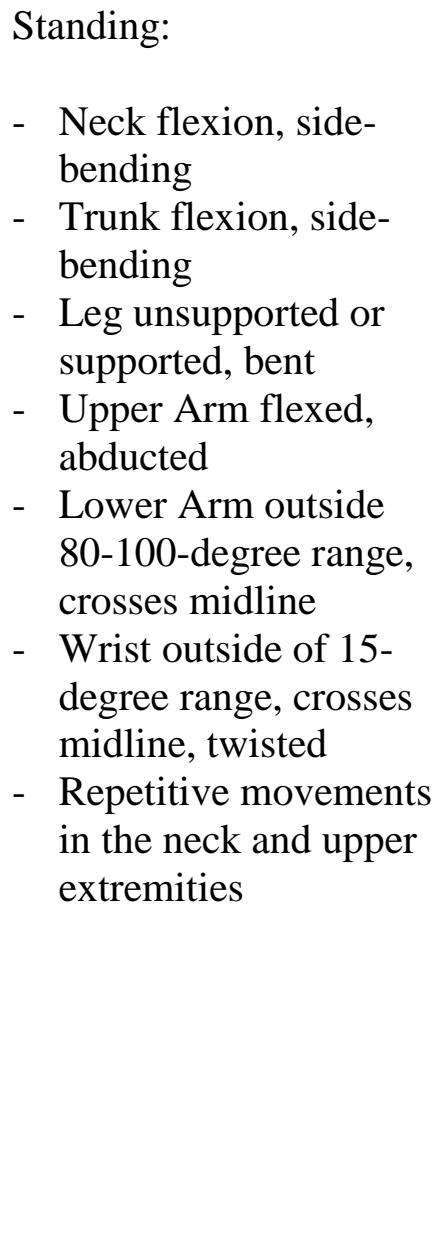 & $\begin{array}{l}\text { REBA } \\
\text { Average } \\
(\mathrm{n}=10): 9,6,5, \\
5,5,7,5,7,6, \\
6=61 \\
61 / 10=\mathbf{6 . 1 0} \\
\text { “4-7 = Medium } \\
\text { Risk. Further } \\
\text { investigate. } \\
\text { Change soon." } \\
\text { RULA } \\
\text { Average } \\
\text { (n=10): 7, 7, 5, } \\
\text { 6, 7, 6, 4, 7,6, } \\
7=62 \\
\text { 62/10 = 6.20 } \\
\text { “5-6 = Further } \\
\text { investigation, } \\
\text { change soon." } \\
\text { "7 = Investigate } \\
\text { and implement } \\
\text { change." }\end{array}$ & $\begin{array}{l}\text { Work practice controls: } \\
\text { - Utilizing the height-adjustable } \\
\text { seats to reposition clients as needed } \\
\text { - Mobile application reminders for } \\
\text { breaks } \\
\text { - Use mirror to check for posture } \\
\text { - Tucking chin in to align ears with } \\
\text { shoulders to keep neck straight } \\
\text { - Maintaining a straight back and } \\
\text { allowing the spine to be in its } \\
\text { natural curve } \\
\text { - Keeping shoulders low and } \\
\text { relaxed } \\
\text { - Positioning elbows low and close } \\
\text { to trunk, as possible } \\
\text { - Maintaining the alignment of the } \\
\text { hands and wrists with the forearm } \\
\text { (neutral grip), as possible } \\
\text { - Avoid locking knees by having } \\
\text { both knees slightly flexed (<30 } \\
\text { degrees) to reduce joint stress } \\
\text { - Keeping both feet on the ground, } \\
\text { shoulder-width apart, for even } \\
\text { distribution of body weight } \\
\text { Administrative controls: }\end{array}$ \\
\hline
\end{tabular}




\begin{tabular}{|c|c|c|c|}
\hline & & & $\begin{array}{l}\text { Taking a } 5 \text { to } 10 \text { minute break per } 1 \\
\text { hour of work } \\
\text { Engineering controls: } \\
\text { - Anti-fatigue mat } \\
\text { - Comfortable, supportive footwear } \\
\text { - Considering ergonomic solutions } \\
\text { for future investments in equipment } \\
\text { (e.g., lighter curling iron [<300 g]) }\end{array}$ \\
\hline Cut & $\begin{array}{l}\text { Standing and Sitting: } \\
\text { Neck flexion/extension, } \\
\text { side-bending, twisting } \\
\text { Trunk flexion, side- } \\
\text { bending } \\
\text { Leg unsupported or } \\
\text { supported, bent } \\
\text { Upper Arm flexed, } \\
\text { abducted } \\
\text { Lower Arm outside } 80- \\
\text { 100-degree range, } \\
\text { crosses midline } \\
\text { Wrist outside of 15- } \\
\text { degree range, crosses } \\
\text { midline, twisted } \\
\text { Repetitive movements in } \\
\text { the neck and upper } \\
\text { extremities }\end{array}$ & $\begin{array}{l}\text { REBA } \\
\text { Average } \\
\text { (n=33): 10, 10, } \\
\text { 9, 10, 10, 10, 8, } \\
\text { 7, 9, 6, 8, 8, 4, } \\
\text { 5, 7, 6, 6, 6, 6, } \\
\text { 5, 8, 5, 5, 4, 9, } \\
\text { 8, 6, 8, 5, 6, 7, } \\
\text { 5, 5 = 231 } \\
\text { 231/33 = 7.00 } \\
\text { “4-7 = Medium } \\
\text { Risk. Further } \\
\text { investigate. } \\
\text { Change soon." } \\
\text { RULA } \\
\text { Average } \\
\text { (n=33): 7, 7, 7, } \\
\text { 7, 7, 7, 7, 7, 7, } \\
\text { 7, 7, 7, 5, 7, 7, } \\
\text { 7, 7, 7, 7, 5, 7, } \\
\text { 7, 5, 6, 7, 7, 7, } \\
\text { 6, 7, 7, 7, 7, 7 = } \\
\text { 223 } \\
\text { 223/33 = 6.76 } \\
\text { "5-6 = Further } \\
\text { investigation, } \\
\text { change soon." } \\
\text { “7 = Investigate } \\
\text { and implement } \\
\text { change.” }\end{array}$ & $\begin{array}{l}\text { Work practice controls: } \\
\text { - Utilizing the height-adjustable } \\
\text { seats to reposition clients as needed } \\
\text { - Mobile application reminders for } \\
\text { breaks } \\
\text { - Use mirror to check for posture } \\
\text { - Tucking chin in to align ears with } \\
\text { shoulders to keep neck straight } \\
\text { - Maintaining a straight back and } \\
\text { allowing the spine to be in its } \\
\text { natural curve } \\
\text { - Keeping shoulders low and } \\
\text { relaxed } \\
\text { - Positioning elbows low and close } \\
\text { to trunk, as possible } \\
\text { - Maintaining the alignment of the } \\
\text { hands and wrists with the forearm } \\
\text { (neutral grip) } \\
\text { - Avoid locking knees by having } \\
\text { both knees slightly flexed (<30 } \\
\text { degrees) to reduce joint stress } \\
\text { - Keeping both feet on the ground, } \\
\text { shoulder-width apart, for even } \\
\text { distribution of body weight } \\
\text { Administrative controls: } \\
\text { Taking a } 5 \text { to } 10 \text { minute break per } 1 \\
\text { hour of work } \\
\text { Engineering controls: } \\
\text { - Anti-fatigue mat } \\
\text { - Comfortable, supportive footwear } \\
\text { - Developing a schedule for } \\
\text { equipment maintenance (e.g., } \\
\text { sharpening and greasing shears for } \\
\text { optimal use) }\end{array}$ \\
\hline
\end{tabular}




\begin{tabular}{|c|c|c|c|}
\hline & & & $\begin{array}{l}\text { - Considering ergonomic principles } \\
\text { for future investments in equipment } \\
\text { (e.g., lighter clippers }[<300 \mathrm{~g}] \text { ) }\end{array}$ \\
\hline $\begin{array}{l}\text { Extension } \\
\text { removal }\end{array}$ & $\begin{array}{l}\text { Sitting: } \\
\text { - } \text { Neck flexion, side- } \\
\text { bending } \\
\text { - } \text { Trunk flexion, side- } \\
\text { bending } \\
\text { - } \text { Leg supported } \\
\text { - } \text { Upper Arm minimally } \\
\text { flexed, abducted } \\
\text { - } \text { Lower Arm outside of } \\
\text { 15-degree range, } \\
\text { crosses midline, } \\
\text { twisted } \\
\text { - } \text { Repetitive movements } \\
\text { in the upper } \\
\text { extremities }\end{array}$ & $\begin{array}{l}\text { REBA } \\
\text { Average }(n=1): \\
6 \\
6 / 1=6.00 \\
\text { “4-7 = Medium } \\
\text { Risk. Further } \\
\text { investigate. } \\
\text { Change soon." } \\
\text { RULA } \\
\text { Average (n=1): } \\
7 \\
7 / 1=7.00 \\
\text { "7 = Investigate } \\
\text { and implement } \\
\text { change." }\end{array}$ & $\begin{array}{l}\text { Work practice controls: } \\
\text { - Utilizing the height-adjustable } \\
\text { seats to reposition clients as needed } \\
\text { - Mobile application reminders for } \\
\text { breaks } \\
\text { - Use mirror to check for posture } \\
\text { - Tucking chin in to align ears with } \\
\text { shoulders to keep neck straight } \\
\text { - Maintaining a straight back and } \\
\text { allowing the spine to be in its } \\
\text { natural curve } \\
\text { - Keeping shoulders low and } \\
\text { relaxed } \\
\text { - Positioning elbows low and close } \\
\text { to trunk, as possible } \\
\text { - Maintaining the alignment of the } \\
\text { hands and wrists with the forearm } \\
\text { (neutral grip) } \\
\text { Administrative controls: } \\
\text { Taking a } 5 \text { to 10-minute break per } 1 \\
\text { hour of work } \\
\text { Engineering controls: N/A }\end{array}$ \\
\hline
\end{tabular}

\section{Summary, Conclusion, and Discussion}

\section{Discussion}

The themes derived from the interviews and the assessments suggest that hairdressers are likely to be performing in their occupations without general knowledge of safe working postures or precautions. This may stem from the possibility of lack of safety education and efficient work practices provided at educational settings. As a result, hairdressers may consequently adopt poor habits which encourage them to engage in their craft with awkward postures and work through fatigue. Furthermore, stress derived from psychological and environmental-extrinsic factors may 
also negatively impact work performance. According to Lindegård, Larsman, Hadzibajramovic, and Ahlborg (2013), stress in conjunction with musculoskeletal discomfort can be related to decreased productivity.

However, the participants also seem to demonstrate some initiatives to help improve their stamina and mood. They recognized the impacts breaks had on their work performances and have made efforts tailoring their schedules to include or avoid them throughout the day. For instance, Participant 1 preferred not to include short breaks throughout her work shift but take a 30-minute lunch break to recover from the fatigue, while Participant 3 would occasionally take short breaks and avoid having a meal break to avoid getting tired from digestion. In addition, the participants expressed collaborating on other health strategies that would ameliorate their discomforts with other coworkers and clients, further showing their efforts to improve their work performance.

The data collected through the REBA and the RULA assessments also identified multiple risks factors that hairdressers may be exposed to when engaging in their occupation. These factors included neck flexion, side-bending, and twisting; trunk flexion and side-bending; unsupported leg stance; upper arm flexion and abduction; and repetitive movements in the neck and upper extremities. The participants were assessed on their "worst posture" for every general task they performed, and each body part was given a score based from this capture. Using these figures, the assessments generated a general score that ranked the severity of risk for each task. Results from the REBA showed that participants were generally at a medium to high risk for WRMSDs and the RULA implied immediate investigation and implementation of change on how they participate in these tasks. 
Once this data analysis from the assessments was completed, a generalized wellness program was developed based on the needs for this group of participants, which served as a model of what the general hairdressing population may need. This wellness program consists of strategies that promote neutral posture and was designed to reduce the frequency and duration of these risk exposures the participants experienced (see Appendix F). Education on what neutral posture is; what these postures might look like; stretching routines; and work strategies aimed to reduce awkward postures were some examples included into this program ("Canadian Centre for Occupational Health”, 2017; Cha et al., 2017; Hansraj, n.d.; Irvine, 2015; Moore, TormaKrajewski, \& Steiner, 2011; O’leary, Cahill, Robinson, Barnes, \& Hong, 2013; Suess, 2017). For instance, education of neutral posture was provided to hopefully reduce neck and trunk flexion. Assuming the participants apply this knowledge into their craft, their REBA and RULA scores for cutting hair, for example, can potentially be lowered. Furthermore, to improve mood and moderate stress levels, strategies such as taking rest and meal breaks; snacking on high-protein snacks; and utilizing mindfulness meditation and deep-breathing were also recommended to improve intrinsic and psychosocial factors (Baer, 2003; Hunter \& Wu, 2015; Kierklo, Kobus, Jaworska, \& Botuliński, 2011; Leidy et al., 2015; Perciavalle et al., 2016; Smith \& Gallagher, 2018). The program concludes with suggested engineering controls, or adaptive technologies, which could potentially help further improve workplace wellness (Isa \& Omar, 2011).

The wellness program was initially delivered via email to all three participants so that they may receive the information at their convenience. The presentation was in a PowerPoint format that was divided into four separate sections and voice-recorded. It was divided with consideration of the participants because this format would allow them to have the ability to navigate to whichever part of the information they prioritized first. Another advantage of this 
method is that it also enables the participants to share and have access to this information at any time. A brief overview of this program was also delivered in-person to Nova Arts Salon, with emphasis on reviewing stretching routines and helpful holistic strategies. The observer was unable to deliver an in-person presentation at Inter Hair due to schedule conflicts with the participant. Lastly, laminated posters of the stretching routines were delivered to each participants' work setting to serve as visual aids that facilitated compliance of stretching.

\section{Limitations}

Several limitations were found in this needs assessment. Firstly, Participants 1 and 3 demonstrated limited functional capacity of this occupation due to their specialized roles in Nova Arts Salon. This salon is unusual in that the hairdressers employed here either specialize in coloring or cutting hair, not both, possibly due to it being a more "high-end" salon. While these participants still participated in certain tasks to some extent (e.g., blow-drying and cleansing), these tasks were typically delegated to their assistants to complete. Thus, Participant 1 was primarily observed with only coloring her clients' hair and Participant 3 was mainly seen only cutting his clients' hair. Participant 2, on the other hand, does not employ any assistants and therefore completed every one of her occupational tasks independently. Additionally, Participants 1 and 3 had dual roles in their occupation, the second having more administrative duties at their respective salon. Participant 2 also has the responsibility in maintaining her own brand and the list of clienteles in order to operate in her occupation. Thus, some of the information collected may be influenced by factors outside of the scope of hairdressing (e.g., stress).

The second limitation was that the assessments used to collect the observable data may contain human error, since the assessment tools and the interviews used involve subjective data 
to completed. Additionally, because filming was restricted at Nova Arts Salon and certain angles from the observable viewpoints were obstructed by furnishings (e.g., cement pillar), these challenges made it difficult to determine the "worst posture" participants at Nova Arts Salon were in for each task. While these barriers to getting a good visual reading may cause the results of the assessments to be less precise, it should also be noted that these assessment tools were very broad in design because they were used to capture only the general idea of what the risks entailed in a given occupation. Thus, although these measurements do not necessarily need to be exact, the lack of specific information collected may lead to an incomplete assessment of this occupation's wellness.

The third limitation was that outside activities may impact work performance. Activities, such as working out at the gym, would further exhaust muscle groups that have already been exposed to cumulative stress from the workplace. By not providing these muscle groups (e.g., low back, shoulders, calves) ample rest periods after work, the muscles may not be primed for the next shift (Hunter \& Wu, 2015; Kierklo, Kobus, Jaworska, \& Botuliński, 2011).

The fourth limitation was that the participants may have been more conscious of their postures and efforts due to their knowledge of an observer present. Participant 2, for example, reported to have received some ergonomic strategies previously to improve her WRMSD symptoms experienced from her occupation. Therefore, she may have placed more efforts in demonstrating postures less awkward and extreme than those made by her colleagues during the observations because she was reminded of these strategies by the observer's presence.

Additionally, some tasks were provided more attention and assessments than others. In particular, the extension removal task was only given one assessment because only one client required the participant to perform this task. Cutting and coloring tasks were more prominently 
assessed in this research because of client demands. Thus, as mentioned previously, certain tasks may not have been thoroughly assessed at the time of observation due to limited exposure to such tasks.

Another limitation was that certain tasks required time in between the initial and the final treatments of the hair for the expected results to come out. For instance, for the coloring process, it takes a varying amount of time for the chemicals found in the color treatments to apply onto a client's hair. Due to this, participants were oftentimes found transitioning to other tasks while still treating their clients' hair. At the start of this research, it was included in the methodology to measure the length of time a task took. As a result of their inherent nature, however, measuring the time spent on these tasks became unfeasible because it would not best represent the actual amount of time a participant spent on a given task for a given client.

It was mentioned earlier that the interviews were not recorded to reduce formalities and adapt this needs assessment to the workplace environment. However, in hindsight, recording these interviews would have been beneficial as it could have served as a source for richer quotes that would have been useful for supporting themes. These recordings would also have been useful as a resource to confirm notes that were taken by the observer. Therefore, the lack of interview recordings is another limitation for this needs assessment.

Finally, the observations made at both salons may have been made on days that were not the best representation of what a typical routine day would otherwise look like. While some efforts were made to help promote the collection of consistent observational data (e.g., observing one participant the whole day for Thursdays and Fridays at Nova Arts), outside factors, such as client bookings, stressors outside of workplace, and the availability of hairdresser, were still present during the observations. Different clients seen on a given day also demanded different 
tasks or techniques to be utilized by each participant. Since the data collection only broadly captured these tasks (e.g., categorizing men's haircuts and women's haircuts together into one “cutting" task), frequencies and durations of exposures to certain factors may have been missed. Consequently, these factors could have impacted the participants' ability to optimally perform in their occupation, and therefore, influenced the quality of the outcome of the results.

\section{Implications for Occupational Therapy}

This capstone project assesses the wellness of the hairdressing population, identifies risk factors, and explores strategies to help treat and reduce exposures to these risks. There are three primary implications for the practice of occupational therapy found in this research. First, a hairdresser's workplace and work performance should be consulted by an occupational therapy practitioner to reduce the risk of injury that can occur in their workplace settings. Second, occupational therapy should be provided to hairdressers with referral to rehabilitate symptoms of WRMSDs. Finally, occupational therapists should advocate and educate safe practice techniques at cosmetology schools to foster safe and efficient working habits.

\section{Future Research}

Future research could be focused on the assessment of other occupations and roles and the use of ergonomics and occupational therapy as tools to enhance wellness for these occupations. In keeping with the focus on the hair industry, other considerations may involve exploring roles of hairdressing assistants since they are also responsible for hairdressing tasks but are subjected to more organizational factors (e.g. management styles).

While many of these suggestions may be helpful in theory, there is also the reality of how applicable these strategies are in actual practice. Even if the education is sound, if the strategies provided hinder or negatively impact the end results of the hairdressers' craft, then such 
strategies would be meaningless to apply. Thus, it is important to encourage hairdressers to explore new ways to incorporate the education and strategies they have received into their daily work performance and adjust or modify techniques accordingly to appropriately meet their needs. Thus, another area of future research could be to conduct a follow-up assessment to see if information was retained and wellness strategies were applied to practice.

\section{Future Projects}

The sample size included for this needs assessment was small (three participants), so this assessment would not concretely portray the general hairdressing population. For future research projects, then, the inclusion of more participants would help improve addressing the wellness for this population. Additionally, confirming with cosmetology schools on the current safety education they provide and comparing that to the needs of the hairdressers could be an additional development of this project. Future projects could also focus on exploring other forms of employment in the beauty industry as they may present with different occupational demands and risk factors.

\section{Conclusions}

Multiple risk factors were found to negatively impact hairdressers' wellness in their workplace setting, including inconsistent meal breaks, work-related stress, and awkward postures. After assessing six general tasks hairdressers were found engaging in, several ergonomic and occupation-based strategies and treatments were incorporated into a generalized wellness program designed to improve their occupational well-being. It was also found that there was a lack of safety training provided for hairdressers throughout their careers. Therefore, to help promote wellness for current and prospective hairdressers, education on neutral posture, safe work practices, and administrative and engineering controls should be included in both school 
and work settings. Assessing other occupations and positions as a whole (e.g., hairdressing assistants) may uncover other factors not observed in this research and may advance occupational therapy treatment options for enhancing wellness and prevention of injury. 


\section{References}

About Occupational Therapy. (n.d.). Retrieved from https://www.aota.org/About-OccupationalTherapy.aspx

Adegoke, B. O., Akodu, A. K., \& Oyeyemi, A. L. (2008). Work-related musculoskeletal disorders among Nigerian physiotherapists. BMC Musculoskeletal Disorders, 9(1). doi:10.1186/1471-2474-9-112

Alberta Blue Cross. (2019). Want to be a workplace wellness champion? You've come to the right place! Retrieved from https://www.workplacewellnessonline.ca/

Amin, N. A., Quek, K. F., Oxley, J. A., Noah, R., \& Nordin, R. (2018). Emotional distress as a predictor of work-related musculoskeletal disorders in Malaysian nursing professionals. The International Journal of Occupational and Environmental Medicine, 9(2), 69-78. doi:10.15171/ijoem.2018.1158

Ansari, N. A., \& Sheikh, M. J. (2014). Evaluation of work posture by RULA and REBA: A case study. IOSR Journal of Mechanical and Civil Engineering, 11(4), 18-23. doi:10.9790/1684-11431823

Baer, R. A. (2003). Mindfulness training as a clinical intervention: A conceptual and empirical review. Clinical Psychology: Science and Practice, 10(2), 125-143. doi:10.1093/clipsy/bpg015

Barbers, Hairstylists, and Cosmetologists. (2018, April 13). Retrieved from https://www.bls.gov/ooh/personal-care-and-service/barbers-hairstylists-andcosmetologists.htm

Behroozy, A., \& Keegel, T. G. (2014). Wet-work exposure: A main risk factor for occupational hand dermatitis. Safety and Health at Work, 5(4), 175-180.

doi:10.1016/j.shaw.2014.08.001

Bradshaw, L., Harris-Roberts, J., Bowen, J., Rahman, S., \& Fishwick, D. (2011). Self-reported work-related symptoms in hairdressers. Occupational Medicine, 61(5), 328-334. doi:10.1093/occmed/kqr089

Canadian Centre for Occupational Health. (2017, November 1). Positioning the monitor. Retrieved from https://www.ccohs.ca/oshanswers/ergonomics/office/monitor_positioning.html

Cha, J. H., Kim, J. J., Ye, J. G., Lee, S. J., Hong, J. M., Choi, H. K., Choi, H. S., \& Shin, W. S. (2017). Static balance according to hip joint angle of unsupported leg during one-leg standing. Journal of Physical Therapy Science, 29(5), 931-935. doi:10.1589/jpts.29.931

Chen, H., Chang, C., Liu, Y., \& Chen, C. (2010). Ergonomic risk factors for the wrists of hairdressers. Applied Ergonomics, 41(1), 98-105. doi:10.1016/j.apergo.2009.05.001 
Chen, C., \& Guo, H. (2014). Varicose veins in hairdressers and associated risk factors: A crosssectional study. BMC Public Health, 14(1). doi:10.1186/1471-2458-14-885

Cho, H., \& Han, K. (2018). Associations among nursing work environment and healthpromoting behaviors of nurses and nursing performance quality: A multilevel modeling approach. Journal of Nursing Scholarship, 50(4), 403-410. doi:10.1111/jnu.12390

Côté, J. N. (2011). A critical review on physical factors and functional characteristics that may explain a sex/gender difference in work-related neck/shoulder disorders. Ergonomics, 55(2), 173-182. doi:10.1080/00140139.2011.586061

Creswell, J. W. (2014). The selection of a research approach. In Research design: Qualitative, quantitative and mixed methods approaches (4th ed.). Thousand Oaks, CA: Sage Publication Inc.

Da Costa, B. R., \& Vieira, E. R. (2009). Risk factors for work-related musculoskeletal disorders: A systematic review of recent longitudinal studies. American Journal of Industrial Medicine. doi:10.1002/ajim.20750

De Kesel, R., Donceel, P., \& De Smet, L. (2008). Factors influencing return to work after surgical treatment for carpal tunnel syndrome. Occupational Medicine, 58(3), 187-190. doi:10.1093/occmed/kqn034

De Looze, M., Bosch, T., \& van Dieën, J. (2009). Manifestations of shoulder fatigue in prolonged activities involving low-force contractions. Ergonomics, 52(4), 428-437. doi:10.1080/00140130802707709

Galiotte, M. P., Kohler, P., Mussi, G., \& Figaro Gattas, G. J. (2008). Assessment of occupational genotoxic risk among Brazilian hairdressers. The Annals of Occupational Hygiene, 52(7), 645-651. doi:10.1093/annhyg/men037

Hairdressers, hairstylists, \& cosmetologists. (2016). Retrieved from https://datausa.io/profile/soc/395012

Hansraj, K. K. (n.d.). Assessment of stresses in the cervical spine caused by posture and position of the head. Surgical Technology International $X X V$. Retrieved from https://motamem.org/wp-content/uploads/2016/06/spine-study.pdf.

Hanvold, T. N., Wærsted, M., Mengshoel, A. M., Bjertness, E., \& Veiersted, K. B. (2015). Work with prolonged arm elevation as a risk factor for shoulder pain: A longitudinal study among young adults. Applied Ergonomics, 47, 43-51. doi:10.1016/j.apergo.2014.08.019

Hardison, M. E., \& Roll, S. C. (2016). Factors associated with success in an occupational rehabilitation program for work-related musculoskeletal disorders. American Journal of Occupational Therapy, 71(1). doi:10.5014/ajot.2016.023200

Hassan, O. M., \& Bayomy, H. (2015). Occupational respiratory and musculoskeletal symptoms among Egyptian female hairdressers. Journal of Community Health, 40(4), 670-679. doi:10.1007/s10900-014-9983-y 
Hauke, A., Flintrop, J., Brun, E., \& Rugulies, R. (2011). The impact of work-related psychosocial stressors on the onset of musculoskeletal disorders in specific body regions: A review and meta-analysis of 54 longitudinal studies. Work \& Stress, 25(3), 243-256. doi:10.1080/02678373.2011.614069

Hedge, A., Morimoto, S. And McCrobie, D. (1999) Effects of keyboard tray geometry on upper body posture and comfort, Ergonomics, 42(10), 1333-1349.

Hignett, S., \& Mcatamney, L. (2000). Rapid entire body assessment (REBA). Applied Ergonomics,31(2), 201-205. doi:10.1016/s0003-6870(99)00039-3

Hunter, E. M., \& Wu, C. (2015). Give me a better break: Choosing workday break activities to maximize resource recovery. Journal of Applied Psychology, 101(2), 302-311. doi:10.1037/ap10000045

Irvine, W. O. (2015). Concepts of etiologies and effects of normal human knee pressure variations. Anatomy \& Physiology, 05(02). doi:10.4172/2161-0940.1000172

Isa, H., \& Omar, A. R. (2011). Prolonged Standing Strain Index (PSSI): A Proposed Method to Quantify Risk Levels of Standing Jobs in Industrial Workplaces. Advanced Materials Research,433-440, 497-506. doi:10.4028/www.scientific.net/amr.433-440.497

Kierklo, A., Kobus, A., Jaworska, M., \& Botuliński, B. (2011). Work-related musculoskeletal disorders among dentists - A questionnaire survey. Annals of Agriculture and Environmental Medicine, 18(1), 79-84.

Krupa, T. (2008). Defining psychosocial practice in occupational therapy. In Cole, M., \& Tufano, R. (Eds.), Applied theories in occupational therapy: A practical approach (pp. 316). Thorofare, NJ: SLACK Inc.

Krupa, T., Kirsh, B., Pitts, D., Fossey, E., \& Bruce, M. A. (2016). Bruce \& Borg's psychosocial frames of reference: Theories, models, and approaches for occupation-based practice, Fourth Edition. Thorofare, NJ: SLACK Incorporated.

Laulan, J., Fouquet, B., Rodaix, C., Jauffret, P., Roquelaure, Y., \& Descatha, A. (2010). Thoracic outlet syndrome: Definition, aetiological factors, diagnosis, management and occupational impact. Journal of Occupational Rehabilitation, 21(3), 366-373. doi:10.1007/s10926-010-9278-9

Leidy, H. J., Todd, C. B., Zino, A. Z., Immel, J. E., Mukherjea, R., Shafer, R. S., Ortinau, L. C., \& Braun, M. (2015). Consuming high-protein soy snacks affects appetite control, satiety, and diet quality in young people and influences select aspects of mood and cognition. The Journal of Nutrition,145(7), 1614-1622. doi:10.3945/jn.115.212092

Letašiová, S., Medved’ová, A., Šovčíková, A., Dušinská, M., Volkovová, K., Mosoiu, C., \& Bartonová, A. (2012). Bladder cancer, a review of the environmental risk factors. Environmental Health, 11(Suppl 1). doi:10.1186/1476-069x-11-s1-s11 
Lindegård, A., Larsman, P., Hadzibajramovic, E., \& Ahlborg, G. (2014). The influence of perceived stress and musculoskeletal pain on work performance and work ability in Swedish health care workers. International Archives of Occupational and Environmental Health, 87(4), 373-379. doi:10.1007/s00420-013-0875-8

Madeleine, P. (2010). On functional motor adaptations: From the quantification of motor strategies to the prevention of musculoskeletal disorders in the neck-shoulder region. Acta Physiologica, 199, 1-46. doi:10.1111/j.1748-1716.2010.02145.x

Mahdavi, S., Mahdavi, M., Safari, M., Rashidi, R., Dehghani, T., \& Kosari, M. (2015). Evaluation of the risk of musculoskeletal disorders using Rapid Entire Body Assessment among hairdressers in Khorramabad, Iran, in 2014. Journal of Occupational Health and Epidemiology, 2(3), 138-145. doi:10.18869/acadpub.johe.2.3.138

Macfarlane, G. J., Pallewatte, N., Paudyal, P., Blyth, F. M., Coggon, D., Crombez, G., Linton, S., Leino-Arjas, P., Silman, A. J., Smeets, R. J., \& Windt, D. V. (2008). Evaluation of workrelated psychosocial factors and regional musculoskeletal pain: Results from a EULAR Task Force. Annals of the Rheumatic Diseases, 68(6), 885-891. doi:10.1136/ard.2008.090829

McAtamney, L. and Corlett, E.N. (1993) RULA: A survey method for the investigation of workrelated upper limb disorders. Applied Ergonomics, 24(2), 91-99.

Moore, S. M., Torma-Krajewski, J., \& Steiner, L. J. (2011). Practical demonstrations of ergonomic principles. Department of Health and Human Services. Retrieved from https://www.cdc.gov/niosh/mining/UserFiles/works/pdfs/2011-191.pdf.

Mussi, G., \& Gouveia, N. (2008). Prevalence of work-related musculoskeletal disorders in Brazilian hairdressers. Occupational Medicine, 58(5), 367-369. doi:10.1093/occmed/kqn047

Naweed, A., Trigg, J., Allan, M., \& Chapman, J. (2017). Working around it: Rail drivers' views on the barriers and enablers to managing workplace health. International Journal of -Workplace Health Management, 10(6), 475-490. doi:10.1108/ijwhm-08-2017-0060

Nordander, C., Hansson, G., Ohlsson, K., Arvidsson, I., Balogh, I., Strömberg, U., Rittner, R., \& Skerfving, S. (2016). Exposure-response relationships for work-related neck and shoulder musculoskeletal disorders - Analyses of pooled uniform data sets. Applied Ergonomics, 55, 70-84. doi:10.1016/j.apergo.2016.01.010

Nordander, C., Ohlsson, K., Åkesson, I., Arvidsson, I., Balogh, I., Hansson, G., Strömberg, U., Rittner, R., \& Skerfving, S. (2009). Risk of musculoskeletal disorders among females and males in repetitive/constrained work. Ergonomics, 52(10), 1226-1239.

doi:10.1080/00140130903056071

O’leary, C. B., Cahill, C. R., Robinson, A. W., Barnes, M. J., \& Hong, J. (2013). A systematic review: The effects of podiatrical deviations on nonspecific chronic low back 
pain. Journal of Back and Musculoskeletal Rehabilitation, 26(2), 117-123. doi:10.3233/bmr-130367

Pak, V. M., Powers, M., \& Liu, J. (2013). Occupational chemical exposures among cosmetologists: Risk of reproductive disorders. Workplace Health \& Safety, 61(12), 522 529. doi:10.3928/21650799-20131121-01

Perciavalle, V., Blandini, M., Fecarotta, P., Buscemi, A., Corrado, D. D., Bertolo, L., Fichera, F., $\&$ Coco, M. (2016). The role of deep breathing on stress. Neurological Sciences, 38(3), 451-458. doi:10.1007/s10072-016-2790-8

Pollard, K. M. (2012). Gender differences in autoimmunity associated with exposure to environmental factors. Journal of Autoimmunity, 38(2-3). doi:10.1016/j.jaut.2011.11.007

Portney, L. G., \& Watkins, M. P. (2015). Sampling. In Foundations of clinical research: Applications to practice (3rd ed.). Philadelphia, PA: F. A. Davis Company.

Roll, S. C. (2016). Current evidence and opportunities for expanding the role of occupational therapy for adults with musculoskeletal conditions. American Journal of Occupational Therapy,71(1). doi:10.5014/ajot.2017.711002

Smith, T. T., \& Gallagher, S. (2018). Impact of loading and work rest intervals on muscle microtrauma. International Journal of Industrial Ergonomics, 66, 161-168.

doi:10.1016/j.ergon.2018.03.002

Suess, J. (2017, July 05). 3 easy steps to improve your posture. Retrieved from https://suesschiropractic.com/dr-jesses-health-blog/2017/7/5/3-easy-steps-to-improveyour-posture

Sy, O., \& Phillips, M. L. (2016). Musculoskeletal symptoms and associated risk factors among African hair braiders. Journal of Occupational and Environmental Hygiene, 13(6), 434441. doi:10.1080/15459624.2015.1130226

Szeto, G. P., Ho, P., Ting, A. C., Poon, J. T., Cheng, S. W., \& Tsang, R. C. (2009). Work-related musculoskeletal symptoms in surgeons. Journal of Occupational Rehabilitation, 19(2), 175-184. doi:10.1007/s10926-009-9176-1

Takata, S., \& Roll, S. (2018). Linking research to practice for upper extremity musculoskeletal disorders: Interventions, outcomes, and diagnoses examined over 10 years. American Journal of Occupational Therapy, 72(4_Supplement_1). doi:10.5014/ajot.2018.72s1rp302d

Wahlström, J., Mathiassen, S. E., Liv, P., Hedlund, P., Ahlgren, C., \& Forsman, M. (2010). Upper arm postures and movements in female hairdressers across four full working days. The Annals of Occupational Hygiene, 54(5), 584-594. doi:10.1093/annhyg/meq028 
Widanarko, B., Legg, S., Devereux, J., \& Stevenson, M. (2014). The combined effect of physical, psychosocial/organisational and/or environmental risk factors on the presence of work-related musculoskeletal symptoms and its consequences. Applied Ergonomics, 45(6), 1610-1621. doi:10.1016/j.apergo.2014.05.018

Yan, P., Yang, Y., Zhang, L., Li, F., Huang, A., Wang, Y., Dai, Y., \& Yao, H. (2018). Correlation analysis between work-related musculoskeletal disorders and the nursing practice environment, quality of life, and social support in the nursing professionals. Medicine, 97(9). doi:10.1097/md.0000000000010026

Yarandi, M. S., Koohpaei, A., Arsang, S., \& Ebrahimi, A. (2018). Ergonomic evaluation of working postures and analysis of relationship between physical activities with musculoskeletal disorders among men barbers in Karaj (Iran). Archives of Hygiene Sciences, 7(2), 98-105. 
APPENDIX A

Rapid Entire Body Assessment and Rapid Upper Limb Assessment Worksheet 
A. Neck, Trunk and Leg Analysis Step 1: Locate Neck Position

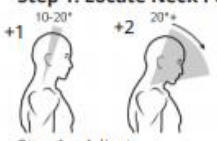

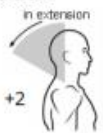

Step 1a: Adjust... If neck is twisted: +1

Step 2: Locate Trunk Position

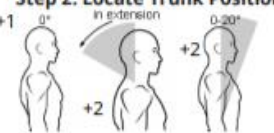

Step 2a: Adjust..

If trunk is twisted: +1 If trunk is side bending: +1

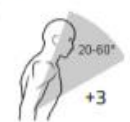

Step 3: Legs

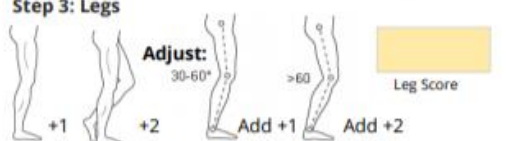

Step 4: Look-up Posture Score in Table A Using values from steps 1.3 above,
Locate score in Table A

Step 5: Add Force/Load Score Posture Score A If load $<11$ lbs, ; +0

If load $>22$ lbs: +2 .

Adjust: If shock or rapid build up of force: add +1 Force $/$ Load Score

Step 6: Score A, Find Row in Table C Add values from steps 4 \& 5 to obtain Score $A$ Find Row in Table C.

Score A

Scoring

$1=$ Negligible Risk

$8-10=$ Medium Risk, Further Investigate. Change Soon,

$8-10=$ High Risk. Investigate and Implement Change

it+ = Very High Risk, Implement Change

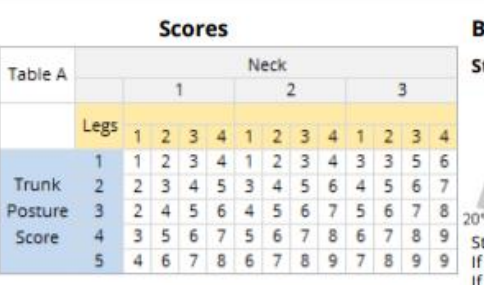

B. Arm and Wrist Analysis

Step 7: Locate Upper Arm Position:

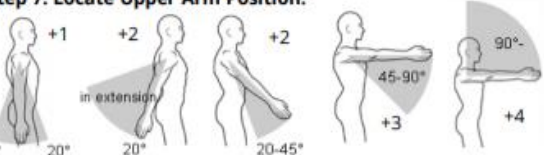

Step 7 adiust

If shoulder is raised: +1

if amer is supported or $p$

Sten 8: Locate Lower Arm Position:

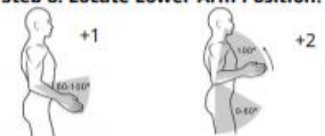

Upper Arm Score

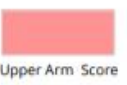

Table B $\quad \begin{array}{ccc}1 & 2\end{array}$

\begin{tabular}{|c|cccccc|}
\hline Wrist & 1 & 2 & 3 & 1 & 2 & 3 \\
1 & 1 & 2 & 2 & 1 & 2 & 3
\end{tabular}

\begin{tabular}{llllllll}
\hline & 2 & 1 & 2 & 3 & 2 & 3 & 4 \\
\hline Upper & 3 & 3 & 4 & 5 & 4 & 5 & 5
\end{tabular}

\begin{tabular}{l|lllllll} 
Arm & 3 & 3 & 4 & 5 & 4 & 5 & 5
\end{tabular}

\begin{tabular}{llllllll|}
\hline Score & 4 & 4 & 5 & 5 & 5 & 6 & 7 \\
5 & 6 & 7 & 8 & 7 & 8 & 8
\end{tabular}

$\begin{array}{lllllllll}6 & 7 & 8 & 8 & 8 & 9 & 9\end{array}$

Sten 9: Locate Wrist Position:

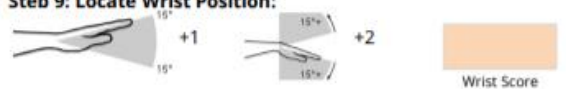

Step 9a: Adjust..

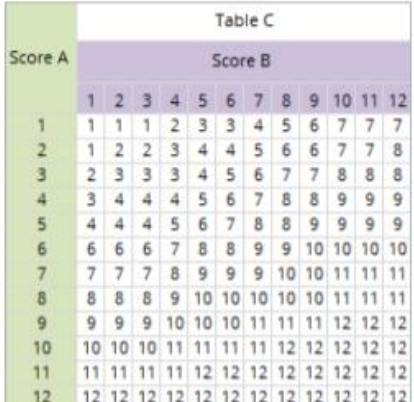

If wrist is bent from midline or twisted : Add +1

Step 10: Look-up Posture Score in Table B Using values from steps $7-9$ above, locate score in Table

Step 11: Add Coupling Score

Posture Scare B

Well fitting Handle and mid rang power grip, good: to

Acceptable but not ideal hand hold or coupling

Hand hold not acceptable by possible, poor: t2

No handles, awkward, unsafe with any body part, Unacceptable: +3

Step 12: Score B, Find Column in Table C

Add values from steps 10 \& 11 to obtain

作

Score A in row from step 6 to obtain Table C Score.

Step 13: Activity Score

+11 or more body parts are held for longer than 1 minute (static)

+1 Repeated small range actions (more than $4 \times$ per minute)

+1 Action causes rapid large range changes in postures or unstable base 


\section{ERGONAMICSS}

A. Arm and Wrist Analysis

Step 1: Locate Upper Arm Position:

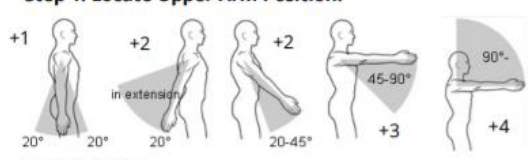

Step 1a: Adjust...

If shoulder is raised: +1

If arm is supported or person is leaning: -1

Step 2: Locate Lower Arm Position:

RULA Employee Assessment Worksheet

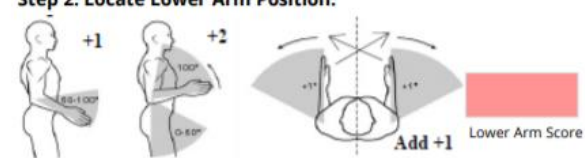

Step 2a: Adjust...
If either arm is working across midline or out to side of body: Add +1

If either arm is working across midline
Step 3: Locate Wrist Position:

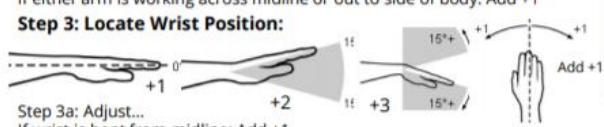

Step 3a: Adjust...
If wrist is bent from midline: Add +1

\section{Step 4: Wrist Twist:}

If wrist is twisted in mid

If wrist is at or near end of range: $+2 \quad$ Wrist Twist Score Wrist Score

Step 5: Look-up Posture Score in Table A: Using values from steps 1.4 above, locate score in

Table A

Step 6: Add Muscle Use Score

If posture mainly static (i.e. held 10 minutes),
Or if action repeated occurs 4 X per minute: +1

Step 7: Add Force/Load Score

If load <. $4.4 \mathrm{lbs}$. (intermittent): +0

If load 4.4 to 22 lbs. (intermittent): +1

If more than 22 lbs. or repeated or shocks: +3

Step 8: Find Row in Table C

Add values from steps 5-7 to obtain
Wrist and Arm Score. Find row in Table C.

\section{Scores}

\begin{tabular}{|c|c|c|c|c|}
\hline Table A & \multicolumn{4}{|c|}{ Wrist Score } \\
& 1 & 2 & 3 & 4 \\
\hline & Wrist & Wrist & Wrist & Wrist \\
\hline
\end{tabular}

Upper Lower Wrist Wrist Wrist Wrist

Arm Arm Twist Twist Twist Twist

$\begin{array}{llllllll}1 & 2 & 1 & 2 & 1 & 2 & 1 & 2\end{array}$

$\begin{array}{llllllllll}1 & 2 & 2 & 2 & 2 & 3 & 3 & 3 & 3\end{array}$

\begin{tabular}{llllllllll}
2 & 3 & 3 & 3 & 3 & 3 & 4 & 4 \\
\hline
\end{tabular}

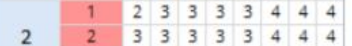

$\begin{array}{lllllllll}1 & 3 & 3 & 4 & 4 & 4 & 4 & 5 & 5\end{array}$

$\begin{array}{lllllllllll}2 & 3 & 4 & 4 & 4 & 4 & 4 & 5 & 5\end{array}$

$4.4,4.4$. 45 : 5

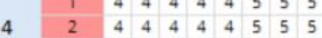

$\begin{array}{llllllll}4 & 4 & 4 & 5 & 5 & 5 & 6 & 6\end{array}$

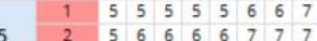

$\begin{array}{lllllllllllll}5 & 2 & 3 & 6 & 6 & 6 & 7 & 7 & 7 & 7 & 8\end{array}$

\begin{tabular}{lllllllllll}
1 & 7 & 7 & 7 & 7 & 7 & 8 & 8 & 9 \\
\hline & & 8 & 8 & 8 & 8 & 9 & 9 & 9
\end{tabular}

$\begin{array}{lllllllllll}6 & 2 & 8 & 8 & 8 & 8 & 8 & 9 & 9 & 9\end{array}$

\begin{tabular}{ccccccccc}
3 & 9 & 9 & 9 & 9 & 9 & 9 & 9 & 9 \\
\hline & Neck, Trunk, Leg Score
\end{tabular}

Table C Neck, Trunk, Leg Score

\begin{tabular}{lllllll|l|l|l}
1 & 1 & 2 & 3 & 3 & 4 & 5 & 5
\end{tabular}

$\begin{array}{llllllllll}2 & 2 & 2 & 3 & 4 & 4 & 5 & 5\end{array}$

$\begin{array}{llllllll}3 & 3 & 3 & 3 & 4 & 4 & 5 & 6\end{array}$

Wrist / Arm $4 \begin{array}{lllllllll}4 & 3 & 3 & 3 & 4 & 5 & 6 & 6\end{array}$

Score $\quad \begin{array}{lllllllll}5 & 4 & 4 & 4 & 5 & 6 & 7 & 7\end{array}$

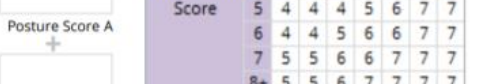

$\begin{array}{llllllll}7 & 5 & 5 & 6 & 6 & 7 & 7 & 7 \\ 8+5 & 5 & 6 & 7 & 7 & 7 & 7\end{array}$

Muscle Use Score Scoring: (final score from Table C)

$1-2=$ acceptable posture
$3-4=$ further investigation, change may be needed

Force / Load Score $\quad \begin{aligned} & 3-6=\text { further investigation, change soon } \\ & \quad 7=\text { investigate and implement change }\end{aligned}$ \begin{tabular}{llllllllll|}
1 & 1 & 2 & 2 & 2 & 2 & 3 & 3 & 3
\end{tabular}

$\begin{array}{lllllllllll}2 & 2 & 3 & 3 & 3 & 3 & 3 & 4 & 4 & 4 \\ & 3 & 3 & 4 & 4 & 4 & 4 & 4 & 5 & 5\end{array}$

Task Name:

Date:

B. Neck, Trunk and Leg Analysis

Step 9: Locate Neck Position:

$(3)+2$ Neck Score

Step 9a: Adjust...

If neck is side bending: +

Step 10: Locate Trunk Position:

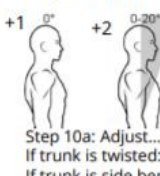

trunk is twisted: +1

If trunk is side bending: +1

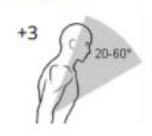

$+4$

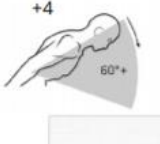

Step 11: Legs:

Trunk Score

If not: +2

\begin{tabular}{|l|l|l|}
\hline Neck & Tabie B: Trunk Posture Score & Leg Score
\end{tabular}

$\begin{array}{llllll}\text { Posture } 1 & 2 & 3 & 4 & 5 & 6\end{array}$

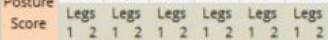

$\begin{array}{llllllllllllll}1 & 1 & 3 & 2 & 3 & 3 & 4 & 5 & 5 & 6 & 6 & 7 & 7\end{array}$

$\begin{array}{llllllllllll}1 & 2 & 3 & 2 & 3 & 4 & 5 & 5 & 5 & 6 & 7 & 7\end{array}$

$\begin{array}{lllllllllllllll}4 & 5 & 5 & 5 & 6 & 6 & 7 & 7 & 7 & 7 & 7 & 8 & 8 \\ 5 & 7 & 7 & 7 & 7 & 7 & 8 & 8 & 0 & 0 & 0\end{array}$

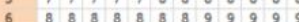

Step 12: Look-up Posture Score in Table B:

Using values from steps 9-11 above,

locate score in Table B

Step 13: Add Muscle Use Score If posture mainly static (i.e. held $>10$ minutes), Or if action repeated occurs $4 \mathrm{X}$ per minute: +

Step 14: Add Force/Load Score
If load $<.4 .4 \mathrm{lbs}$. (intermittent): +0

If load 4.4 to 22 lbs, (intermittent): +1

If load 4.4 to 22 lbs. (static or repeated): +2

Wrist \& Arm Score RULA Score Step 15: Find Column in Table C Neck, Trunk and Leg Score. Find Column in Table C. Neck, Trunk, Leg Score 


\section{APPENDIX B}

Interview Questions 
Interview - The purpose of this interview is to holistically identify risk factors which increase the risk for negative health symptoms. This list of questions will help consider aspects of the participants' occupation of hairdressing. Responses will be used to understand underlying intrinsic (e.g., cognitive, physiological, psychological) and extrinsic (e.g., organizational culture, social support) factors that impact the hairdressing population and facilitate the development of a program which will help address these needs. The interview process is expected to last roughly 30 minutes.

\section{Person-Intrinsic}

- Credentials with years of experience - "How many years of experience do you have with this current occupation? What credentials have you earned?"

- Years of formal education (safety education) - "Did you receive any safety education or program during your tenure at a beauty academy or at a previous workplace?" If yes:

○ "What was taught in this safety program (e.g., safe work postures, risk of hair product exposures, time-management and pacing)?"

○ "How was it taught (e.g., face-to-face with an instructor, 1-hour video, training materials, modeling)

○ "How long was the safety education (e.g., one hour, one week, throughout the course curriculum)?

○ "Have you consistently applied it into your own routines? If yes, how?"

\section{Anthropometric}

- Age of participant(s) - "How old are you?"

- Gender - "What gender do you identify yourself as by?"

- Height - "What is your height?"

- Weight - "What is your weight?"

- Dominant Hand - "Are you Left-handed or Right-handed?

\section{Cognitive}

- "Do you find it difficult to process information from multiple sources at work like listening to clients while making hair decisions?"

- "How does it feel to solve problems and make decisions in the moment at work?"

- "Do you feel like you can focus at work?"

\section{Physiological}

- Current condition - "Do you currently experience any pain, discomfort, or other symptoms now? If yes:

○ "Are you currently experiencing any pain at this moment? If so, how?"

○ "Where is the condition located?"

○ "How would you describe the pain?"

○ "How long have you experienced this pain for?"

○ "What activities or movements exacerbate the condition?" 
- Fatigue - "How fatigued or tired do you get during and after work?" *Can use a scale if participant has trouble providing a description.

- RULA - "What are the most difficult postures and work tasks? Why?"

\section{Psychological}

- Diet - "Do you feel that you eat regularly during the day? If not, do you feel it influences your energy or mood?"

- Diet - "How long are your meal breaks? Do you typically prepare your own meals or order take out?"

- Psychological - "How do you feel when you have to come to work (e.g., anxious, unmotivated, eager, etc.)?"

- Psychological - "How does your work impact you emotionally?"

- Psychological - "How much control do you feel like you have at work?"

- Psychological - "How satisfied are you with your job?"

Environment-Extrinsic

Organizational culture

- Culture - "How would you describe the culture of the work environment?"

- Health promotion - "How does the hair salon promote personal health and wellness?"

Social support

- Emotional support - "How satisfied are you with management?"

- Emotional support - "How does this hair salon provide emotional support for you?"

- Social Interactions - "How do you feel when you are interacting with clients? What about with your coworkers?

- Stress - "What causes you stress at work and how does this affect your work day?"

- Time management - "How many assistants do you have to help you with your tasks?"

- Time management - "How are you with managing your time?"

- $\quad$ Time management - "What measures do you take to ensure time is managed efficiently?"

- $\quad$ Time management - "Do you find time to take breaks during your work shift? If so, how long do you spend?" 
APPENDIX C

Male/Female Cornell Musculoskeletal Discomfort Questionnaires (Standing Worker) 

position of the body parts referred to in the questionnaire. Please answer by marking

the appropriate box.

\begin{tabular}{|c|c|c|c|c|c|c|c|c|c|c|}
\hline \multicolumn{5}{|c|}{$\begin{array}{l}\text { During the last work week } \\
\text { how often did you experience } \\
\text { ache, pain, discomfort in: }\end{array}$} & \multicolumn{3}{|c|}{$\begin{array}{l}\text { If you experienced ache, pain, } \\
\text { discomfort, how uncomfortable } \\
\text { was this? }\end{array}$} & \multicolumn{3}{|c|}{$\begin{array}{l}\text { If you experienced ache, } \\
\text { pain, discomfort, did } \\
\text { this interfere with your } \\
\text { ability to work? }\end{array}$} \\
\hline Never & $\begin{array}{l}1-2 \\
\text { times } \\
\text { last } \\
\text { week }\end{array}$ & $\begin{array}{l}3-4 \\
\text { times } \\
\text { last } \\
\text { week }\end{array}$ & $\begin{array}{l}\text { Once } \\
\text { every } \\
\text { day }\end{array}$ & $\begin{array}{l}\text { Several } \\
\text { times } \\
\text { every } \\
\text { day }\end{array}$ & $\begin{array}{l}\text { Slightly } \\
\text { uncomfortable }\end{array}$ & $\begin{array}{l}\text { Moderately } \\
\text { uncomfortable }\end{array}$ & $\begin{array}{l}\text { Very } \\
\text { uncomfortable }\end{array}$ & Not at all & $\begin{array}{l}\text { Slightly } \\
\text { interfered }\end{array}$ & $\begin{array}{l}\text { Substantially } \\
\text { interfered }\end{array}$ \\
\hline$\square$ & $\square$ & $\square$ & $\square$ & $\square$ & $\square$ & $\square$ & $\square$ & $\square$ & $\square$ & $\square$ \\
\hline $\begin{array}{l}\square \\
\square\end{array}$ & $\begin{array}{l}\square \\
\square\end{array}$ & $\begin{array}{l}\square \\
\square\end{array}$ & $\begin{array}{l}\square \\
\square\end{array}$ & $\begin{array}{l}\square \\
\square\end{array}$ & $\begin{array}{l}\square \\
\square\end{array}$ & $\begin{array}{l}\square \\
\square\end{array}$ & $\begin{array}{l}\square \\
\square\end{array}$ & $\begin{array}{l}\square \\
\square\end{array}$ & $\begin{array}{l}\square \\
\square\end{array}$ & $\begin{array}{l}\square \\
\square\end{array}$ \\
\hline$\square$ & $\square$ & $\square$ & $\square$ & $\square$ & $\square$ & $\square$ & $\square$ & $\square$ & $\square$ & $\square$ \\
\hline $\begin{array}{l}\square \\
\square\end{array}$ & $\begin{array}{l}\square \\
\square\end{array}$ & $\begin{array}{l}\square \\
\square\end{array}$ & $\begin{array}{l}\square \\
\square\end{array}$ & $\begin{array}{l}\square \\
\square\end{array}$ & $\begin{array}{l}\square \\
\square\end{array}$ & $\begin{array}{l}\square \\
\square\end{array}$ & $\begin{array}{l}\square \\
\square\end{array}$ & $\begin{array}{l}\square \\
\square\end{array}$ & $\begin{array}{l}\square \\
\square\end{array}$ & $\begin{array}{l}\square \\
\square\end{array}$ \\
\hline$\square$ & $\square$ & $\square$ & $\square$ & $\square$ & $\square$ & $\square$ & $\square$ & $\square$ & $\square$ & $\square$ \\
\hline $\begin{array}{l}\square \\
\square\end{array}$ & $\begin{array}{l}\square \\
\square\end{array}$ & $\begin{array}{l}\square \\
\square\end{array}$ & $\begin{array}{l}\square \\
\square\end{array}$ & $\begin{array}{l}\square \\
\square\end{array}$ & $\begin{array}{l}\square \\
\square\end{array}$ & $\begin{array}{l}\square \\
\square\end{array}$ & $\begin{array}{l}\square \\
\square\end{array}$ & $\begin{array}{l}\square \\
\square\end{array}$ & $\begin{array}{l}\square \\
\square\end{array}$ & $\begin{array}{l}\square \\
\square\end{array}$ \\
\hline $\begin{array}{l}\square \\
\square\end{array}$ & $\begin{array}{l}\square \\
\square\end{array}$ & $\begin{array}{l}\square \\
\square\end{array}$ & $\begin{array}{l}\square \\
\square\end{array}$ & $\begin{array}{l}\square \\
\square\end{array}$ & $\begin{array}{l}\square \\
\square\end{array}$ & $\begin{array}{l}\square \\
\square\end{array}$ & $\begin{array}{l}\square \\
\square\end{array}$ & $\begin{array}{l}\square \\
\square\end{array}$ & $\begin{array}{l}\square \\
\square\end{array}$ & $\begin{array}{l}\square \\
\square\end{array}$ \\
\hline$\square$ & $\square$ & $\square$ & $\square$ & $\square$ & $\square$ & $\square$ & $\square$ & $\square$ & $\square$ & $\square$ \\
\hline $\begin{array}{l}\square \\
\square\end{array}$ & $\begin{array}{l}\square \\
\square\end{array}$ & $\begin{array}{l}\square \\
\square\end{array}$ & $\begin{array}{l}\square \\
\square\end{array}$ & $\begin{array}{l}\square \\
\square\end{array}$ & $\begin{array}{l}\square \\
\square\end{array}$ & $\begin{array}{l}\square \\
\square\end{array}$ & $\begin{array}{l}\square \\
\square\end{array}$ & $\begin{array}{l}\square \\
\square\end{array}$ & $\begin{array}{l}\square \\
\square\end{array}$ & $\begin{array}{l}\square \\
\square\end{array}$ \\
\hline $\begin{array}{l}\square \\
\square\end{array}$ & $\begin{array}{l}\square \\
\square\end{array}$ & $\begin{array}{l}\square \\
\square\end{array}$ & $\begin{array}{l}\square \\
\square\end{array}$ & $\begin{array}{l}\square \\
\square\end{array}$ & $\begin{array}{l}\square \\
\square\end{array}$ & $\begin{array}{l}\square \\
\square\end{array}$ & $\begin{array}{l}\square \\
\square\end{array}$ & $\begin{array}{l}\square \\
\square\end{array}$ & $\begin{array}{l}\square \\
\square\end{array}$ & $\begin{array}{l}\square \\
\square\end{array}$ \\
\hline $\begin{array}{l}\square \\
\square\end{array}$ & $\begin{array}{l}\square \\
\square\end{array}$ & $\begin{array}{l}\square \\
\square\end{array}$ & $\begin{array}{l}\square \\
\square\end{array}$ & $\begin{array}{l}\square \\
\square\end{array}$ & $\begin{array}{l}\square \\
\square\end{array}$ & $\begin{array}{l}\square \\
\square\end{array}$ & $\begin{array}{l}\square \\
\square\end{array}$ & $\begin{array}{l}\square \\
\square\end{array}$ & $\begin{array}{l}\square \\
\square\end{array}$ & $\begin{array}{l}\square \\
\square\end{array}$ \\
\hline $\begin{array}{l}\square \\
\square\end{array}$ & $\begin{array}{l}\square \\
\square\end{array}$ & $\begin{array}{l}\square \\
\square\end{array}$ & $\begin{array}{l}\square \\
\square\end{array}$ & $\begin{array}{l}\square \\
\square\end{array}$ & $\begin{array}{l}\square \\
\square\end{array}$ & $\begin{array}{l}\square \\
\square\end{array}$ & $\begin{array}{l}\square \\
\square\end{array}$ & $\begin{array}{l}\square \\
\square\end{array}$ & $\begin{array}{l}\square \\
\square\end{array}$ & $\begin{array}{l}\square \\
\square\end{array}$ \\
\hline
\end{tabular}




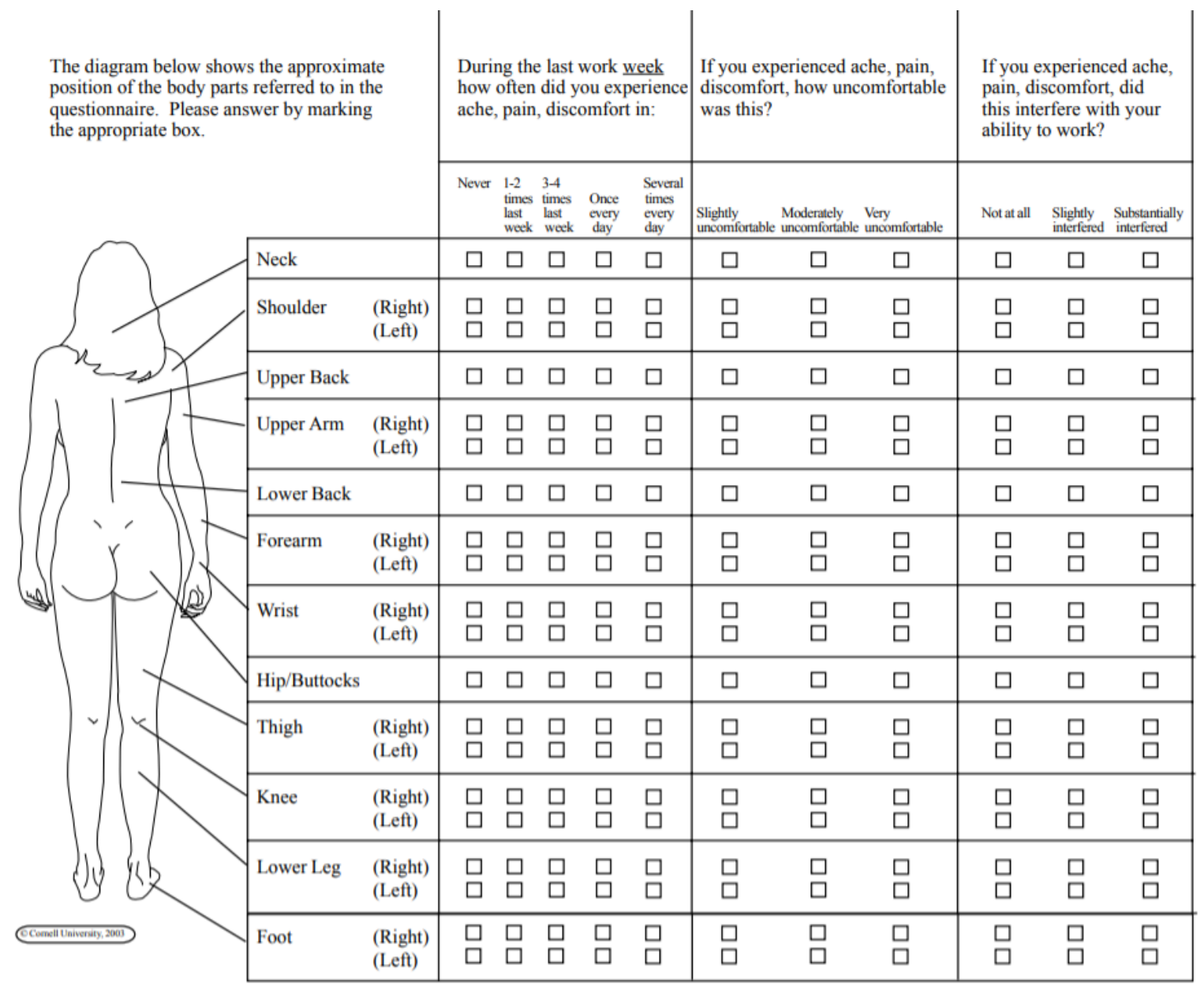




\section{APPENDIX D}

Proposed Interview Consent Form 


\section{Interview Consent Form}

- Voluntary Consent. You are being asked to volunteer for a student project. It is up to you whether you choose to participate or not. There will be no penalty or loss of benefits to which you are otherwise entitled if you choose not to participate or discontinue participation.

- Purpose. The purpose of this research is to examine the hairdressing occupation as a whole, assess the health-related needs of hairdressers, and create a holistic program that would address current needs and future preventative treatments for this occupation.

- Duration. It is expected that your participation will last roughly 30 minutes.

- Procedures and Activities. You will be asked about questions regarding your personal work experiences and workplace setting.

- Risks. Some of the foreseeable risks or discomforts of your participation include strong emotions or reactions related to discussing potential workplace stress and concerns.

- Benefits. No direct benefit.

1. I agree to be interviewed for the purposes of this student project.

2. The purpose of this interview has been explained to me.

3. Any questions that I asked about the purposes of this interview and study have been answered to my satisfaction.

Name of Participant:

Signature of Participant:

Date:

I have explained the study and the implications of the interview to the participant and I believe that the consent is informed and that he/she understands the implications of participation.

Name of Interviewer:

Signature of Interviewer:

Date: 
APPENDIX E

\section{Task Analysis}




\section{Task Analysis}

Biomechanical

- Haircutting

- Due to the variety of styles and techniques used by hairdressers, it would be most appropriate to measure the amount of times the hairdressers perform a certain movement rather than a certain section of a task:

- Lateral head tilt

- Head flex/extension

- Lateral trunk tilt

- Trunk flexion

- Shoulder elevation (flex/extension, ab/adduction)

- Wrist flex/extension

- Arm flex/extension

- Digit manipulation (grasping combs, using vibrating instruments such as clippers, and repetitive pincer grasp and release from using shears)

- Standing

- Duration of positions

- Proper body positioning

- Pumping and moving the seat throughout the haircutting

- Roughly 45 minutes to over an hour

O One example of haircutting sequence:

- Putting the cape around the client's neck

- Pumping and moving the chair seat throughout the haircutting

- Wash the hair

- Part the hair using the comb

- Section the hair into 4 quadrants using the comb

- Cut the hair from the back of the client's head first

- Adjust how much needs to get cut off using fingers to measure

- Cut the hair using shears; keep the hair between the fingers tight or in the comb depending on the haircut

\section{- Coloring}

- Continue cutting hair section by section (moving around the client)

○ Consultation with client (psychosocial)

- Looking through their hair to check for texture and hair (fine motor control, wrist control)

$\circ$ Reaching and grasping for color products (exposure to dyes) and utensils for mixing process

- Squeezing color products (extrinsic/intrinsic muscle activation)

- Stirring color formulation content (wrist flex/extension, ulnar/radial deviation)

- Using brush (wrist flex/extension, ulnar/radial deviation)

- Using digits to manage color application on hair (fine motor control, wrist flex/extension, elbow flexion, shoulder stabilization) 
- Applying foils (fine motor control, wrist flex/extension, elbow flexion, shoulder stabilization)

- Setting time (time management)

\section{- Cleansing}

- Providing client with towel

○ Reaching for client's hair (trunk flexion)

- Turning faucet on (fine motor control, wrist rotation)

- Checking for water temperature (sensation)

- Saturating client's hair with water using a faucet hose (grasping, wrist rotation, ulnar/radial deviation)

- Using hands to thoroughly saturate hair with water (fine motor control)

○ Reaching for cleansing products

- Pumping or squeezing cleansing products onto hands

○ Applying cleansing products onto client's hair and thoroughly washing it (fine motor control)

○ Rinsing the client's hair with water with hose (grasping, wrist rotation, ulnar/radial deviation)

- Drying client's hair with towel (bilateral grasping, wrist rotation, wrist flex/extension, ulnar/radial deviation, elbow flex/extension, shoulder stabilization)

- Wrapping client's hair with towel after drying (fine motor control, elbow flex/extension, shoulder flexion, shoulder stabilization)

- Blow-drying

- Due to the different styles of blow drying a hair, observation should be focused more on the movements made rather than the specific sections involved in the task:

- Shoulder flexed/abducted

- Elbow flex/extension

- Wrist flex/extension, ulnar/radial deviation (wrist rotation)

- Resistance of hair through brush (applies tension on wrists)

- Grasping for tools

- Pumping and moving the chair throughout the blowdrying

- Roughly 20-45 minutes, but may exceed to an hour depending on hair density and texture

- Inventory (Possibly done by hairstylists, but may also be performed by their assistance)

- Managing products used in the hair salon (time management, sequencing, fine motor control, UE control, balance)

- Sweeping the work station (Possibly done by hairstylists, but may also be performed by their assistance)

○ Sweeping the floor using a broom (neck flexion, visual attention, bilateral grasping, wrist rotation, wrist flex/extension, ulnar/radial deviation, elbow flex/extension, shoulder stabilization, trunk flexion, trunk rotation, balance) 
- Collecting fallen materials using a dust pan (neck flexion, visual attention, ankle dorsiflexion, knee flexion, hip flexion, trunk flexion, shoulder flexion/abduction, elbow flex/extension, wrist flex/extension, ulnar/radial deviation, fine motor control, bilateral coordination)

- Standing after collecting fallen materials (neck extension, ankle plantarflexion, knee extension, hip extension, trunk extension, shoulder extension/adduction, unilateral elbow flexion, unilateral wrist stabilization, unilateral fine motor control for grasping)

○ Disposing fallen material into appropriate disposal bin (visual attention, unilateral shoulder flexion, unilateral elbow extension, unilateral wrist rotation, fine motor control for grasping)

- Laundry (Possibly done by hairstylists, but may also be performed by their assistance)

- Collect articles of clothing

- Carry bin upstairs

- Throw clothes into washer

- Apply detergent

○ Turn on washer

- Take articles of clothing out and place in dryer

- Apply drying sheet

- Turn on dryer

- Collect articles of clothing and throw it in the hamper

- Sanitation of the work station

- Sweeping (see above)

- Cleaning shears, combs, clippers, cape, etc. (fine motor control, UE stabilization)

○ Putting away tools, laundry, towels, etc.; placing combs into the barbicide (fine motor control, UE stabilization)

○ Cleaning seat and placing it stationary (fine motor control, UE stabilization)

Chemical

- Shampoo

- Conditioner

- Hair dyes

- Bleach

- Hair products (sprays, wax, etc.)

- Barbicide

Organizational/Environmental

- Temperature

- Lighting

- Number of hours worked in a shift

- Rest breaks

- Protective gloves and other measures 
- Salon management

- Bowl design 


\section{APPENDIX F}

Presentations and Deliverables 


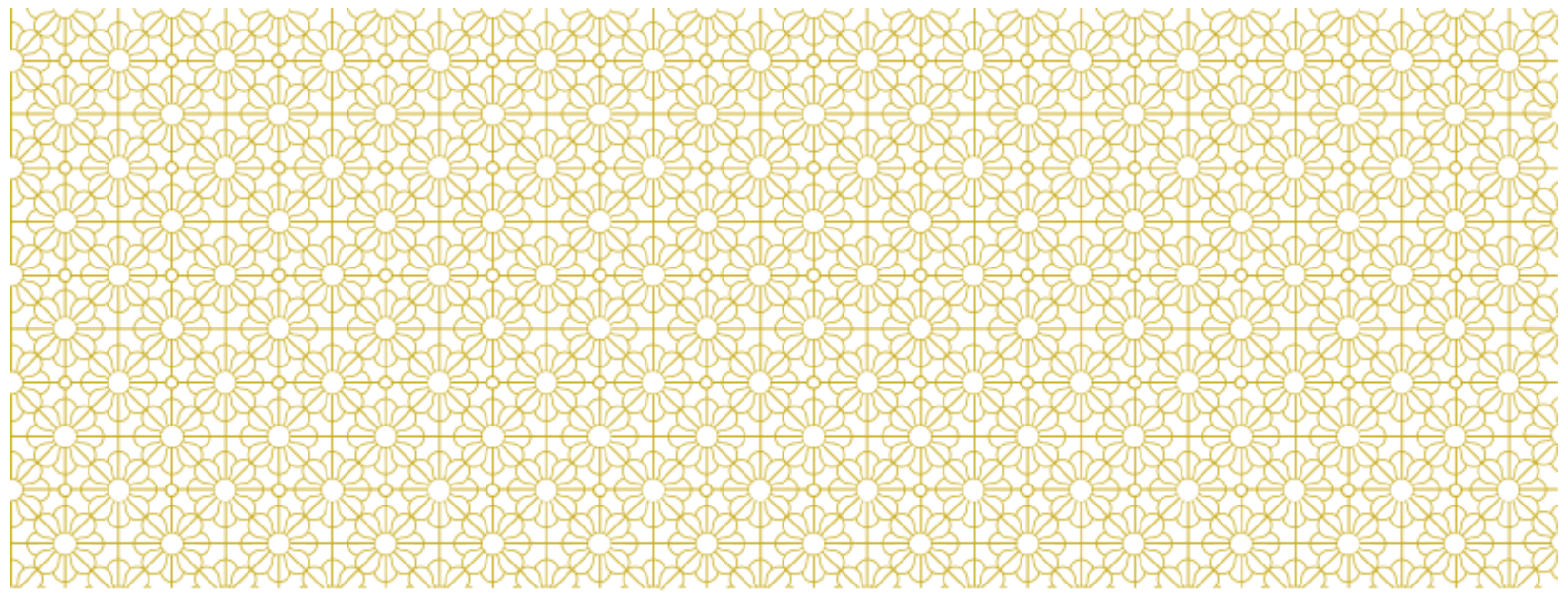

\section{RECOMMENDATIONS FOR IMPROVING WORKPLACE WELLNESS IN HAIRDRESSING \\ Alex Kim, OTD/S \\ University of St. Augustine, San Marcos}
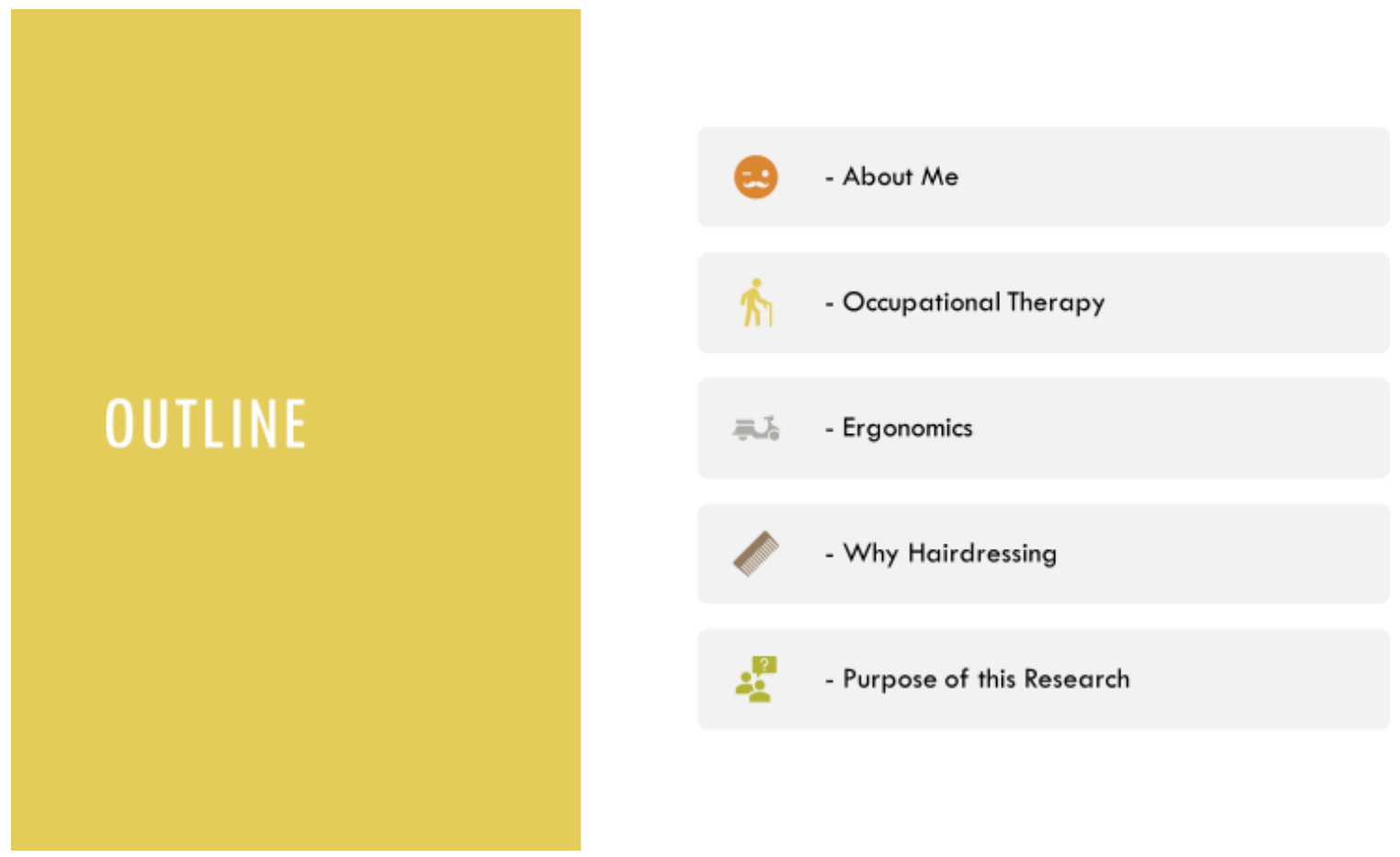

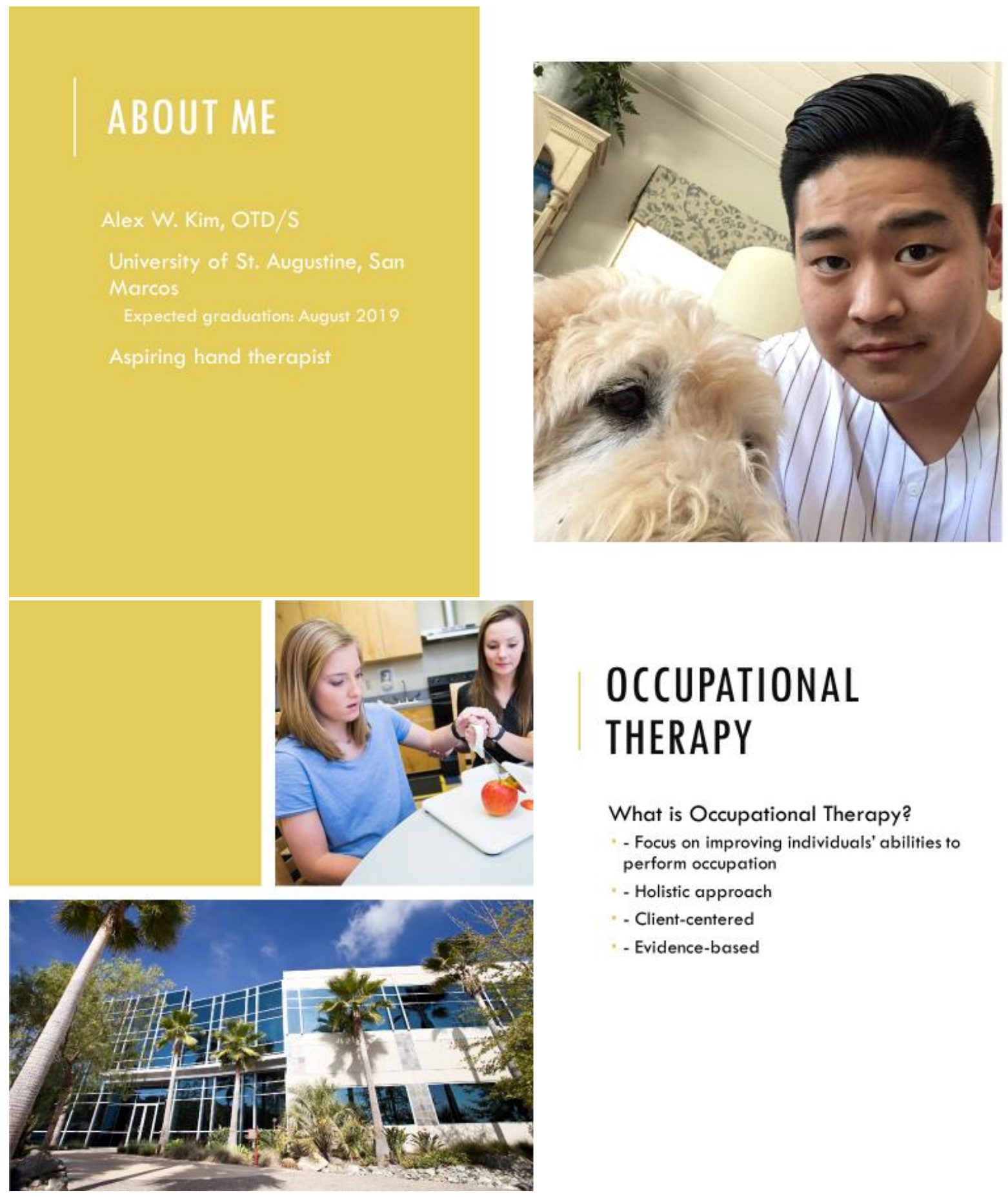

\section{OCCUPATIONAL THERAPY}

What is Occupational Therapy?

- Focus on improving individuals' abilities to perform occupation

- Holistic approach

- - Client-centered

- Evidence-based 


\section{ERGONOMICS}

What is Ergonomics?

- Fitting the workplace to the worker

- Workspace improvements lead to increased productivity
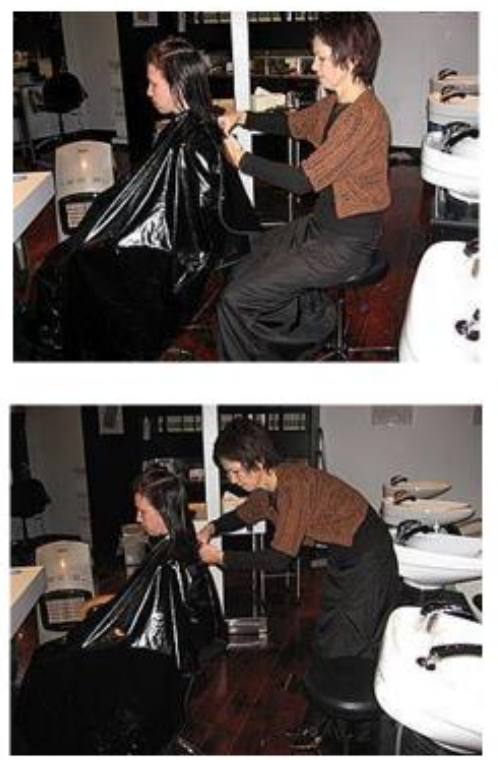

WHY HAIRDRESSING?

- Various risk factors associated with

hairdressing

- Lack of study which analyze the

occupation as a whole

- Hairdressing population in the U.S. (2016): 673,700 workers

- Average age: 39.2 years 
ASSESSING WORKPLACE WELLNESS FOR THE OCCUPATION OF HAIRDRESSING 69

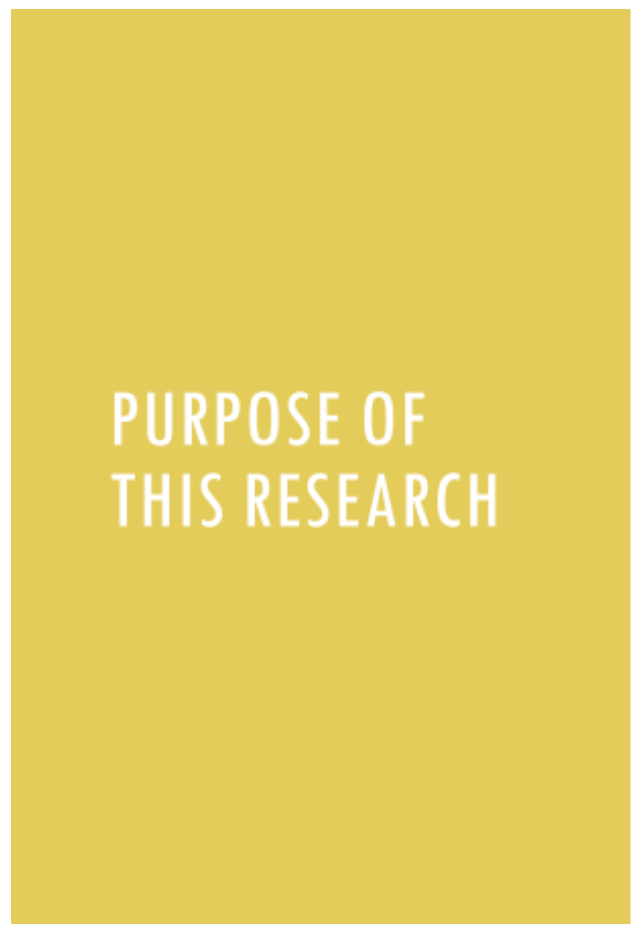

A - Examine the hairdressing occupation
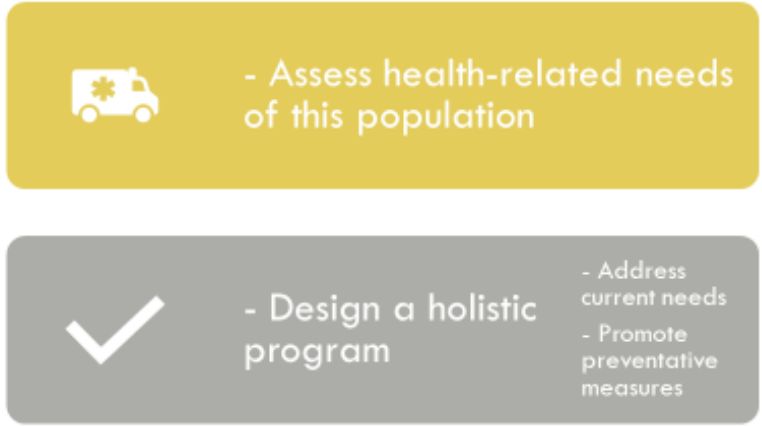


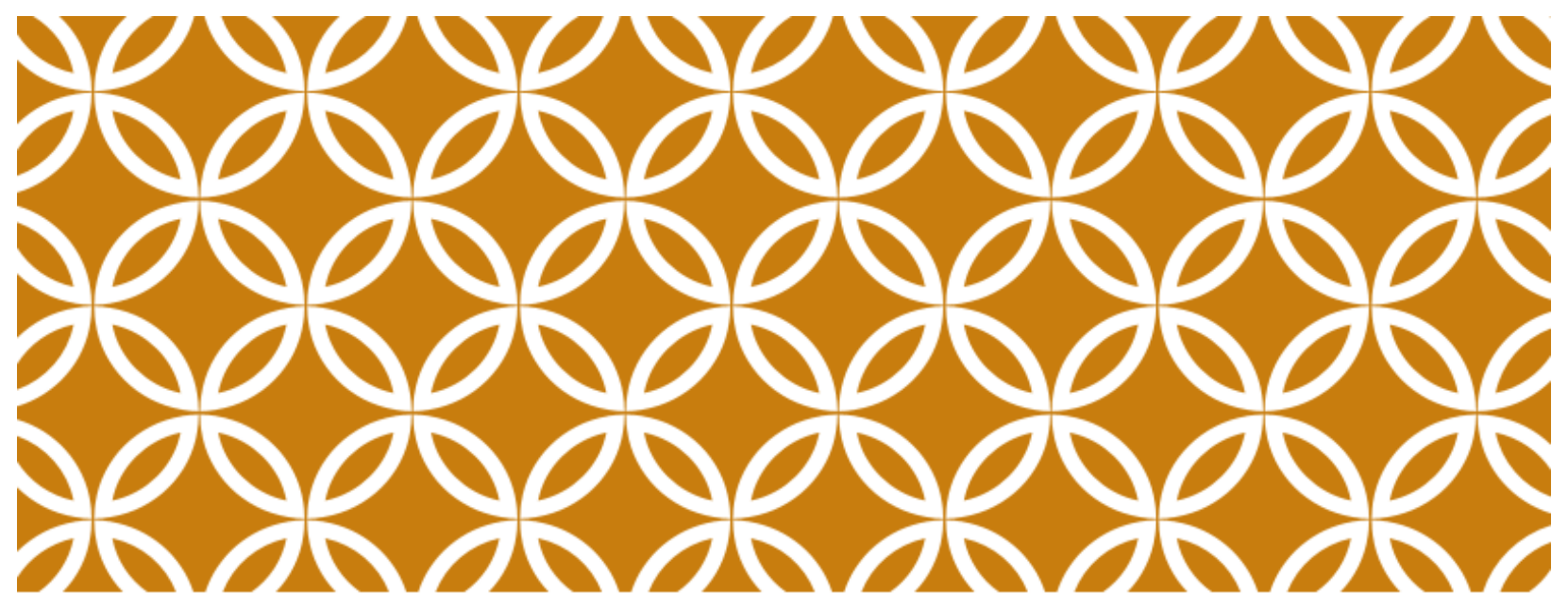

\section{MAINTAINING NEUTRAL POSTURE \\ By Alex Kim, OTD/S \\ University of St. Augustine, San Marcos}

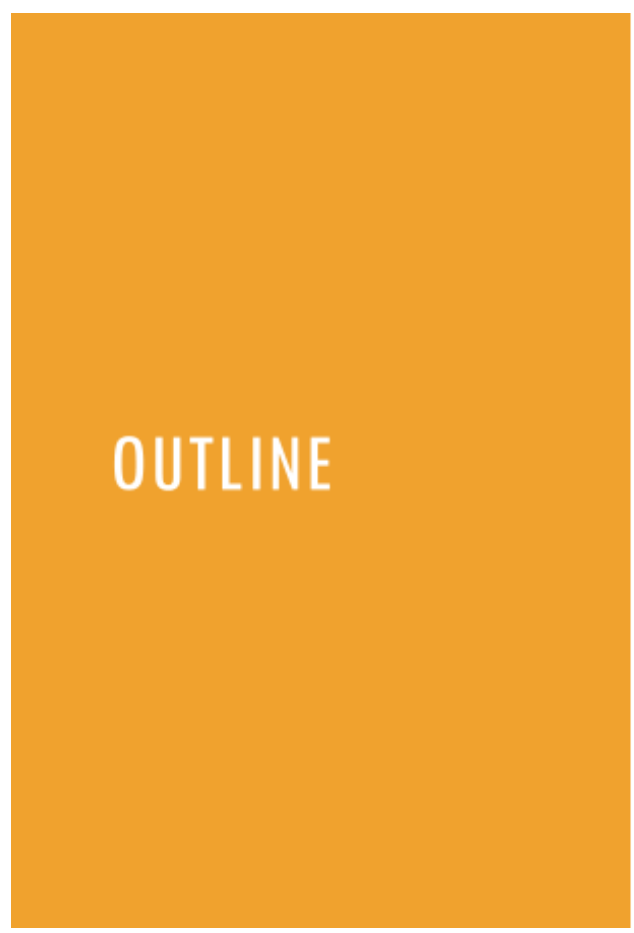

Neutral Posture
Weck and Trunk
Wrists
Feet Positioning
References




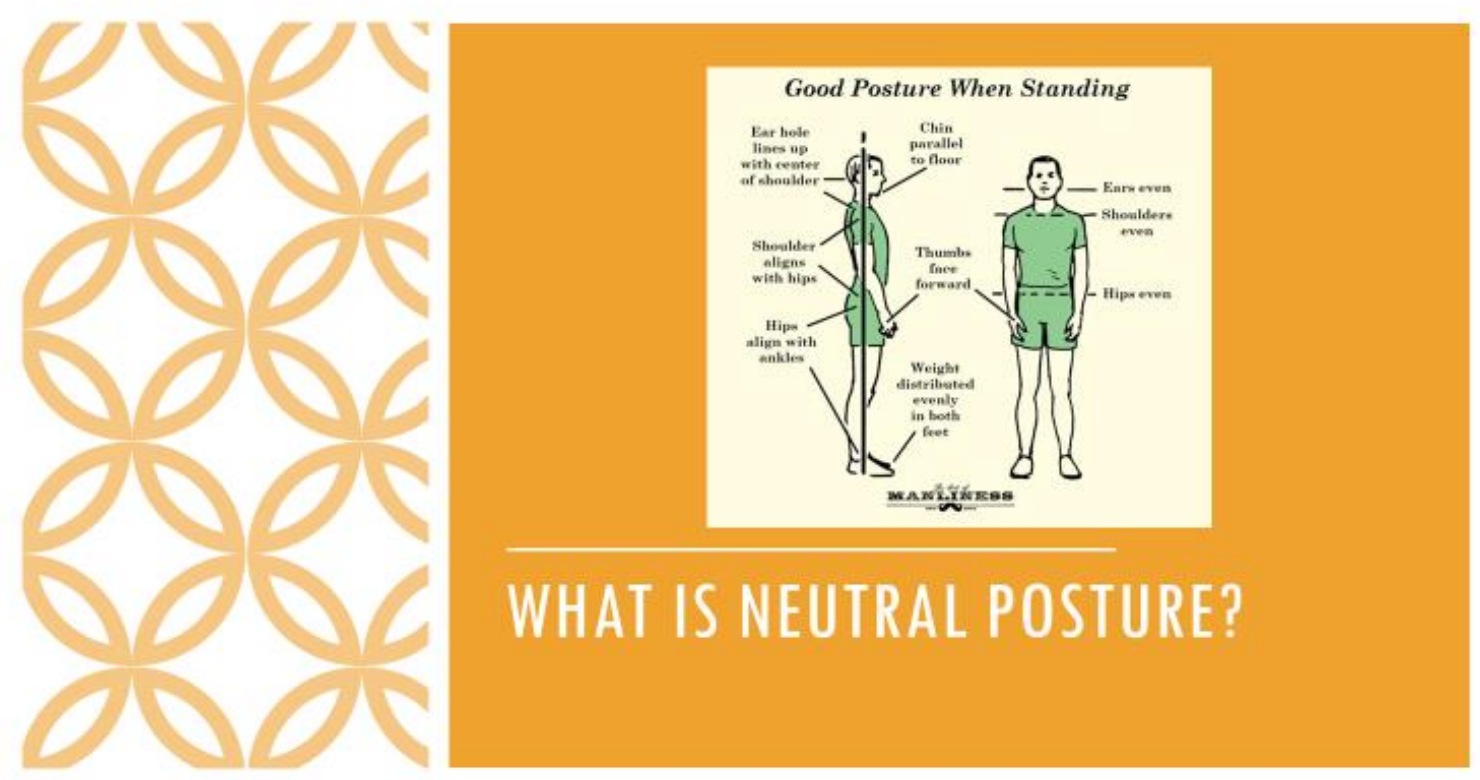

\section{NECK AND TRUNK}

- Minimize neck and trunk

flexion/extension

- Use eyes to look down

- Align ears with shoulders

- Chin tucks:

- Reduce neck and trunk twisting and side-bending

- Reposition the body

- Maintain good distance between body and client

- Not too far, but not too close

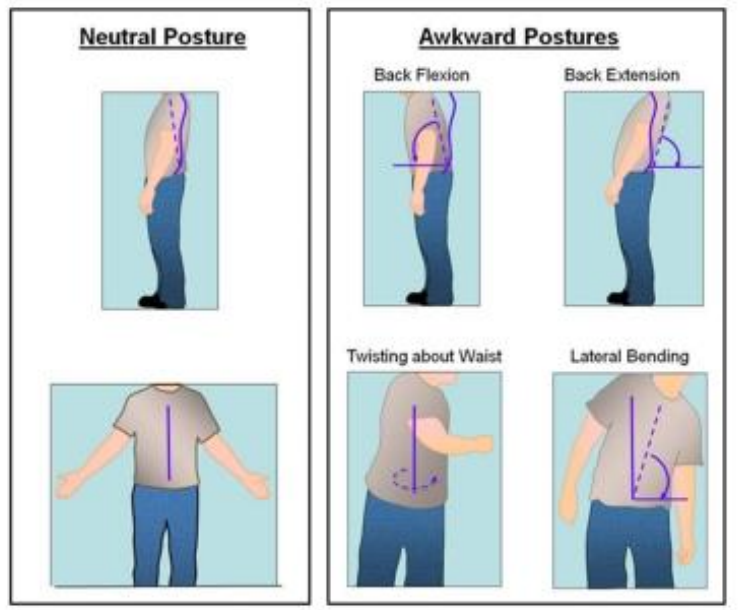




\section{SHOULDERS AND ELBOWS}

- Reduce shoulder flexion/extension

- Maintaining good distance between body and client

- Maintain good elbow angle

- Between 80 to 100 degrees

\section{WRIST}

- Minimize wrist movement as much as possible!

- Flexion/Extension (bending front and back)

- Radial/Ulnar deviation (bending side to side)

- Pronation/Supination (twisting)
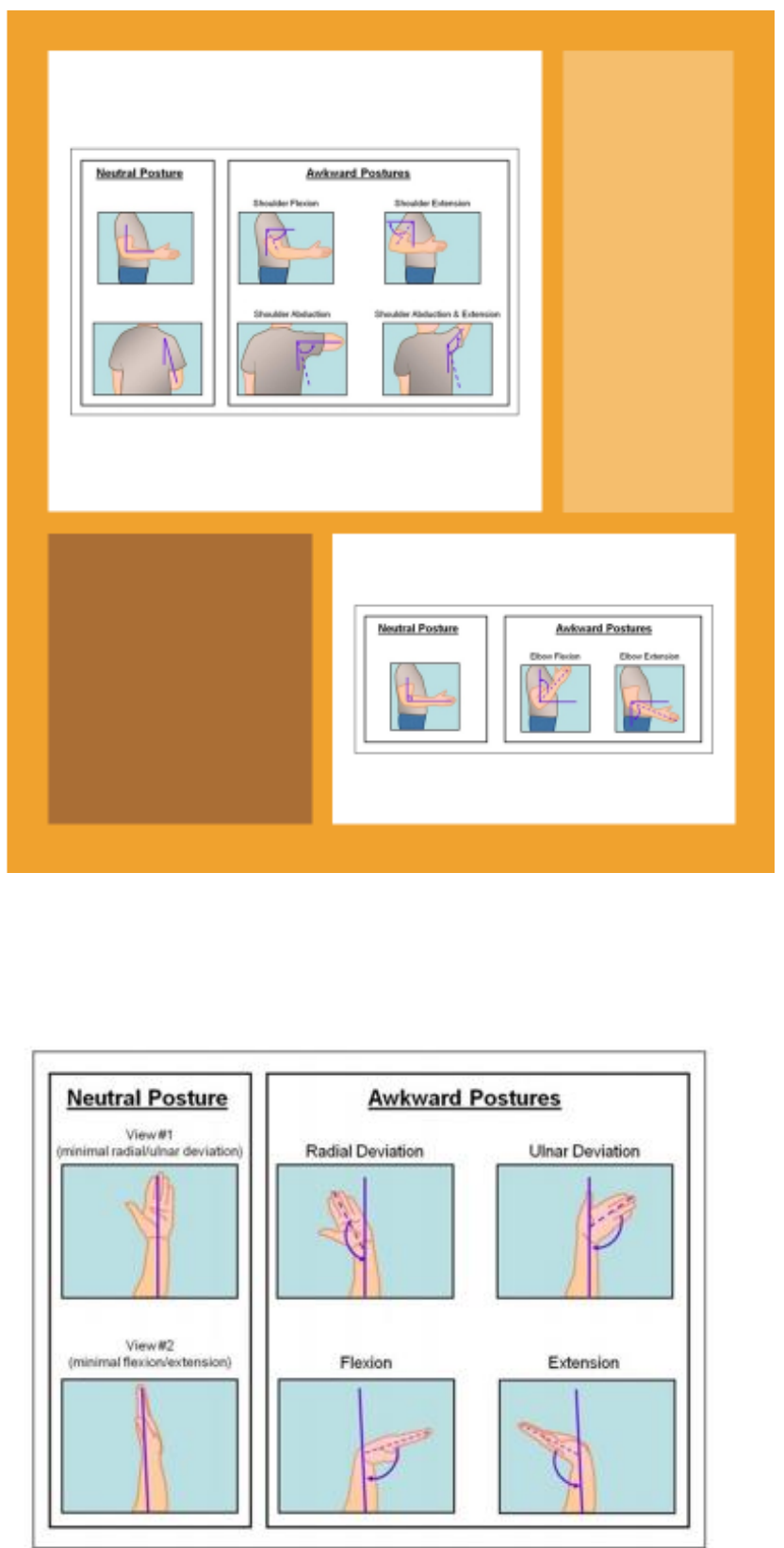


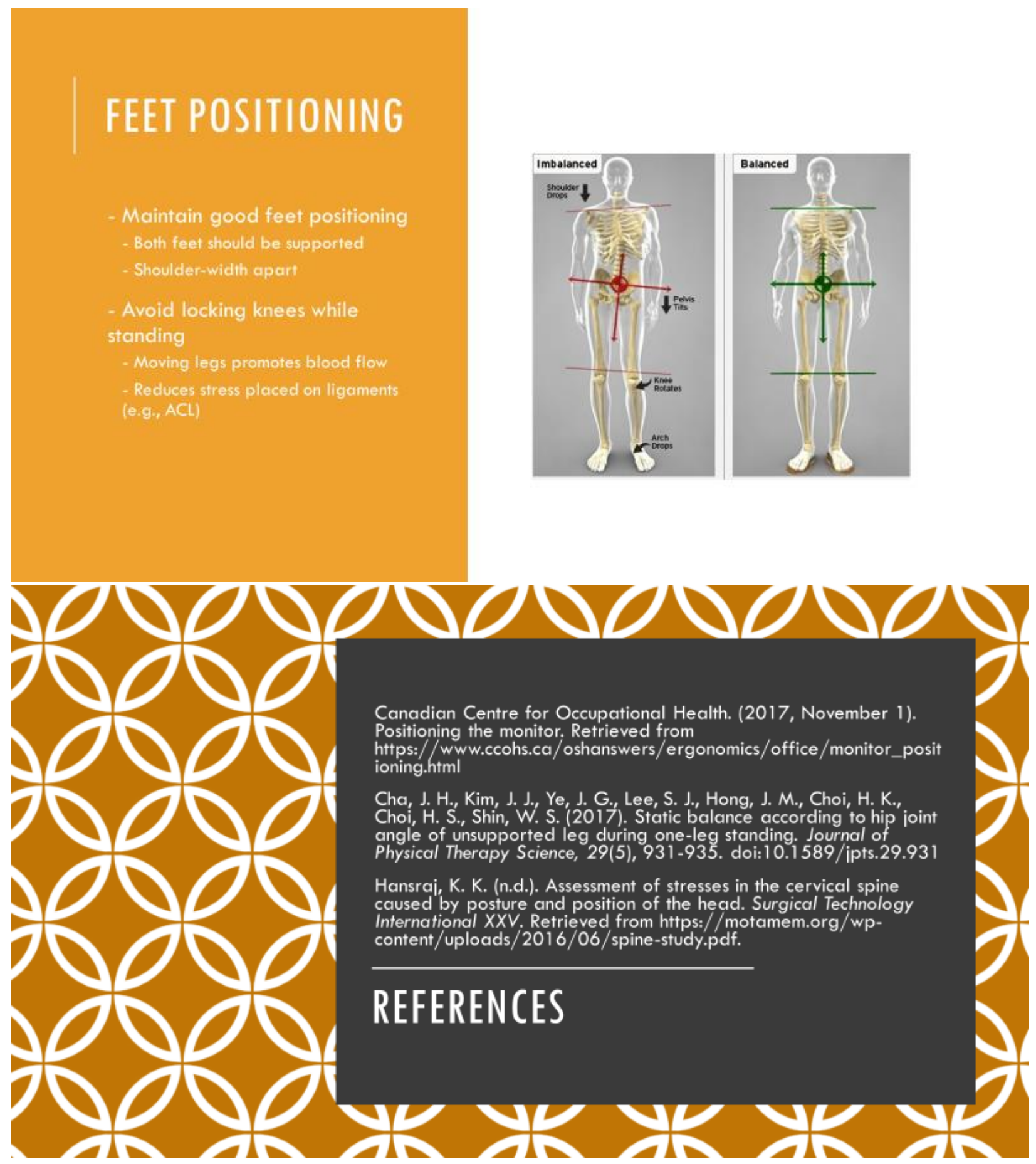




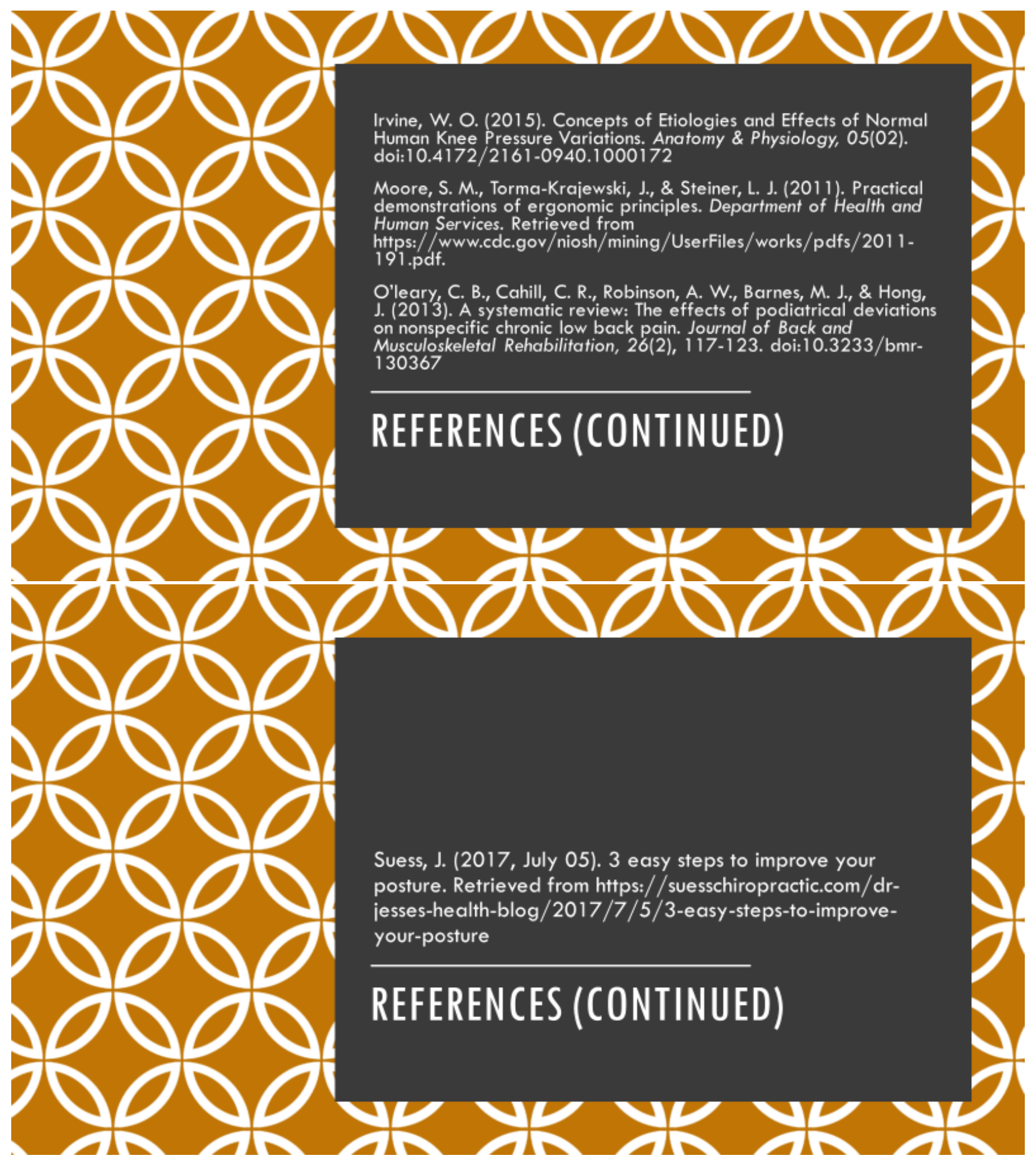




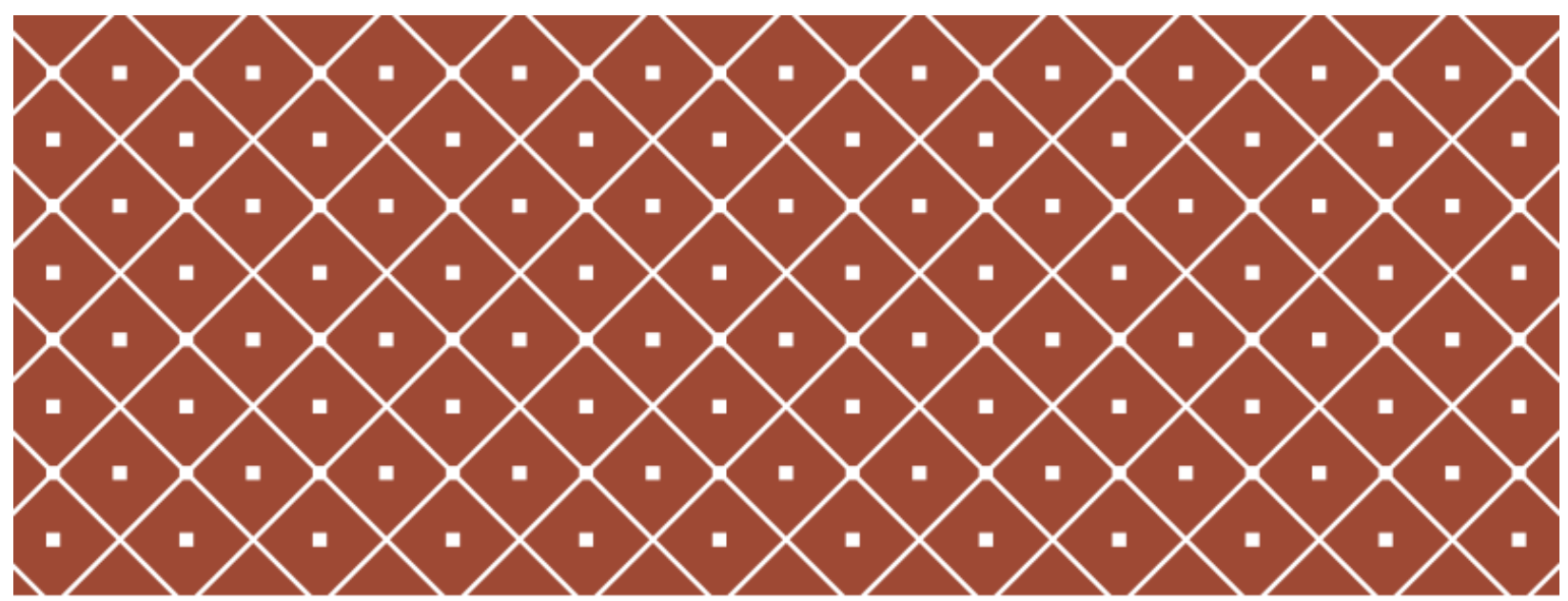

\section{STRETCHING EXERCISES}

By Alex Kim, OTD/S

University of St. Augustine, San Marcos

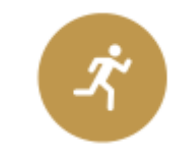

IMPORTANCE OF STRETCHING

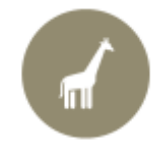

NECK

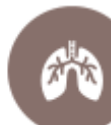

CHEST AND SHOULDER

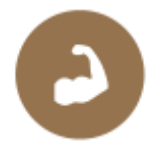

FOREARM

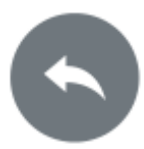

LOW BACK

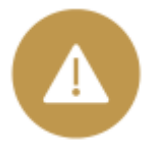

CAUTION

\section{OUTLINE}




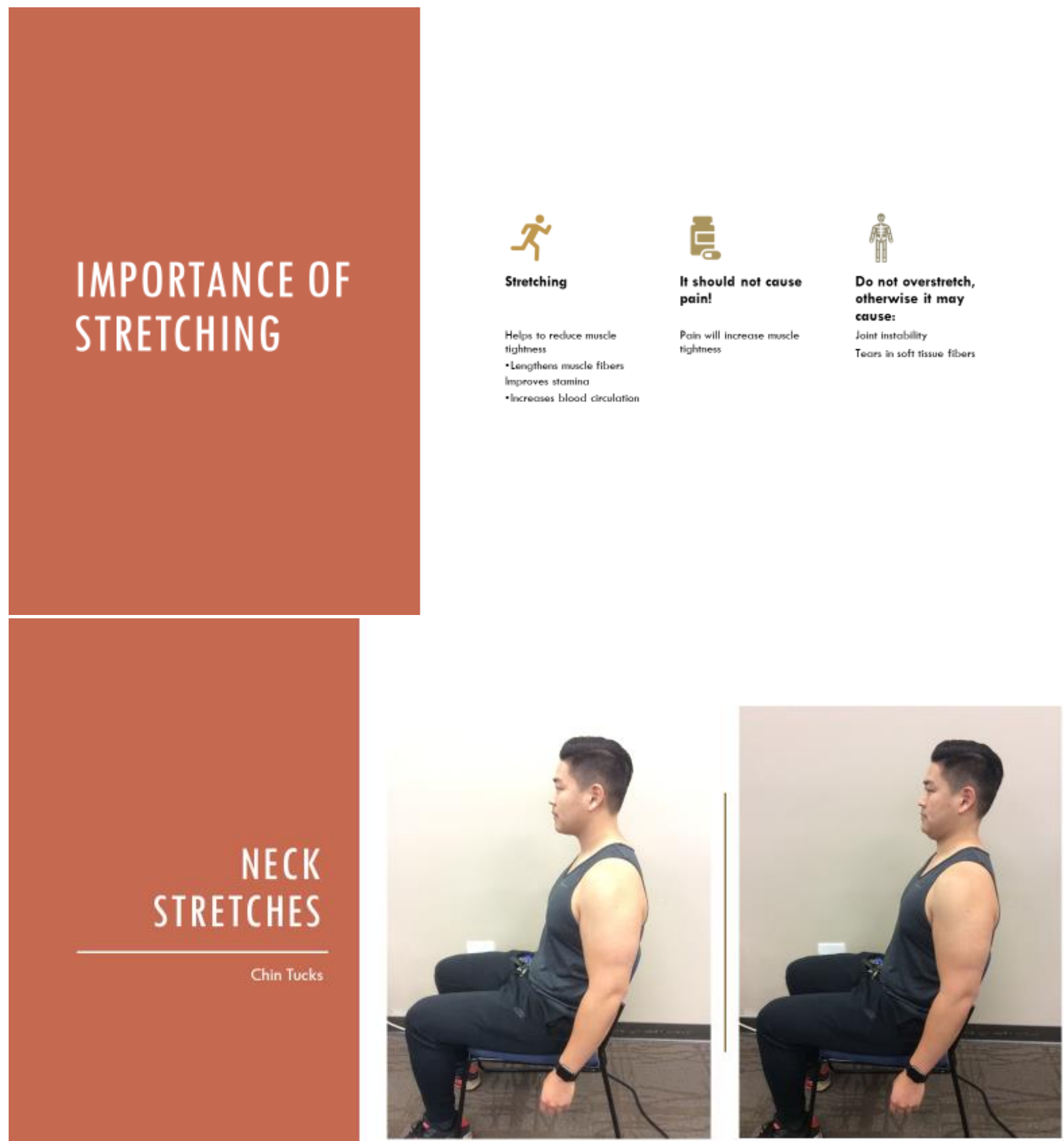



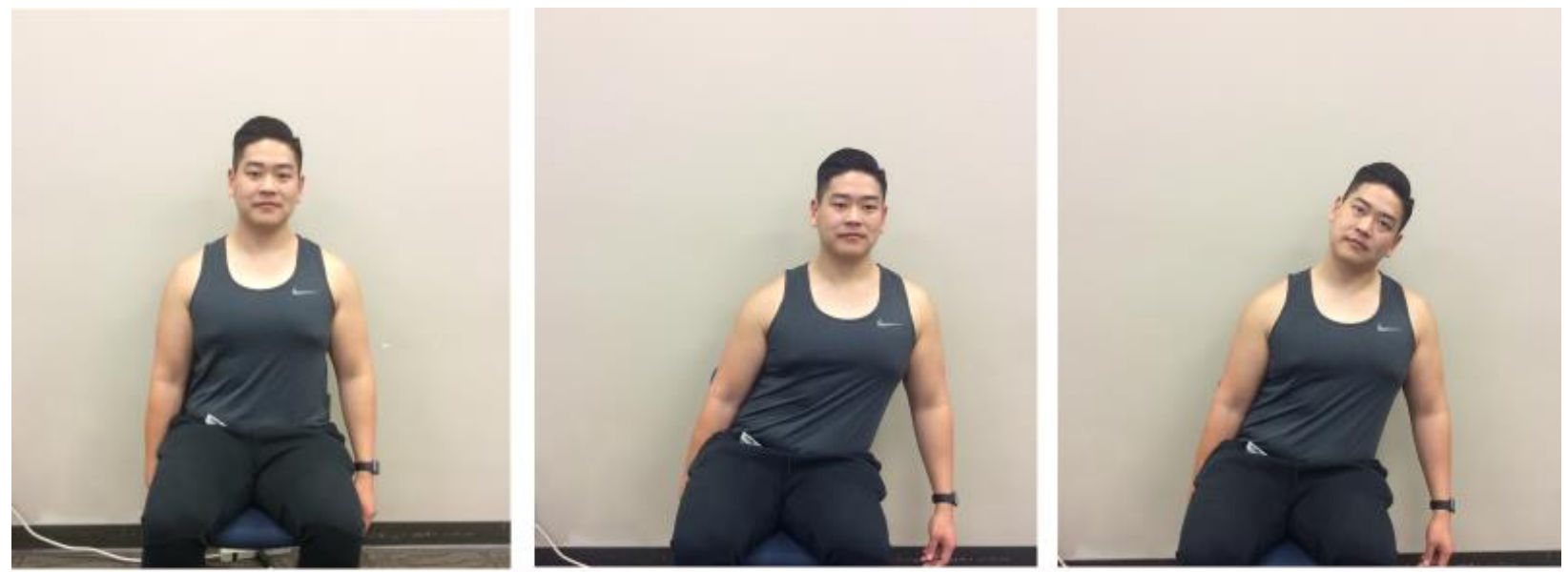

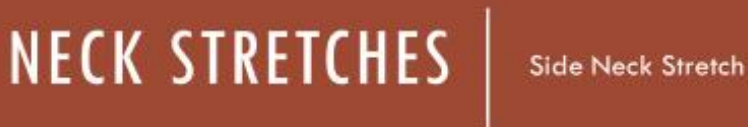

\section{ADDITIONAL NECK STRETCHES}

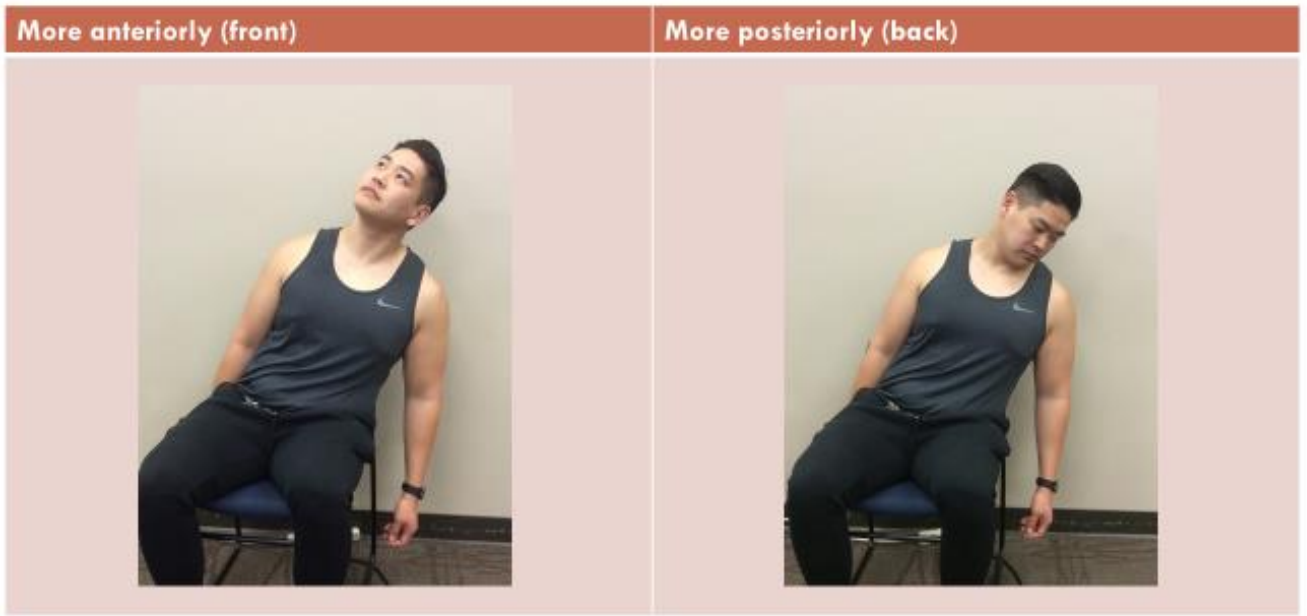



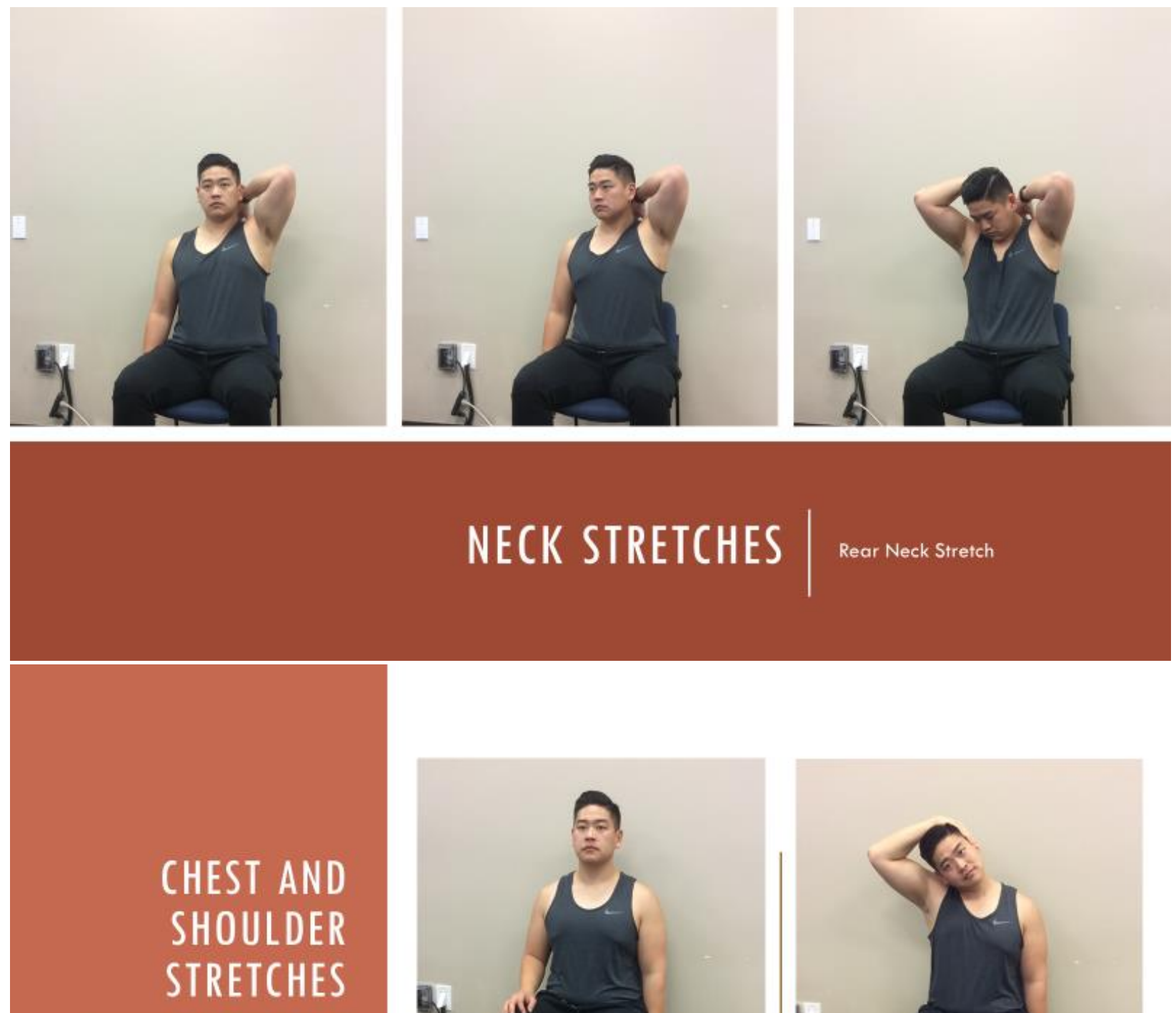

Upper Shoulder Stretch
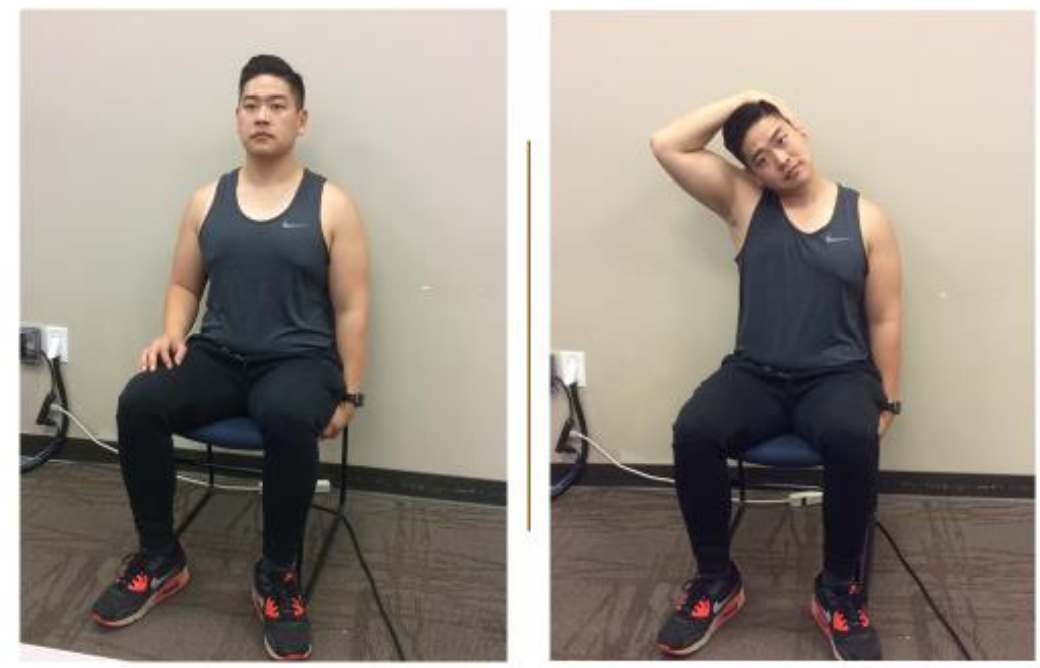
CHEST AND SHOULDER STRETCHES

Doorway Stretch
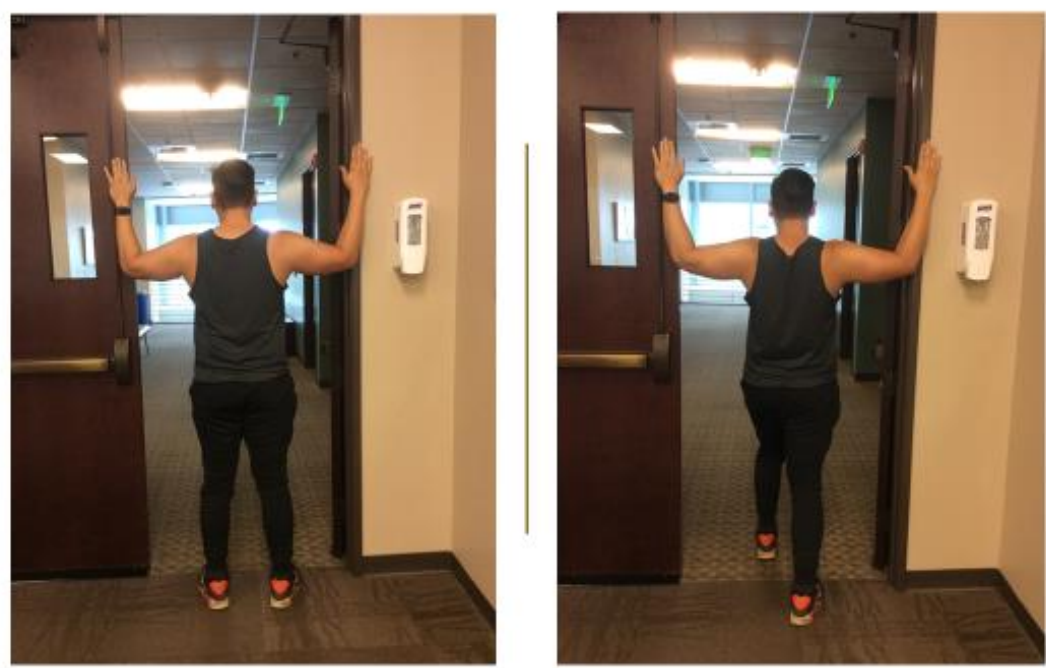

\section{ADDITIONAL CHEST AND SHOULDER STRETCHES}

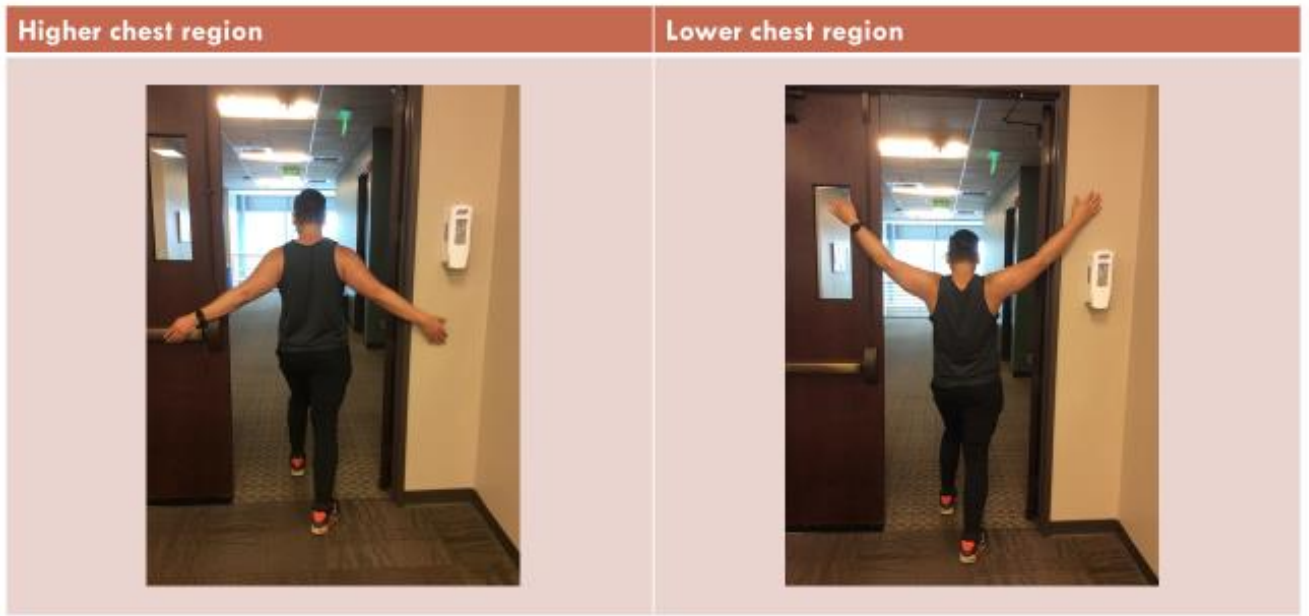




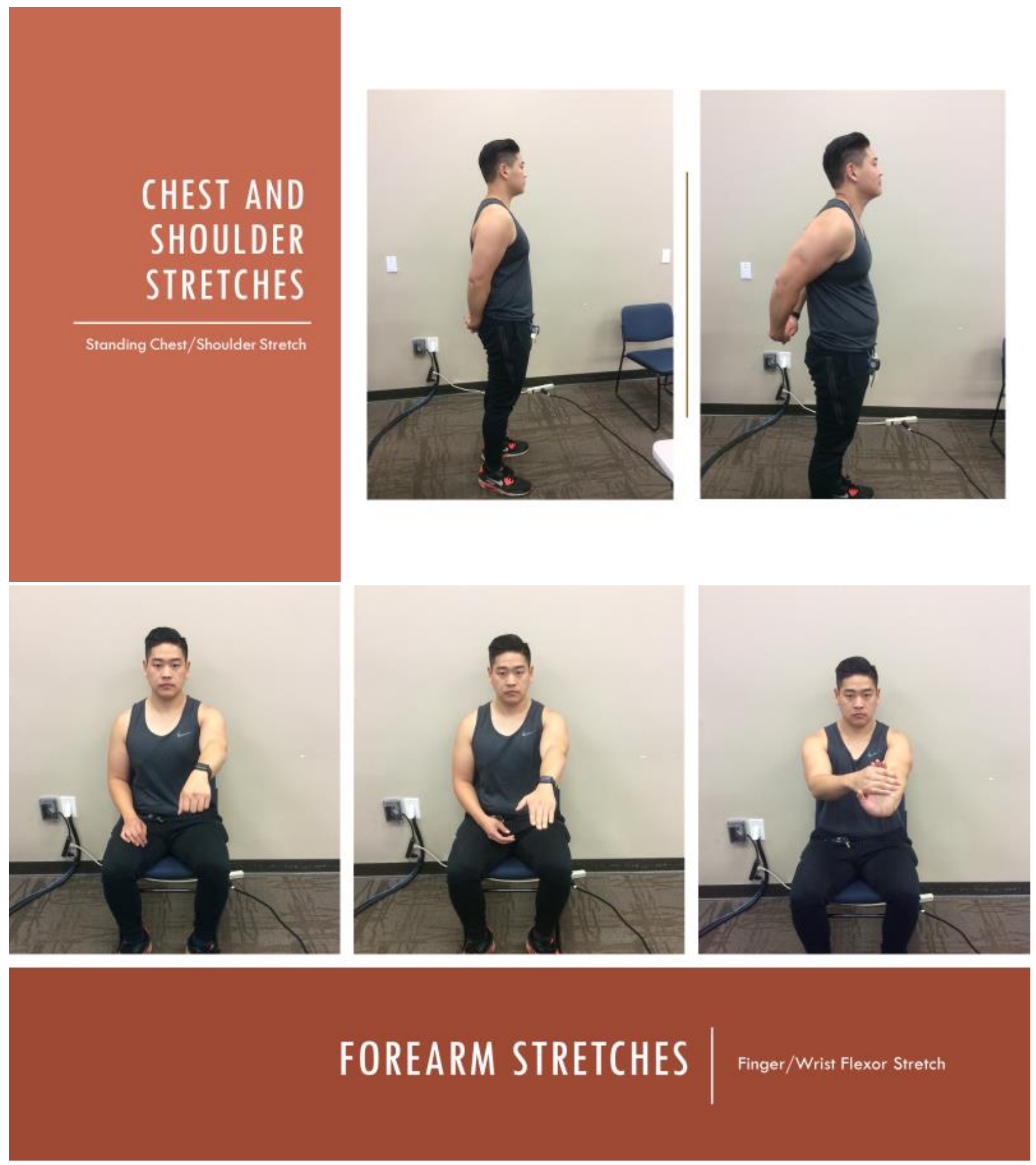



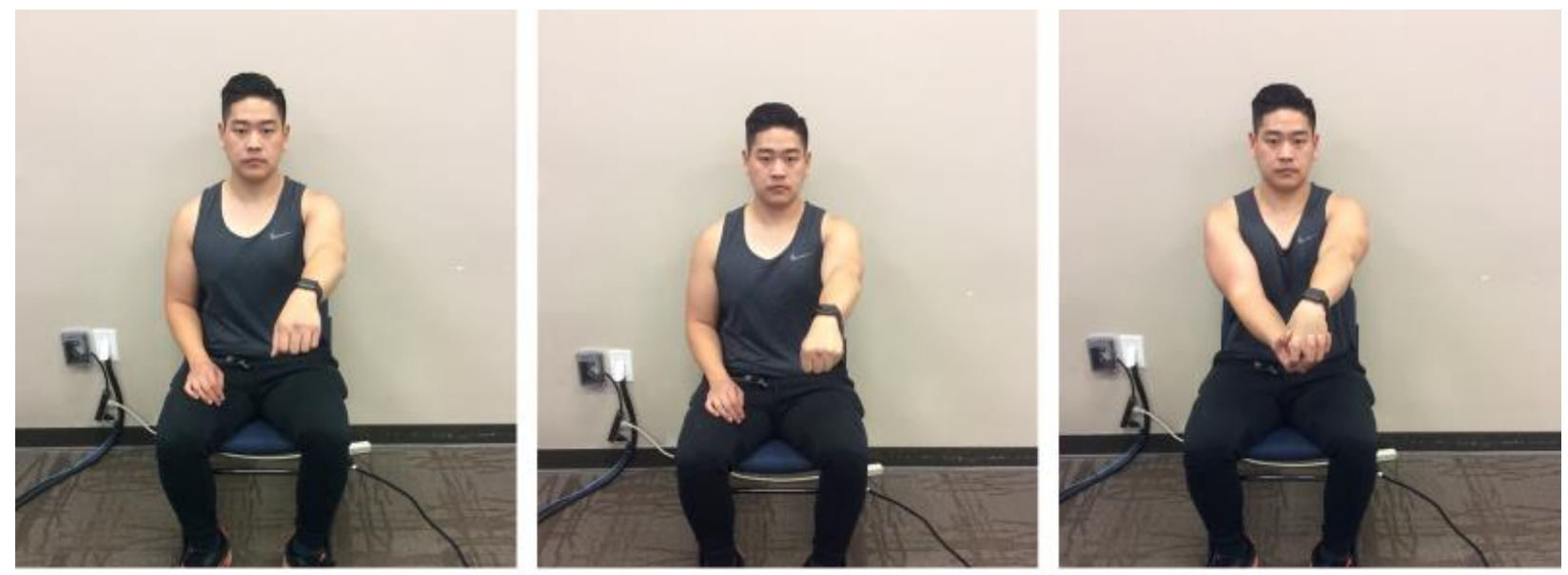

\section{FOREARM STRETCHES}
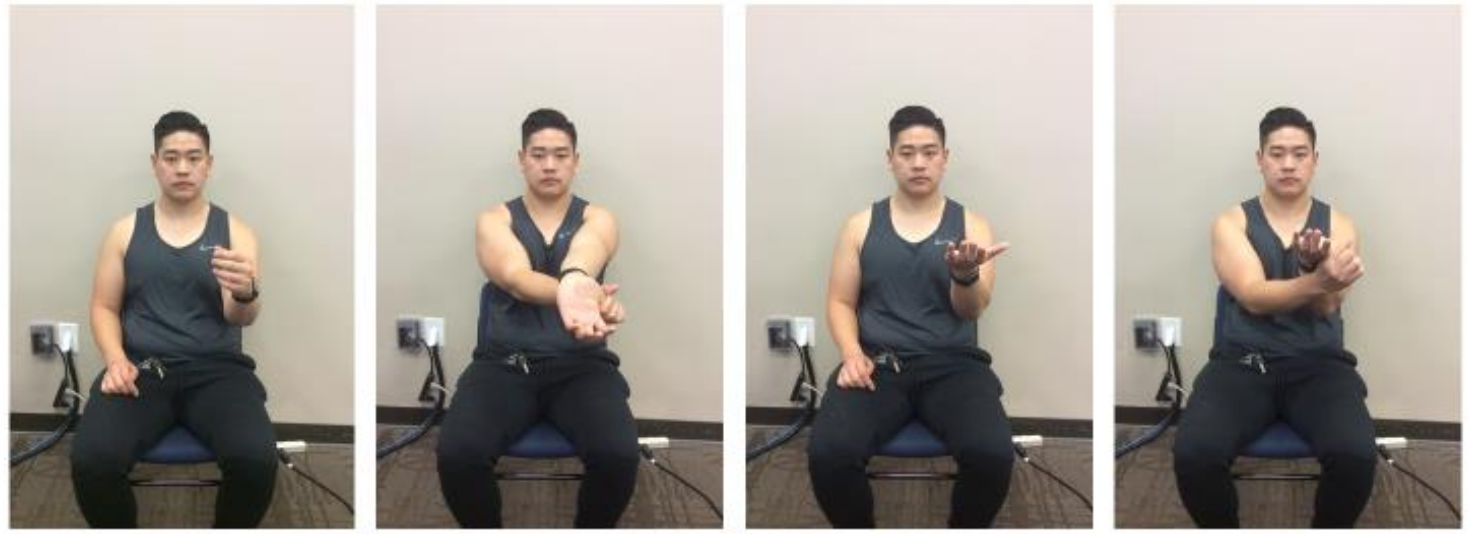

\section{ADDITIONAL FOREARM STRETCH}

Thumb Flexion Stretch 

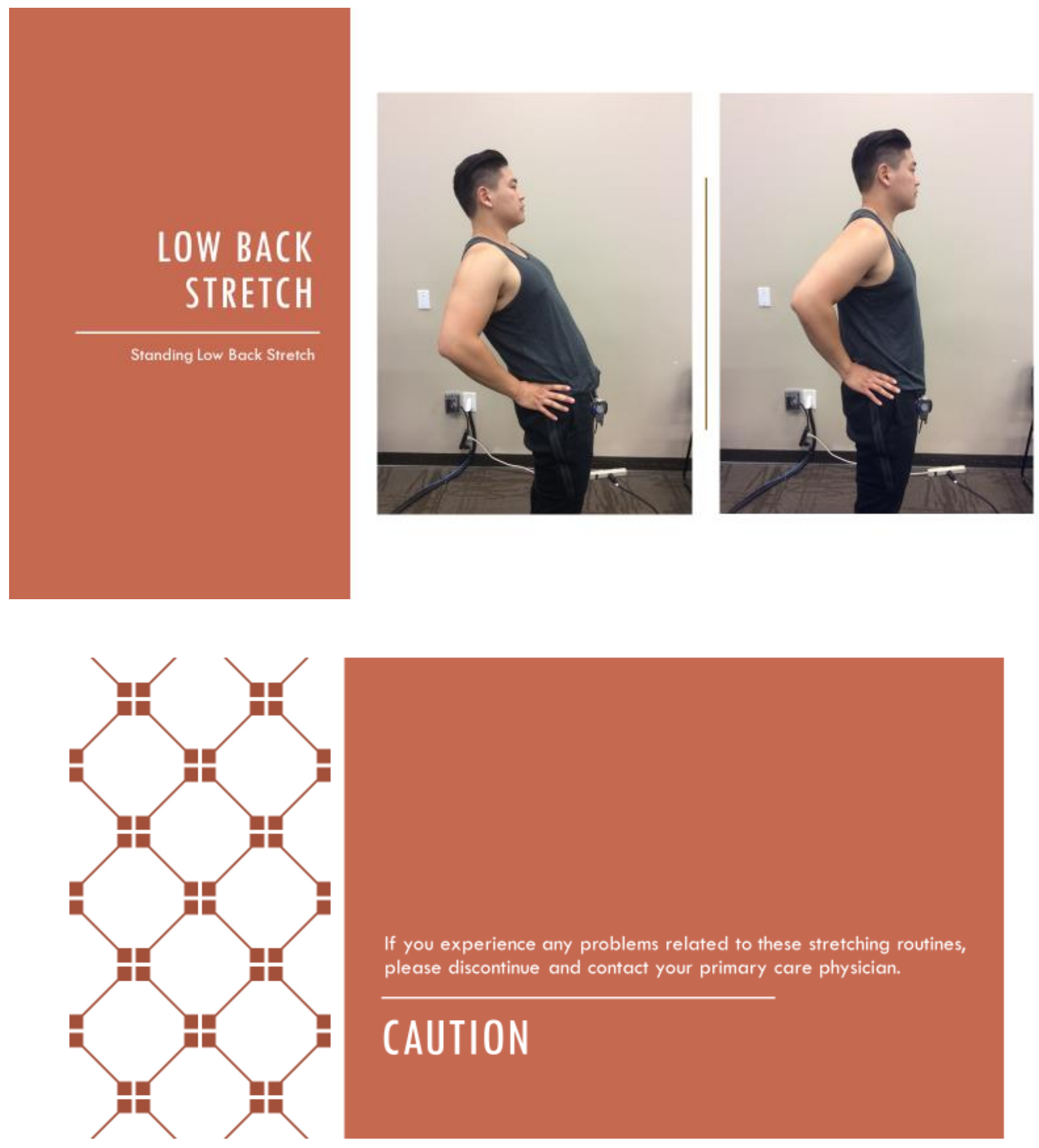

If you experience any problems related to these stretching routines, please discontinue and contact your primary care physician.

\section{CAUTION}




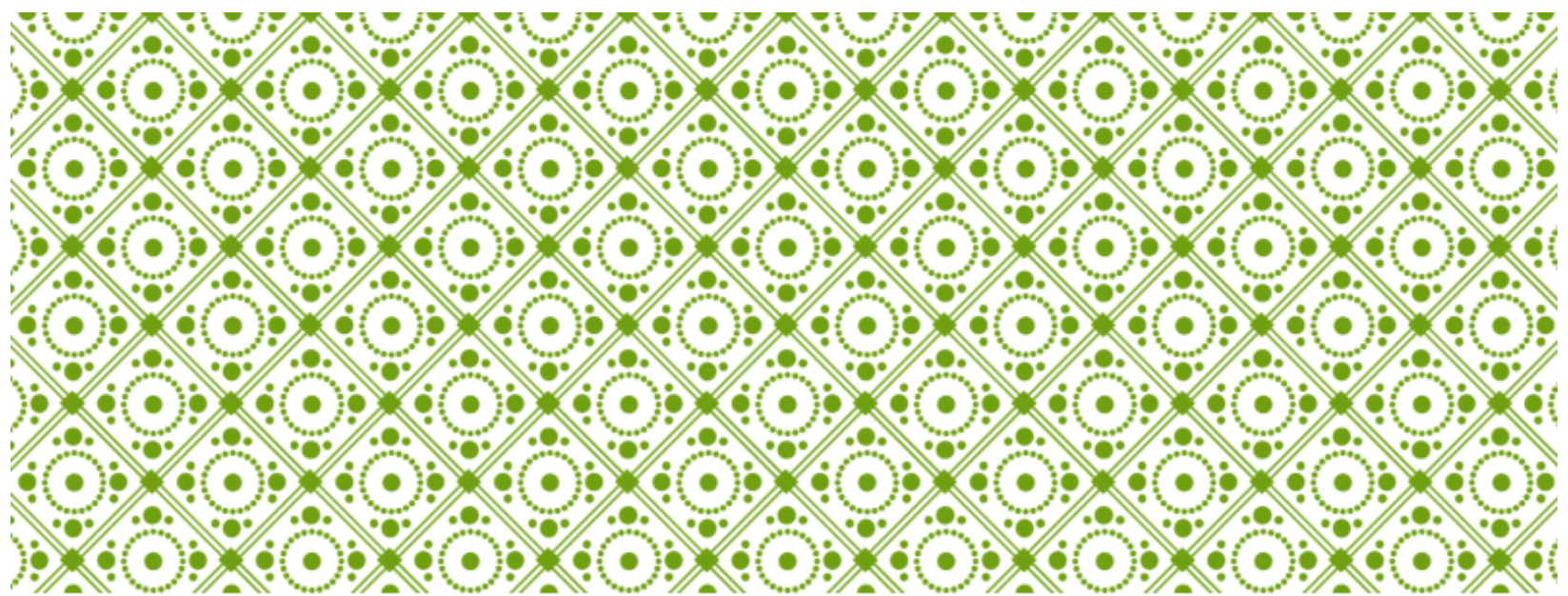

\section{OTHER STRATEGIES TO CONSIDER}

By Alex Kim, OTD/S

University of St. Augustine, San Marcos

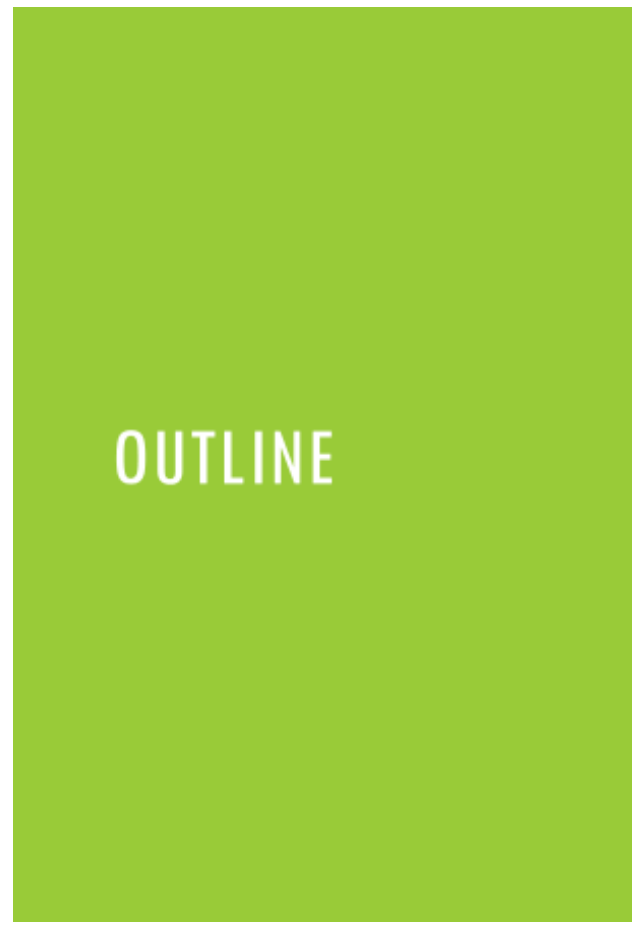

- Deep Breathing and Mindfulness Training

- Snacking

- Taking breaks

- Developing workplace habits

- Working with your clients

- Activities outside of work

- Adaptive equipment to consider

- Final thoughts

- References 

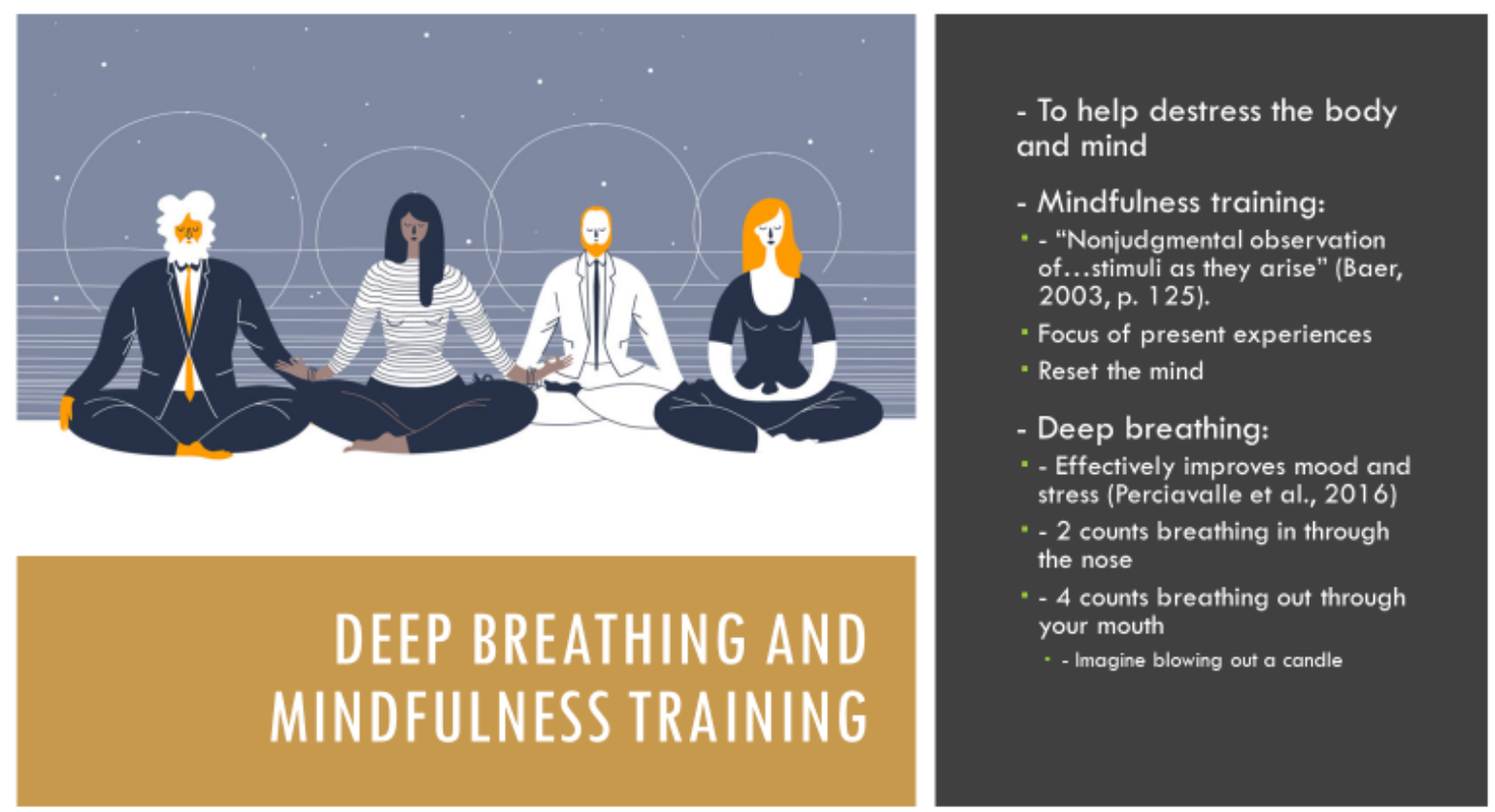

\section{DEEP BREATHING AND MINDFULNESS TRAINING}

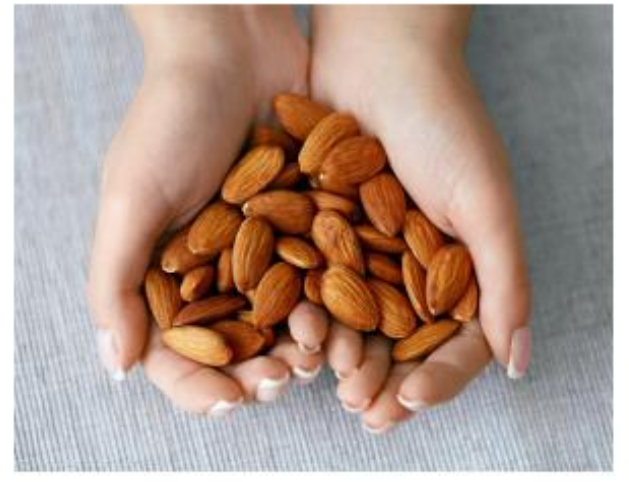

\section{SNACKING}

- According to Leidy et al. (2015), High protein snacks:

" - Improved appetite control

- Improved diet quality

- - Improved satiety

- Promoted cognitive flexibility

- Decreased feelings of confusion-bewilderment

* - Prevented decline in feelings of vigor-activity 


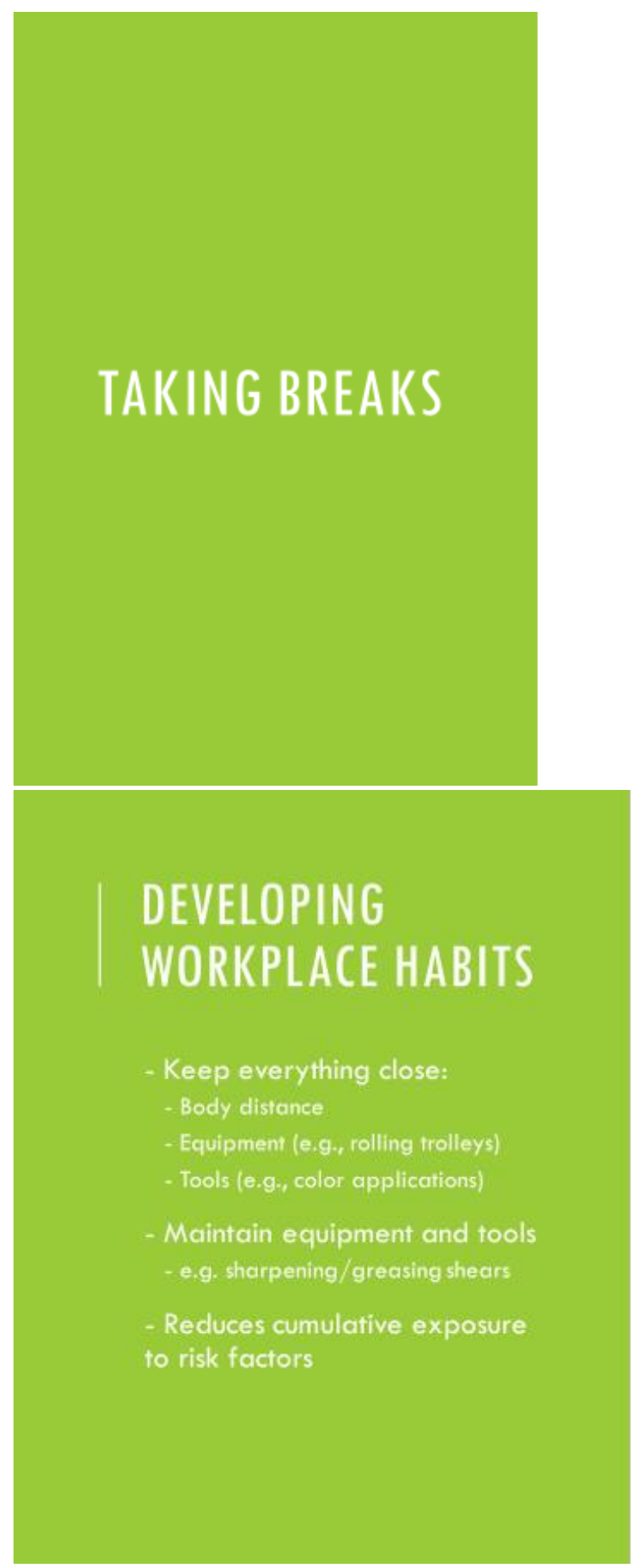

\section{(i) - 5-10 minute break per 1 hour of work}
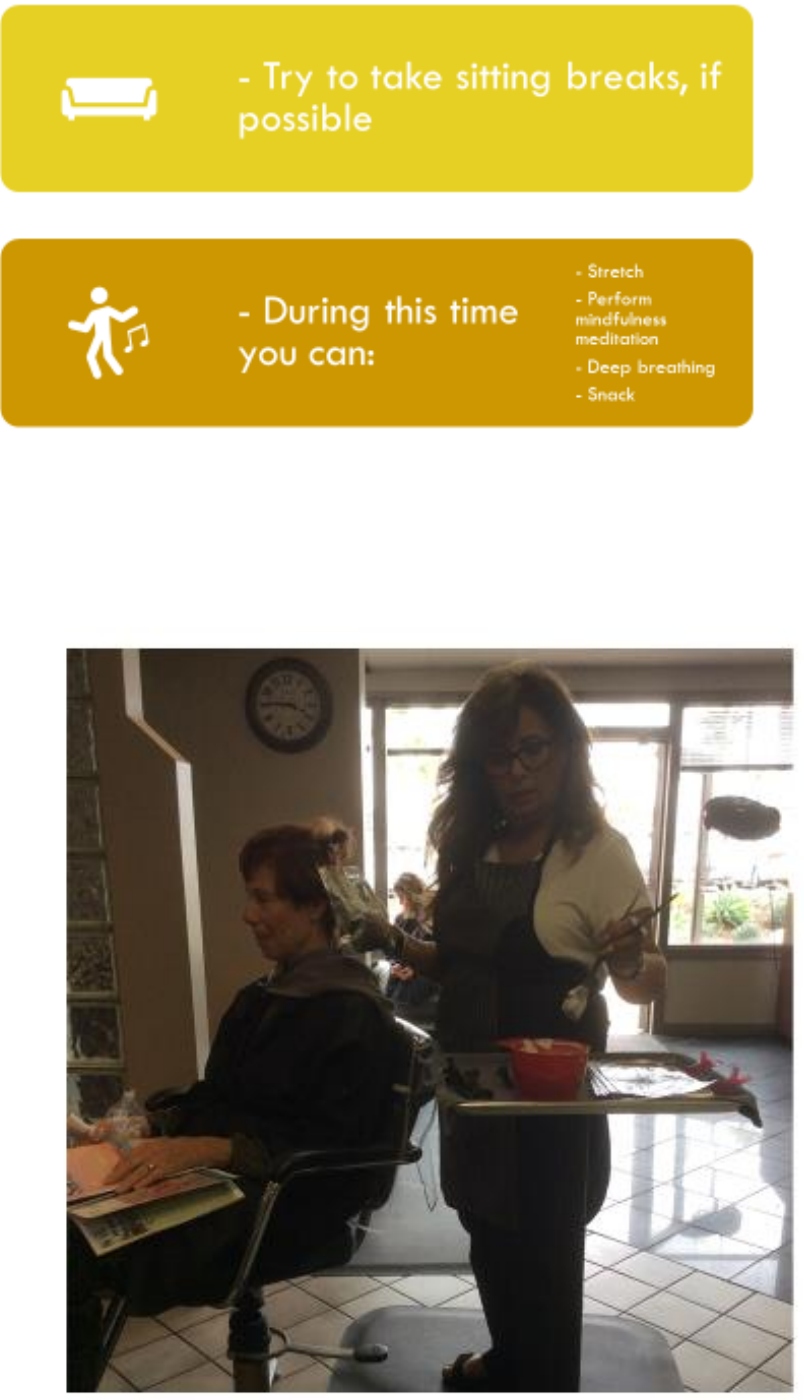


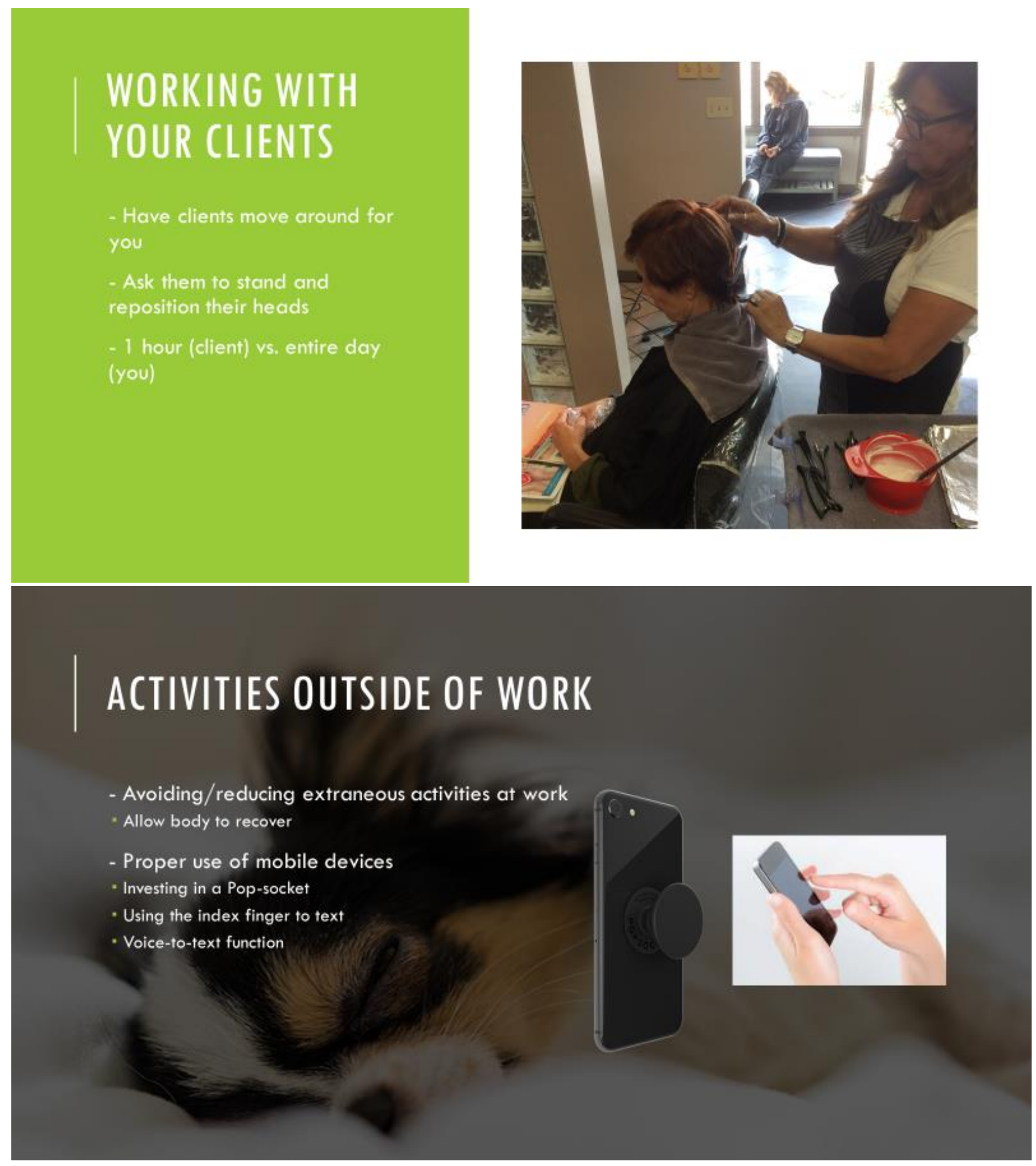




\title{
ADAPTIVE EQUIPMENT TO CONSIDER
}

Anti-fatigue mat

- Blow dryor atrachment (Smooth Air T-360)

- Mobile applications

- Breaks

- Posture (can also use post-it)

- Lighter tools $(<300 \mathrm{~g})$

-e.g. blow dryer, clippers, curling iron

Comfortable, low-hoelod thoes

- Non-skid

- Provides good arch support and body woight
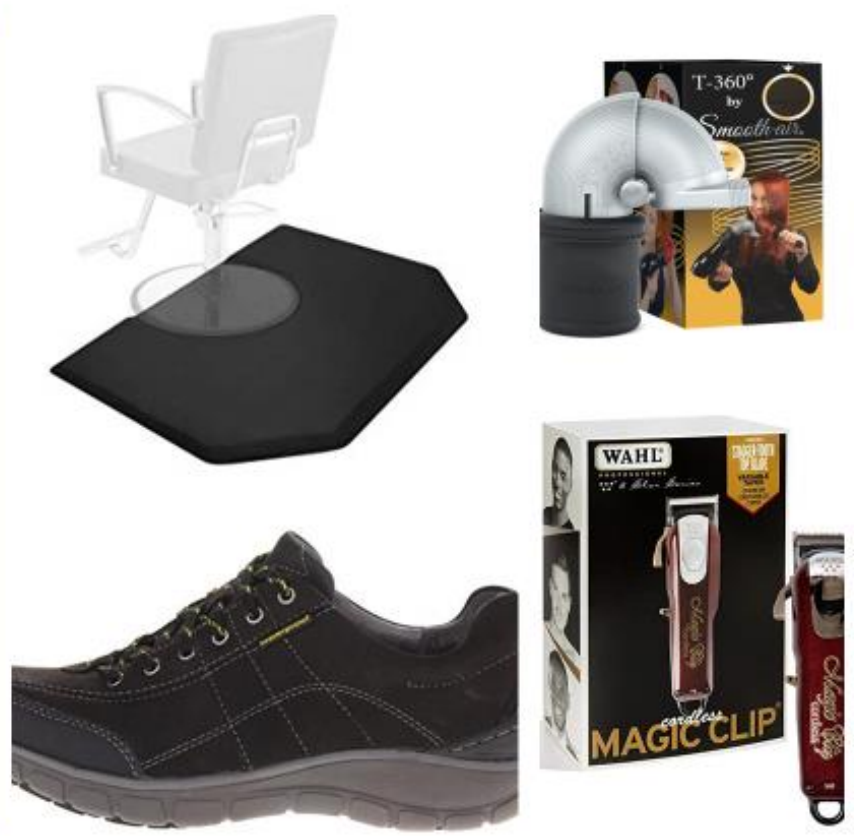

\author{
-Your responsibility \\ Explore what works for you! \\ Try to be consistent \\ FINAL \\ Work with your judgment and experience \\ -Through this experience, I: \\ THOUGHTS \\ - Learned how much more involved hairdressing was \\ Understood the needs for this population \\ Grew, both professionally and personally
}

-Thank you, thank you, thank you!!! 


\section{REFERENCES}

Baer, R. A. (2003). Mindfulness training as a clinical intervention: A conceptual and empirical review. Clinical Psychology: Science and Practice, 10(2), 125-143. doi:10.1093/clipsy/bpg015

Isa, H., \& Omar, A. R. (2011). Prolonged Standing Strain Index (PSSI): A Proposed Method to Quantify Risk Levels of Standing Jobs in Industrial Workplaces. Advanced Materials Research, 433-440, 497-506. doi: 10.4028/www.scientific.net/amr.433-440.497

Leidy, H. J., Todd, C. B., Zino, A. Z., Immel, J. E., Mukherjea, R., Shafer, R. S., Ortinau, L. C., Braun, M. (2015) Consuming high-protein soy snacks affects appetite control, satiety, and diét quality in young people and influences select aspects of mood and cognifion. The Journal of Nutrition, 145(7), 1614-1622. doi: $10.3945 /$ in. 115.212092

Perciavalle, V., Blandini, M., Fecarotta, P., Buscemi, A., Corrado, D. D., Bertolo, L., Fichera, F., Coco, M. (2016). The role of deep breathing on stress. Neurological Sciences, 38(3), 451-458.' doi:10.1007/s1007'2-016-2790. 8

Smith, T. T., \& Gallagher, S. (2018). Impact of loading and work rest intervals on muscle micro-

trauma. International Journal of Industrial Ergonomics, 66, 161-168. doi:10.1016/j.ergon.2018.03.002 


\section{STRETCHING EXERCISES FOR HAIRDRESSERS}

Stretching - Stretching helps to reduce muscle tightness by lengthening the muscle fibers and improves stamina by increasing blood circulation (blood carries oxygen, which muscle fibers need to function).

Stretching should never cause pain. If you start to feel pain, back out of the stretch a little. Stretching to cause pain will cause the muscles to tighten further. Additionally, it is important to not overstretch muscles, as this may cause joint instabilities and tears in soft tissue fibers.

Perform these stretches daily for best results.

Caution: If you experience any problems related to these stretching routines, please discontinue and contact your primary care physician.

Chin Tuck: Slide the chin backwards and hold for 3-5 seconds. Relax and repeat 10 times.

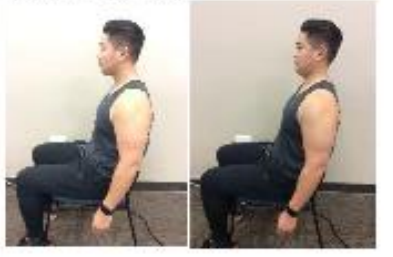

Side Neck Stretch: Sit upright and grasp the chair seat with one hand. Lean body away from this side. Keep shoulders low and relaxed while leaning. Make sure the shoulders are still parallel to the floor. Tilt head away from the grasping side and bring the ear closer to the shoulder. Hold for 10 seconds, then repeat on other side. Perform three sets.

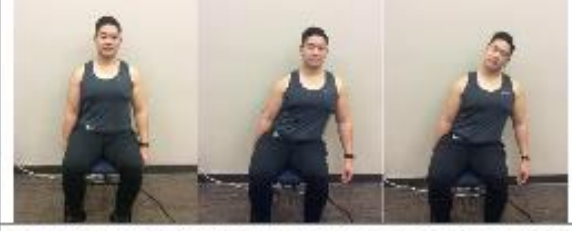

Rear Neck Stretch: Raise and place one hand over the shoulder on the same side. Point head towards the knee of the opposite side. Place the other hand behind the head to pull head down. Hold for 10 seconds, then repeat for other side. Perform three sets.

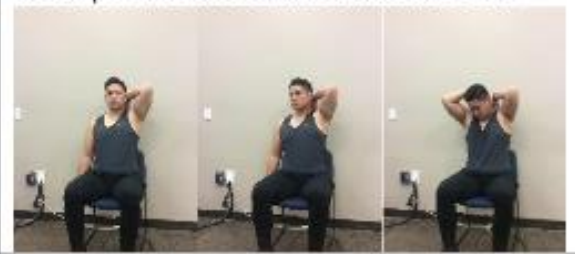

Upper Shoulder Stretch: Grasp one side of chair. With the other arm, place hand onto the opposite side of head and bring the ear closer to the pulling side of the shoulder. Hold for 10 seconds, then repeat on other side. Perform three sets.

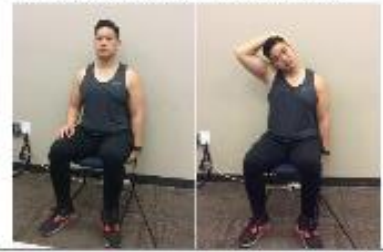

\section{Alex Kim - Alexwonkim@gmail.com}

Doorway Stretch: Standing in front of an open doorway, place each arm onto each side of the door frame. Keep the upper arm at shoulder level and elbows bent at 90 degrees with palms facing forward. Take one step forward while maintaining neutral posture of the head and trunk. Hold for 10 seconds, then relax. Repeat three times.

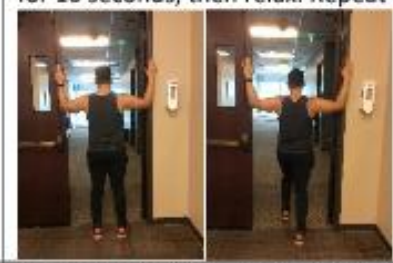

Standing Chest/Shoulder Stretch: Stand up straight. Lace fingers behind the back with arms straight. Gently pull back and out to feel a stretch in the shoulders. Hold for 10 seconds, then relax. Repeat three times.

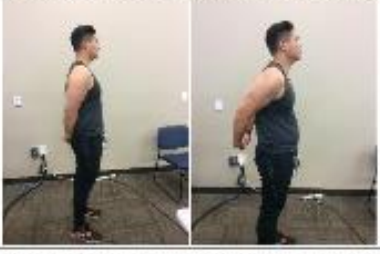

Finger/Wrist Flexor Stretch: Position one arm forward. Straighten elbow and position you open hand with the palm facing the floor. Point fingers towards the ceiling and use the other hand to gently pull back on the palm and fingers (towards your body). Repeat with other arm. Hold for 30 seconds, then repeat on other side.

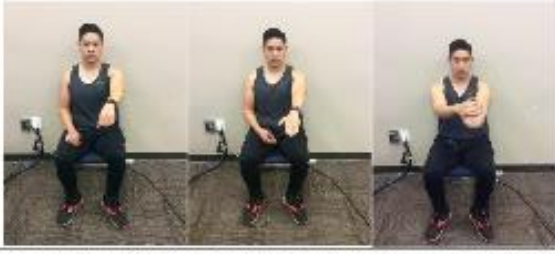

Finger/Wrist Extensor Stretch: Position one arm forward. Straighten elbow and form a fist with palm facing the floor. Bend wrist down towards the floor and use the other hand to gently pull on the fist towards the body. Hold for 30 seconds, then repeat on other side.

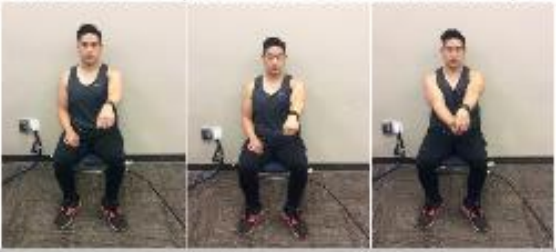

Standing Low Back Flexor Stretch: Stand upright. Place hands on hips and lean back gently. Do not hold. Repeat 10 times.

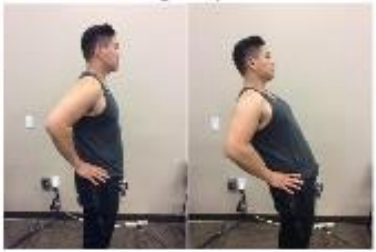

